MODELING, IDENTIFICATION AND CONTROL, 1999, VOL. 21, NO. 1, 3-64

doi:10.4173/mic.2000.11

\title{
Thirty years of research on the application of cybernetic methods in fisheries and aquaculture technology
}

\author{
JENS G. BALCHEN $\dagger$ \\ Keywords: Cybernetics, Fisheries technology, Aquaculture, Ocean ranching, \\ Mathematical modeling, Ocean systems, Model identification, Fish behavior, \\ Control of fish behavior, Instrumentation and biotelemetry, lobster culture
}

The paper surveys the research activities at the Department of Engineering Cybernetics, Norwegian University of Science and Technology, Trondheim, Norway, in the application of cybernetic principles in fisheries technology, aqua-culture technology and ocean ranching during the period 1969-1999. It is believed that the results obtained in these activities will have an impact upon the future developments in on of the most important sectors of the Norwegian economy. Numerous reports and publications are listed in the comprehensive bibliography.

\section{Introduction}

At the end of the 1960s there was a trend among many control scientists to take an interest in the modeling and control of biological systems with particular emphasis on the human biological system. This was also the situation at the Division of Automatic Control (later the Department of Engineering Cybernetics) at the Norwegian Institute of Technology (later the Norwegian University of Science and Technology (NTNU)), in Trondheim, Norway.

The primary aim of this activity became the development of new techniques for diagnosis and treatment in medical fields.

An example was the development of a model-based state and parameter estimator for the human cardiovascular system. It employed an analog computer model of the cardiovascular system and utilized a number of different sensors (ultrasound blood flow sensor, blood pressure sensor, etc) for updating the model from measurements in a real human body (a Kalman filter) (Aaslid 1974).

These early developments eventually led to some very successful industrial products for clinical use, but this involved a long 15 year struggle for funding and acceptance. One major cause of such struggles is that the field of medicine with its institutions (hospitals) belongs to the expense side of the society and the research and development of new technologies has to compete with a large number of other fields of research for funding.

Recognizing this problem it was suggested to look for potential fields of activity where cybernetic methods (modeling, identification, control) could be applied to biological systems belonging to the income side of the society. At a Norwegian university the answer is quite simple: fisheries technology and aquaculture technology.

Norway has for a long time been one of the world's leading nations in traditional fisheries and fishing technology. During the past 35 years Norway has played a dominant role in the development of new aquaculture technologies. Therefore it

$\dagger$ Professor Emeritus, Department of Engineering Cybernetics, Norwegian University of Science and Technology, 7491 Trondheim, Norway. 
appears that proper conditions should be present for the development of a set of new technological tools based on a cybernetic foundation.

From around 1969 the Department of Engineering Cybernetics, in cooperation with other research organizations, in particular SINTEF in Trondheim, and Norwegian industries has undertaken a large number of research and development programs which will now be reviewed.

In 1969 a preliminary proposal was submitted to the Royal Norwegian Council for Scientific and Industrial Research for a research program entitled 'Control of fish behavior' and followed by detailed plans during the next year.

The first research grant was offered in 1970 and the program was continued until the end of 1981.

During this period a very fine experimental facility was established in Hopavågen, $120 \mathrm{~km}$ west of Trondheim (Hopavågen is a bay (våg = bay) near the farm Hopen). A large former schoolhouse was acquired and used as dormitory and laboratory and a number of floating stages and instrumentation systems were installed in the bay.

The bay has an area of about $500000 \mathrm{~m}^{2}$ and is up to $30 \mathrm{~m}$ deep. It is connected to the ocean with a natural canal about $200 \mathrm{~m}$ long and $15 \mathrm{~m}$ wide. The tidal changes force a quite active exchange of salt water in the bay leading to a level change up to $1 \mathrm{~m}$ twice a day.

For experimental purposes loads of about $30 \mathrm{hl}$ of saithe (Pollachius virens), obtained from local purse seiners, were released twice in the bay. This provided a very useful system for large scale experiments over many years.

Around 1981 the whole facility was donated by the project to The University of Trondheim which invested considerable funds into establishing a modern biological field station for research and education.

During the following two decades, numerous projects and studies have been conducted in this broader field of 'Fish Cybernetics' or 'Aqua-Bio-Cybernetics'. Some of these activities are included in this paper.

\section{Modeling of ocean system}

\subsection{Background}

From a cybernetic point of view, any study of the many processes taking place in an ocean, must start with the development of mathematical models of the ocean system.

Mathematical modeling is the most effective single tool to help understand the basic internal mechanisms of ocean subsystems and the interactions between such subsystems.

A hierarchy of subsystems and their interactions is indicated in Figure 1.

When implemented as a numerical model in a modern computer system a mathematical model may be used:

- for simulation purposes to study the behavior of the system under different internal and external conditions.

- for estimating internal variables and model parameters which are not directly measurable.

- as part of a model-based system for estimating the present and predicting future ocean resources and providing data for controlling the harvesting facilities.

- as part of a model-based system for the control of the behavior of individual members of the biological populations e.g. schools of fish. 

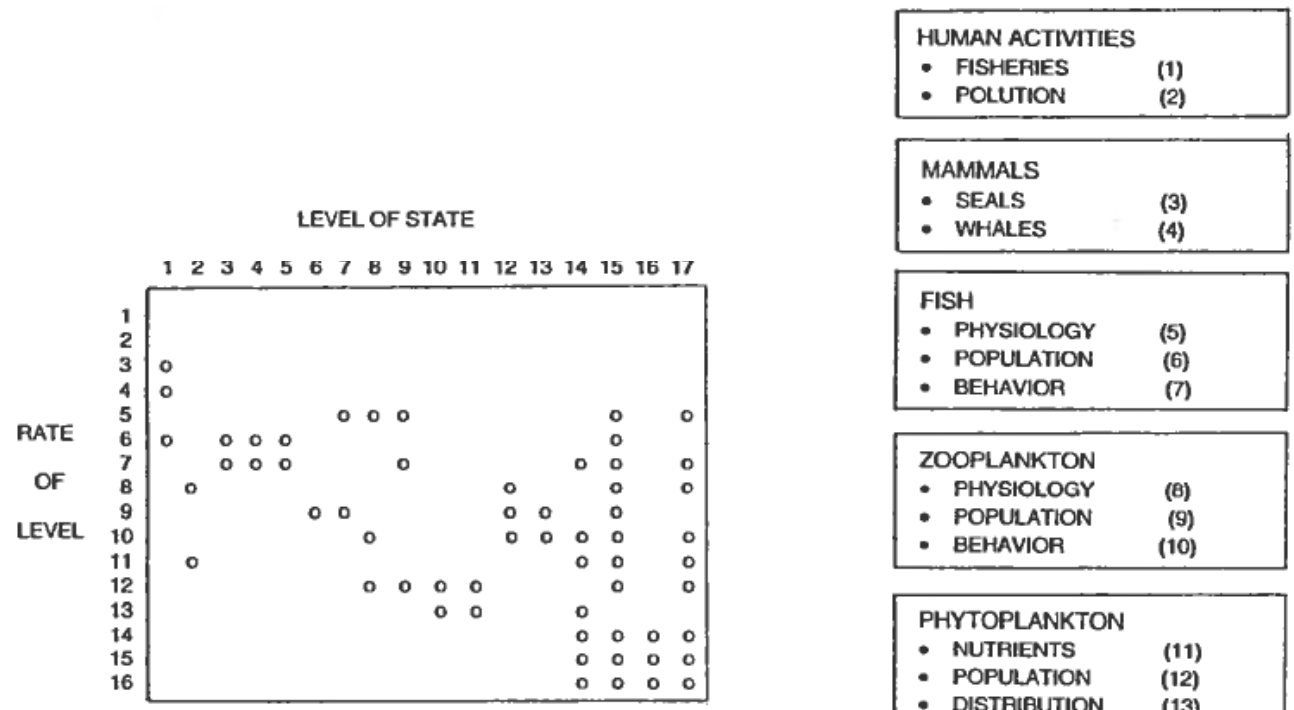

\begin{tabular}{|ll|}
\hline MAMMALS & \\
0 SEALS & (3) \\
WHALES & (4) \\
\hline
\end{tabular}

\begin{tabular}{|ll|}
\hline FISH & \\
: PHYSIOLOGY & (5) \\
: POPULATION & (6) \\
BEHAVIOR & (7) \\
\hline
\end{tabular}

\begin{tabular}{|ll|}
\hline ZOOPLANKTON & \\
: PHYSILLOGY & (8) \\
: POPULATION & (9) \\
BEHAVIOR & (10) \\
\hline
\end{tabular}

\begin{tabular}{|ll|}
\hline PHYTOPLANKTON & \\
: NUTRIENTS & $(11)$ \\
POPULATION & $(12)$ \\
\hline DISTRIBUTION & $(13)$ \\
\hline
\end{tabular}

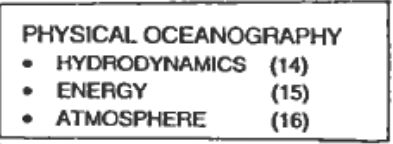

OTHER GEOPHYSICAL FORCES

(17)

Figure 1. The hierarchy of interacting subsystems in an ocean.

The objectives of the OCEAN-BIO-MODELS-project (HAVBIOMODELLER) which was active for nearly 10 years (1974-1983) (Slagstad et al. 1975, Balchen et al. 1979, Balchen 1980, Balchen 1981a) belonged primarily the third category listed above.

When this project was temporarily terminated in 1983 it was clear that the potential Norwegian users of the system were not yet prepared to adopt such a methodology in their routines for marine resource assessment. Gradually towards the end of the 1990 s the situation has changed and there is reason to believe that 'a model-based system for marine resource assessment and management' will be available and used within few years in Norway.

The OCEAN-BIO-MODELS project is described in a large number of reports and papers listed in the References of this paper under 'Ocean-Bio-Modeling, Modelbased Resource Estimation'. Since the number of references is so large, only a general mention of them are made except in special cases.

\subsection{Model-based Resource Estimation}

A set of conclusions can be drawn from the nearly 30 years of studies and development in 'modeling ocean systems':

- Assessment of fisheries resources in the future will be an application of 'modelbased estimation (MBE)'.

The basis for this statement is that any estimation procedure which utilizes a priori information about the physical and biological processes can be interpreted 
as model-based since a dynamic model is the most efficient way to represent the behavior of a complex dynamic process. A model can be given many different forms e.g:

- nonlinear partial differential equations in vector space

- nonlinear ordinary differential equations in vector space

- linear/nonlinear transform representations of input/output relationships in vector space (e.g. transfer matrices)

- statistical relationships (e.g. correlation matrices).

- All the tools needed for MBE are available today at an acceptable cost and people with the proper theoretical and practical background can be hired to develop operational systems.

- Since all basic tools for MBE are available, the main tasks of a development group are:

- to decide about the structure of the computational network in which the models and the estimation algorithms are to be implemented

- to organize the interaction between the groups involved in the design of the different models.

- to deliver and maintain the total system and train the customer in its use.

- An MBE-system consists of a number of different kinds of dynamic models. The most important ones are listed below.

(a) Models of ocean hydrodynamics and energy flow have been developed. Such a model of e.g. the Barents Sea with a horizontal grid of $5 \times 5 \mathrm{~km}$ and 5 vertical layers runs at a speed that is about 5 times faster than real time on a standard computer workstation (e.g. SUN UltraSparc 1).

Since this is the most demanding model this means that such computing capacity will be adequate for most of the oceans of interest for any estimation of Norwegian fisheries resources (the Barents Sea and the Norwegian Sea).

The estimator needs the model running in real time and will be updated (identified, assimilated) by measurement data coming from other computers in the network.

When the quality of this model is gradually improved the most important function of the updating feedback becomes the calculation of proper boundary conditions representing the influences of the surrounding oceans which are not parts of the model.

(b) Models of nutrients, phytoplankton and zooplankton have been developed in Norway for many years and need a computational capacity of about the same size as under a) above (Slagstad 1981a, 1981b, 1982, 1983, 1984, 1985), (Slagstad and Iversen 1997), (Slagstad and Støle-Hansen 1991), (Slagstad and Tande 1981, 1996).

The most important challenge of the future is the updating of these models since real-time measurements of plankton distributions are not yet available to a great extent. The consequence is that the behavior of the higher trophic layers (fish, mammals) must be based primarily on 'ballistic' simulations of the plankton distribution even though there will be an indirect updating of the plankton models from the much richer observations of the fish distribution and behavior. A number of promising techno- 
logies for measuring plankton distributions are now appearing (e.g. laser spectroscopy, drop probes) and should soon be implemented.

(c) Population models

- of each year class

- of each species of fish.

These models are conceptually relatively simple and not very demanding on computing capacity. They express the outcome of the spawning process, the natural death and the predation on eggs, larvae and juveniles, the predation by mammals and the harvest by fishing.

Very much data are available from research vessels and the fishing fleets for updating (identification, data assimilation) these models, but still it is quite obvious that the quality of the reported observations could be very much improved.

(d) Migration behavior models

- of each year class

- of each species of fish.

Some research has been done on mathematical modeling of fish behavior from elementary concept of sensory physiology ('first principles') which may provide a proper structural framework for adaptation of estimated behavior to real observed behavior. These models need more development, but adequate migration algorithms are available to get started. These models are not very demanding in terms of capacity.

(e) Models of the measuring processes of the physical oceanography, the plankton and the local fish behavior related to the surface vessel motion and the sonic detection system. These models are necessary for the 'calibration' of the detection system, but they are relatively simple and not very demanding in terms of capacity.

- As stated above, all the models need to be updated (identified, assimilated) against observations (measurements) in the real system. This problem has many theoretical and practical aspects which have not yet been fully explored.

There are two levels of updating:

- State updating depending on observability

- Parameter updating (adaptation) depending on identifiability

Efficient updating algorithms are available:

- Augmented/Extended Kalman Filter (AKF), (Henriksen 1998)

- Recursive Prediction Error Method (RPEM), (Ljung 1987), (Ljung and Søderstrøm 1987),

- Recursive Line-Search Method (RLM), (Ljungquist and Balchen 1994),

- etc.

but there is a clear lack of simplified algorithms to save computational capacity.

- Sources of measurements are:

- Research vessels

- Commercial fishing vessels

- Buoys

- Standard available solutions

- New concepts (active probes with satellite communication etc) 
- Aircraft (commercial, military), remote sensing

- Satellite remote sensing

- Acoustic tomography.

- An efficient database system is needed for collecting, storing and distributing the data to and from all the models. This is one of the critical components of the system determining the operational efficiency.

- The development and implementation of these models should preferably be made in a decentralized computer architecture in which the individual computers interact over a network (Internet). Thereby the development groups may be distributed, but managed by a central body.

The decentralized structure yields a desirable degree of parallelism at a low cost and a high level of convenience to the user provided the computer network structure has been properly planned.

- One important aspect of the MBE is its application in guiding the surveying operations and the data collection:

- The MBE-system tells where the fish is and how much there is and thus gives guidance about where measurements should be made.

- Measurements in a neighborhood give data for model updating.

- The MBE-structure lends itself to continued improvements when experience is gained through its use. Therefore it is regarded as essential to start with simple model assumptions and apply gradual improvements in complexity as the observed data permit this.

- The estimate of the total fish population is by definition the sum of the populations in each grid cell of the spatial distribution.

In many cases the models do not need to be 3-dimensional, but rather 2dimensional with depth integration. This applies to the population models since it is usually enough to know about the horizontal migration and distribution.

- An MBE-system as outlined above has an ideal structure for interaction with modem visualization tools in computer graphics. Such tools will make the communication with the End User very convenient.

- When the MBE-system estimates are used for setting up fishing quota and time regulations new data are being generated which will act as inputs to the model system and thus generate new responses. The MBE-system thus will be an essential tool in optimal dynamic management of fish resources.

The structure of an MBE-system based on these components is shown in Figure 2. This illustrates how the different models (and modeling tasks) are distributed to about seven computers interconnected in a network (Internet). These computers may be located in one institution or spread over the entire country or even internationally.

The 'Database' is a 'real-time' database with time increments between data points which are shorter than a critical value determined for each particular model. The shortest time increment appears in the model of physical oceanography and its associated data and will be of the order 10 to 50 minutes. Other phenomena, such as fish population, demand data at a far lower rate of input, say an increment of days or weeks.

The time step (time increment in the discretized differential equations) can be different in the various models. The shortest time step is in the model of physical oceanography and is about 10 minutes when the grid is about $5 \mathrm{~km}$. 


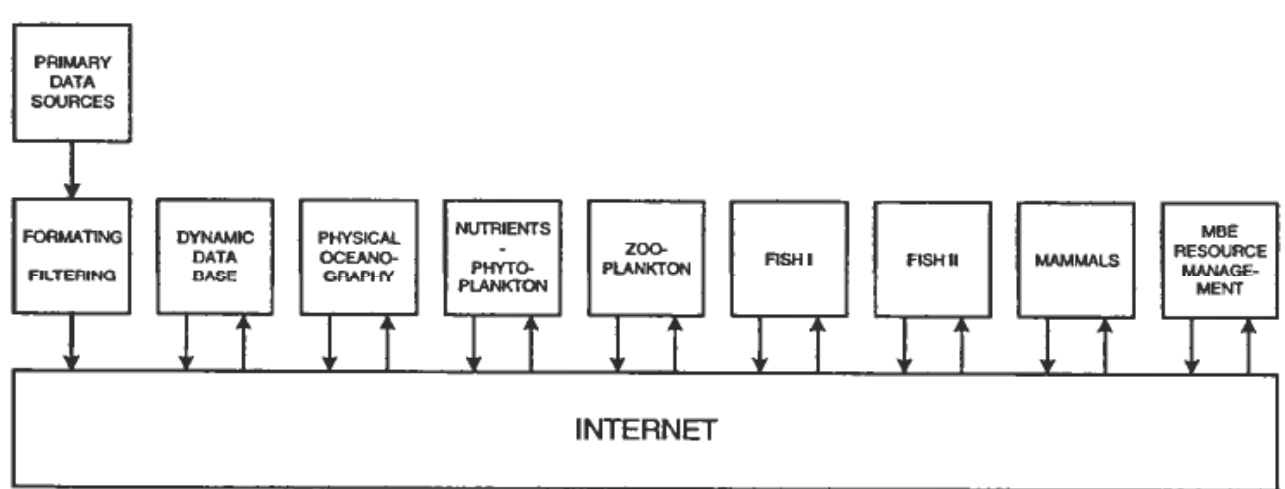

Figure 2. The structure of a MBE-system.

The total ocean of interest will have an area of about $3500000 \mathrm{~km}^{2}$. With a grid of $5 \times 5=25 \mathrm{~km}^{2}$ this gives about 140000 grid cells in the models.

Figure 3 illustrates the outcome of a simulation of the model of physical oceanography in terms of horizontal velocity fields in an ocean at different discrete times (Berntsen et al. 1981).

Figure 4 illustrates an early attempt (Reed and Balchen 1982) to simulate the population dynamics and behavior of the Barents Sea capelin (Mallotus villosus) based on models of physical oceanography and plankton and with an optimization-based model of behavior (Balchen 1979). The contours show population densities of capelin at four different times in the Barents Sea north of Norway.

\section{Modeling fish behavior}

One very interesting and challenging subset of the total modeling problem outlined in Section 2 is that of modeling the behavior of fish.

The subject of mathematical modeling of the behavior of individual animals in general is both difficult and controversial. There is a vast amount of literature on the subject of behavior, but relatively little useful is written on mathematical modeling of behavior.

The behavior of individual animals is governed by so many external influences and a model of the animal itself demands such high dimensionality that the modeling endeavor seems to be rather useless.

The situation will be different, however, when attention is directed towards the study of groups of individuals such as schools of fish (Giske, Huse and Fiksen 1998). Then average or expected behavior will replace detailed individual behavior. If the modeling of behavior is limited to large-scale motions such as migration, rather than detailed movements of the individuals, there is a chance that models can be derived which are useful.

Models of fish behavior could have applications in fisheries technology in the development of fishing gear, in aquaculture for the development of large-scale fish farming and as part of a MBE-system for resource assessment.

Certain species of fish (herring, mackerel etc) exhibit distinctive schooling behavior. The consequence of this is that behavioral tendencies of an individual is suppressed by the school so that the school behaves like a 'big fish'.

This 'big fish' will have behavior in terms of motion and physiology which is similar 


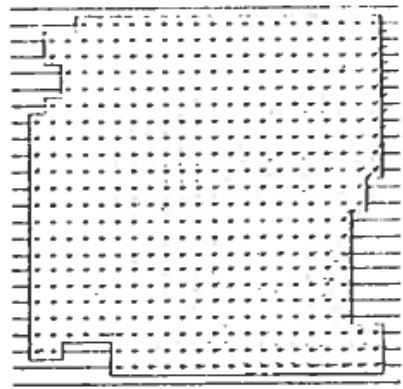

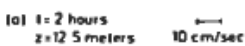

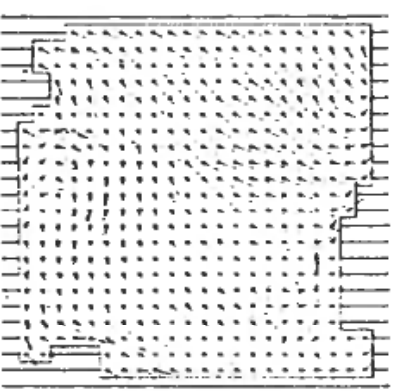

[b] $\begin{aligned} & x+10 \text { howrs } \\ & x=125 \text { melers }\end{aligned} \quad 10=\overrightarrow{z m} / \mathrm{sec}$

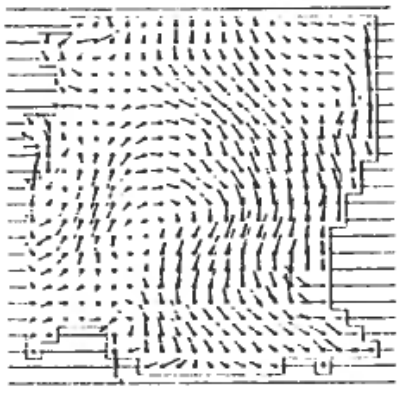

$\begin{aligned} & \text { (c) } 1,18 \text { Mours } \\ & 1,125 \text { meters }\end{aligned} \quad 10 \mathrm{~cm} / \mathrm{sec}$

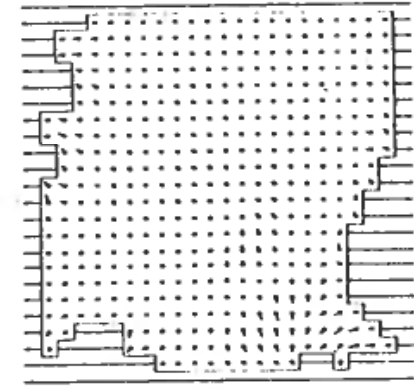

(a) $1: 2$ mours 10 meters

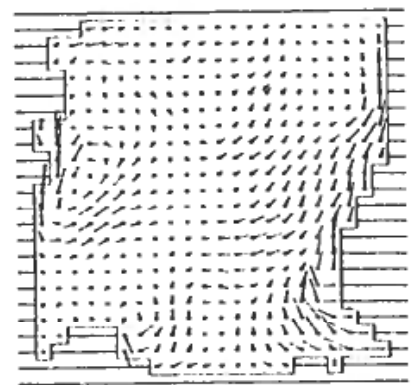

(b) $\begin{aligned} & 1=10 \text { hours } \\ & x=75 \text { meters }\end{aligned}$

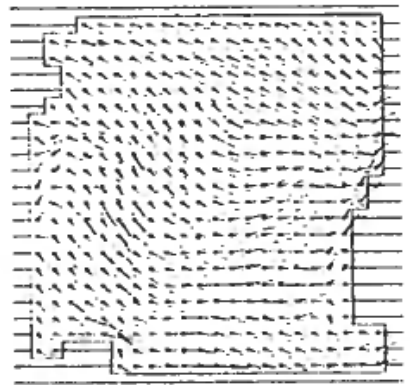

(c) i:18 hours $\quad 10 \overrightarrow{\mathrm{cm} / \mathrm{sec}}$

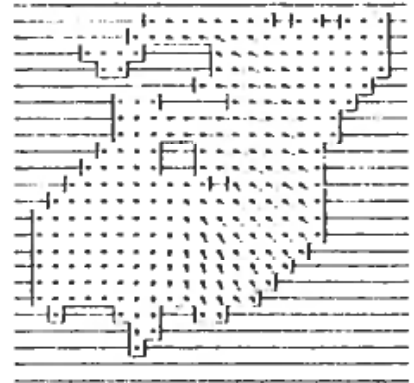

(a) $\begin{aligned} & i=2 \text { hours } \\ & z=250 \text { meters }\end{aligned} 10 \stackrel{\mathrm{cm} / \mathrm{sec}}{\mathrm{c}}$

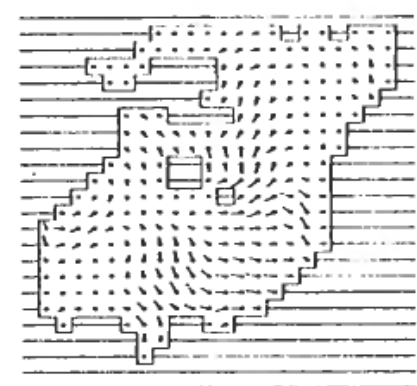

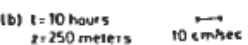

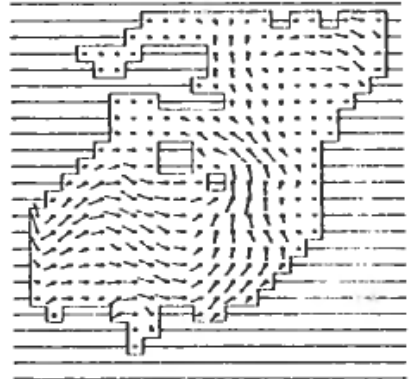

(c) $1=16$ hours 10 cmmec

Figure 3. Simulation of horizontal velocity fields in an ocean. (from Berntsen et al. 1981).

to that of an individual fish (Balchen 1972, Balchen 1975a). The schooling behavior during feeding or spawning migration belongs to this category whereas schooling for the purpose of avoidance/protection in relation to predators is more complicated (e.g. school of herring attacked by killer whales).

The internal dynamics of schools of fish has been the subject of research for many years and the theories have been verified by experiments to a high extent. The result is that we may regard the school as an object in itself (Keenleyside 1975, Shaw 1978, Balchen 1979a, Sannomiya 1984, Weihs 1973a, 1973b).

This means that the 'big fish' has an energy storage system, a metabolism, and a sensory system which are similar, but not necessarily identical to that of an individual 

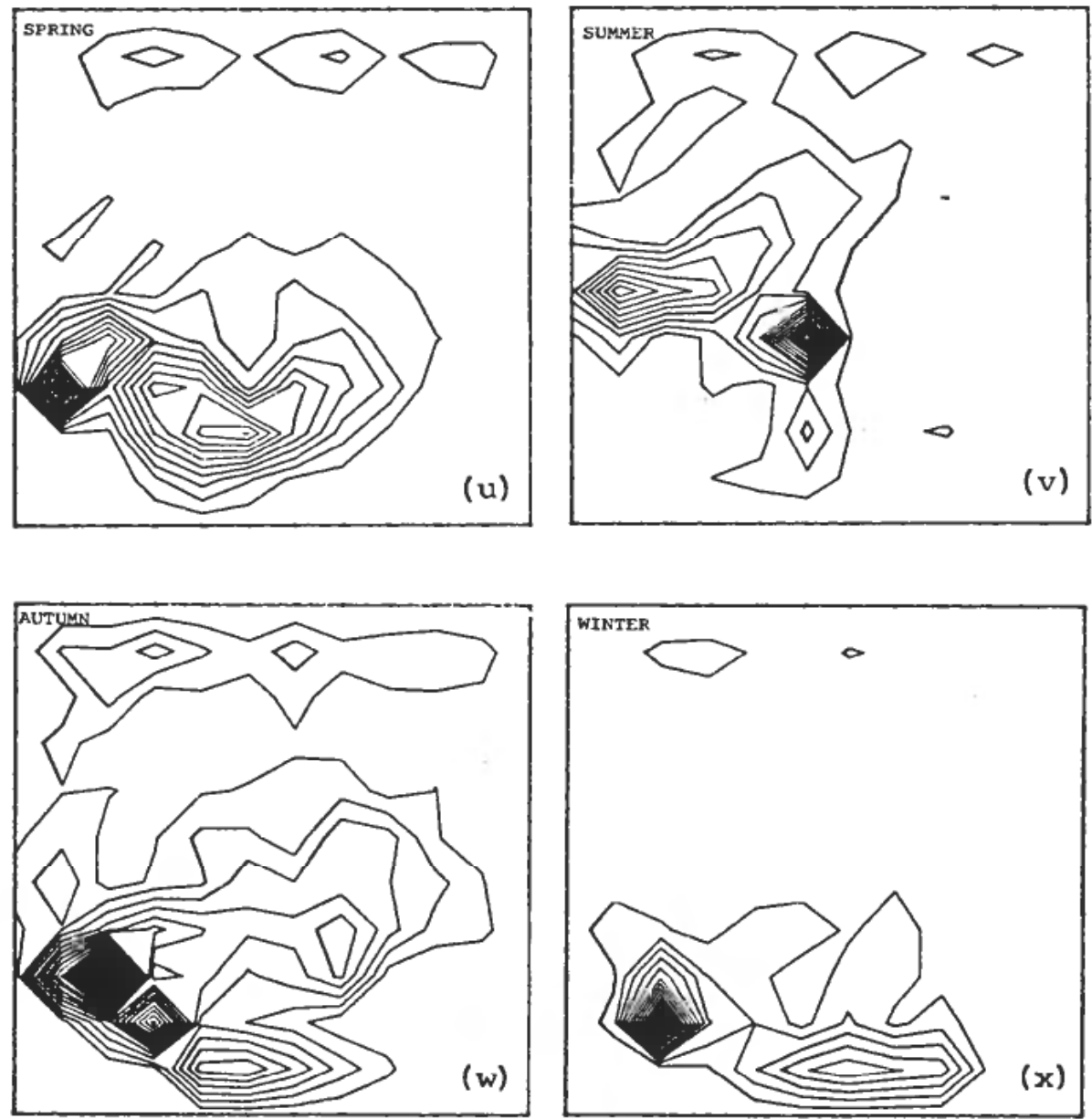

Figure 4. Simulation of the population dynamics and migration of the Barents Sea capelin. (from Reed and Balchen 1982).

fish. Of particular interest is that the sensitivity of the equivalent 'big fish' sensory system (say the hearing of a school of fish) is higher than that of an individual fish by a factor between $\sqrt{\mathrm{n}}$ and $\mathrm{n}$, where $\mathrm{n}$ is the number of individuals in the school (Balchen 1972).

This phenomenon may be an ecological explanation for the existence of schooling behavior in some species. Interpreted in terms of optimization it says that the physiological parameters that lead to schooling are selected for maximal probability of survival.

A school of fish is thus regarded as a collection of a large number of individuals which move in the water masses as one body with a center of gravity determining its collective motion and an average diameter as a measure of its geometric extension. Each individual in the group at different locations may have different velocities and directions of motion because of the internal dynamics of the school. But the nearest neighbors tend to move almost identically because there is a heavy penalty associated with moving differently than the nearest neighbors.

The motion of a school of fish can be defined in an earth fixed coordinate system in which also the geophysical and biological environment around the fish is moving. 
Some aspects of the fish behavior may be explained relative to the earth topography itself such as the bottom, coastline and rivers, whereas other aspects must be defined relative to the motion of the water masses because the fish behaves relative to temperature gradients, passively drifting plankton etc. Furthermore, the behavior of a school of fish may be relative to another school of fish in a predator-prey relationship, and in this case both schools are moving in the same water masses.

Modeling the interaction between two or more species e.g. in a predator-prey relationship, is preferably done by including all the species in one large model. The simplest case occurs when a single species e.g. a school of herring, feeds on a patch of zooplankton which in turn is only exhibiting vertical migration behavior controlled by the ambient light intensity. The principles of multispecies behavior modeling are not any different from single species modeling, but the models become more complex and include the interaction between the species.

For single species behavior modeling a number of general behavioral hypothesis have been suggested which could be used as a basis for the overall behavior description (e.g. Weihs 1982, Brett 1971).

The principle of maximization of comfort, as introduced by Balchen (1976b) and (1979), is now presented and adopted in modeling fish behavior.

According to this principle: the school of fish will at any time move in such a way (direction and velocity) so as to maximize its 'comfort'.

The comfort is defined as a physiological sensation of well being which is a scalar function of the physiological state $(x)$ of the fish (all individuals are assumed identical) and of the geophysical and biological state of the environment $(v)$ of the fish such as water temperature, food concentration, and light intensity.

The physiological state of the fish is the outcome of the past development of the fish in its environment and can be described by a set of ordinary differential equations in a state space of reasonable dimension (say 5 to 8). In Balchen (1979a) it is suggested that five state variables $\left(x_{1}, x_{2}, \ldots x_{5}\right)$ could describe energy related variables such as stomach content (satiation), reversible and irreversible energy content, whereas three state variables $\left(x_{6}, \ldots x_{8}\right)$ are allotted for endocrinologically related variables closely associated with behavior.

A comprehensive model of fish physiology is presented in Olsen and Balchen (1992).

The physiological model of a school of fish is thus given by

$$
d / d t(x)=\dot{x}=f(x, v,|\dot{\boldsymbol{r}}|, t)
$$

where

$$
\begin{aligned}
& \boldsymbol{x} \text { - physiological state vector of the fish } \\
& \boldsymbol{v} \text { - geophysical and biological state vector of the fish environment } \\
& |\boldsymbol{r}| \text { - magnitude of the velocity vector of fish motion } \\
& \boldsymbol{t} \text { - time }
\end{aligned}
$$

The environment of the fish which influences both its physiological changes and its behavior is composed of a combination of phenomena some of which are of scalar character (nondirectional) and some are vectorial (directional). The environmental state vector is either a scalar- or a vectorial field of the three-dimensional coordinate vector $(z)$ defining the position in earth fixed coordinates.

The modeling of the motion of a school of fish regarded as a point in space and 
based on the principle of maximization of comfort requires a definition of the term comfort.

The comfort $C(x, v, a)$ is a scalar function of the physiological state $(x)$, the environmental state $(v)$ and a set of genetic parameters $(a)$. The behavior model is based on the hypothesis that the fish, at any time, move with a velocity vector which is a function of the gradient with respect to location of the field of comfort such that

$$
\dot{r}=g(\partial C(x, v, a) / \partial r)
$$

where $\boldsymbol{r}$ is the three-dimensional position vector of the school of fish in the earth fixed coordinate system $(z)$. A simple approximation of the general function $(g()$.$) in (2)$ may be a linear transformation

$$
\dot{r}=G(z) \partial C(.) / \partial r
$$

where $G(z)$ is a matrix of appropriate dimension generally dependent of the space coordinates $\boldsymbol{z}$.

In Balchen (1979a) the structure of a mathematical model of fish physiology is proposed to have eight state variables as follows:

$x 1$ - energy stored in stomach

$x 2$ - energy stored in 'blood'

$x 3$ - energy stored in irreversible growth (bones, skin, etc)

$x 4$ - energy stored in reversible storage except gonades (muscle tissue etc)

$x 5$ - energy stored in gonads

$x 6$ - conc. of thyroid hormone

$x 7$ - conc. of adrenocortico stereoids

$x 8$ - conc. of the sexual hormone

The interactions between these 'storages' are illustrated in Figure 5 (Balchen 1979a)

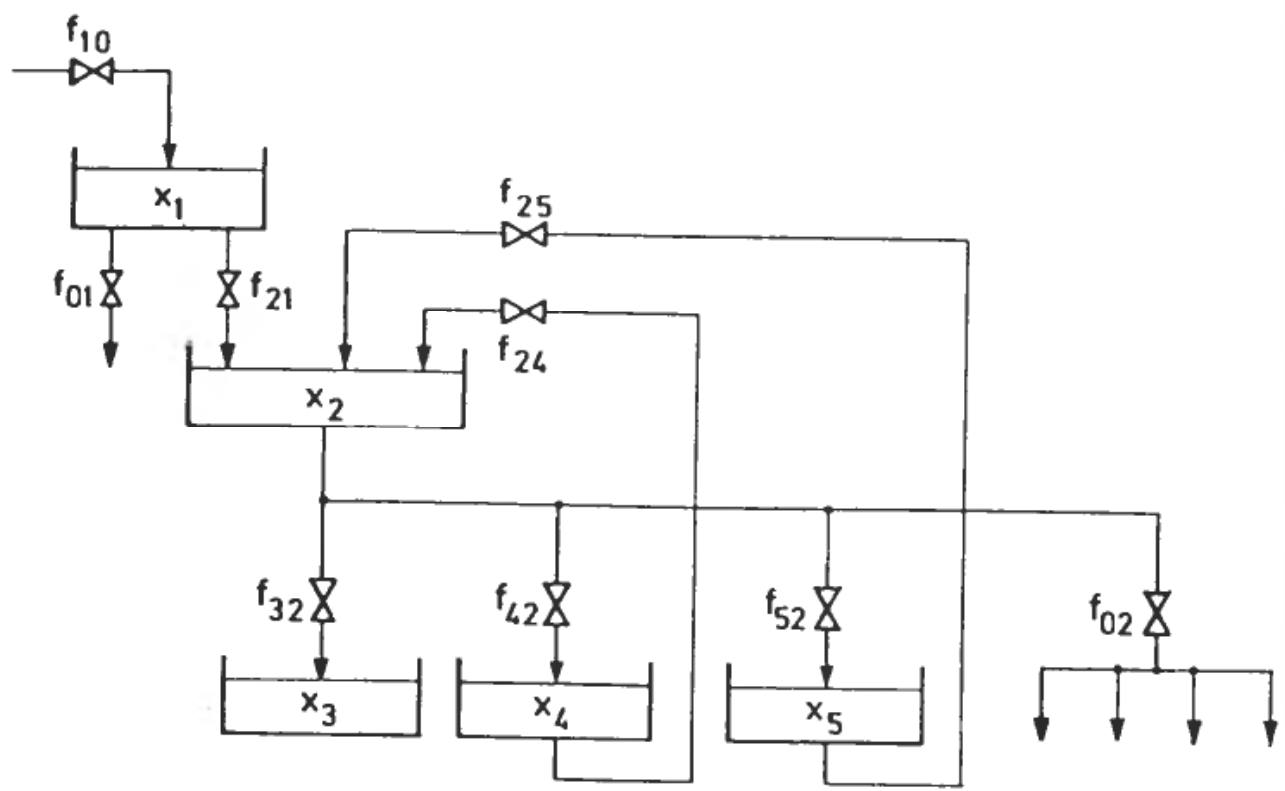

Figure 5. The structure of the mathematical model of energy storages. (from Balchen 1979a). 
Some environmental variables have been identified as follows:

$v 1$ - temperature in the water

$v 2$ - conc. of food in the water

$v 3$ - general light intensity in the water

$v 4$ - intensity of predators

$v 5$ - salinity of the water

$v 6$ - conc. of dissolved oxygen in the water

$v 7$ - conc. of single olfactory agent

$v 8$ - east component of a vectorial quantity

$v 9-$ north ..................

$v 10-$ down................

The comfort function $C($.$) has been studied in some detail (Balchen 1979a) and it has$ been suggested that it, under certain conditions, can be decomposed in a number of specialized comfort functions which depend only on very few variables. Examples of such specialized comfort functions are shown in Figures 6, 7 and 8.

Figure 6 shows the contribution to the comfort by the environmental temperature $(v 1)$ and the 'hormonal' state $(x 7)$. As can be seen, both high and low temperatures are associated with low comfort i.e. there is a range of temperatures preferred by the fish. This range and the sensitivity to temperature changes is dependent upon the 'hormonal' state $(x 7)$

Figure 7 indicates the comfort associated with the physiological state $(x 8)$

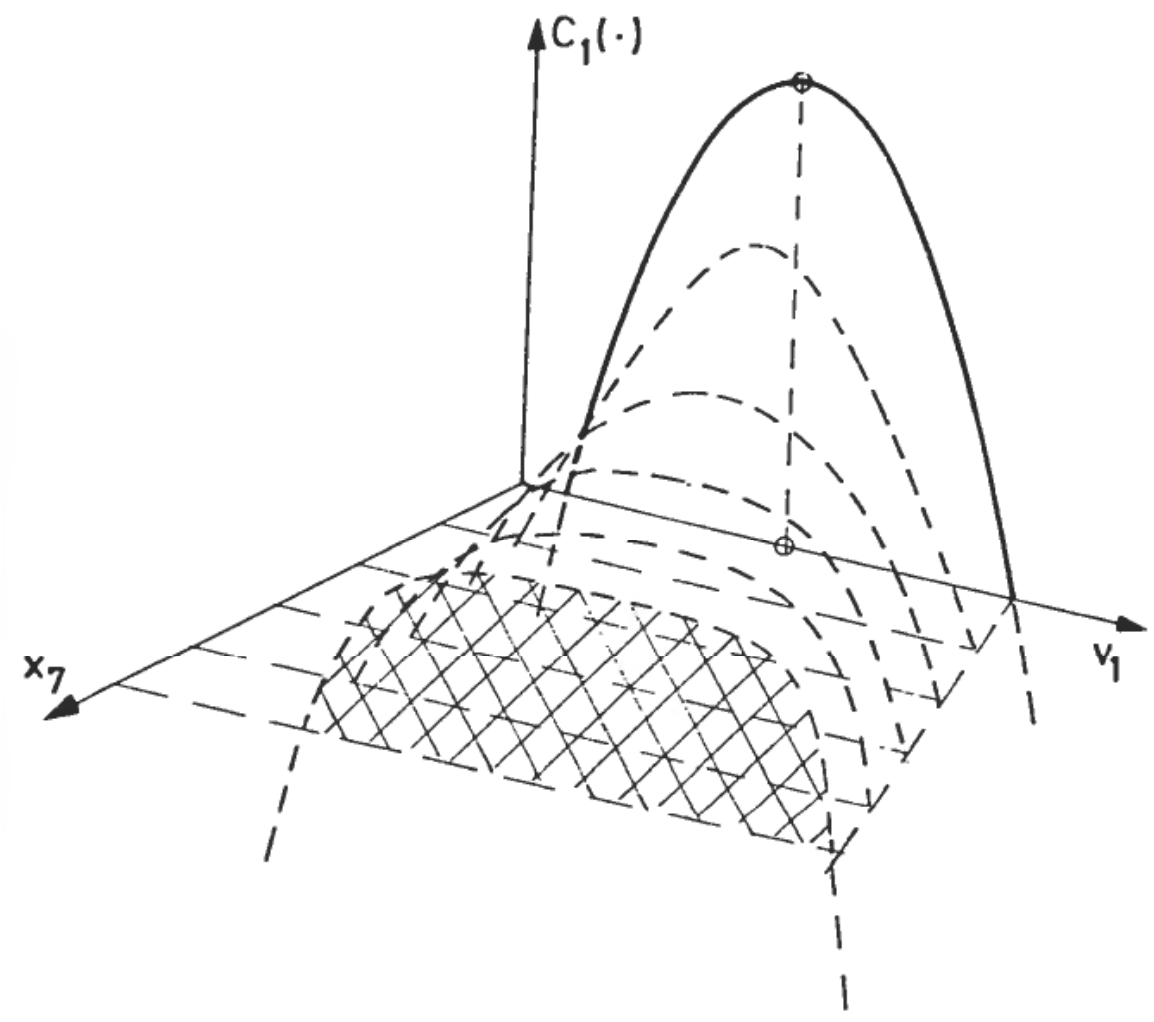

Figure 6. The comfort as a function of $(x 7)$ and the temperature (v1). (from Balchen 1979a). 


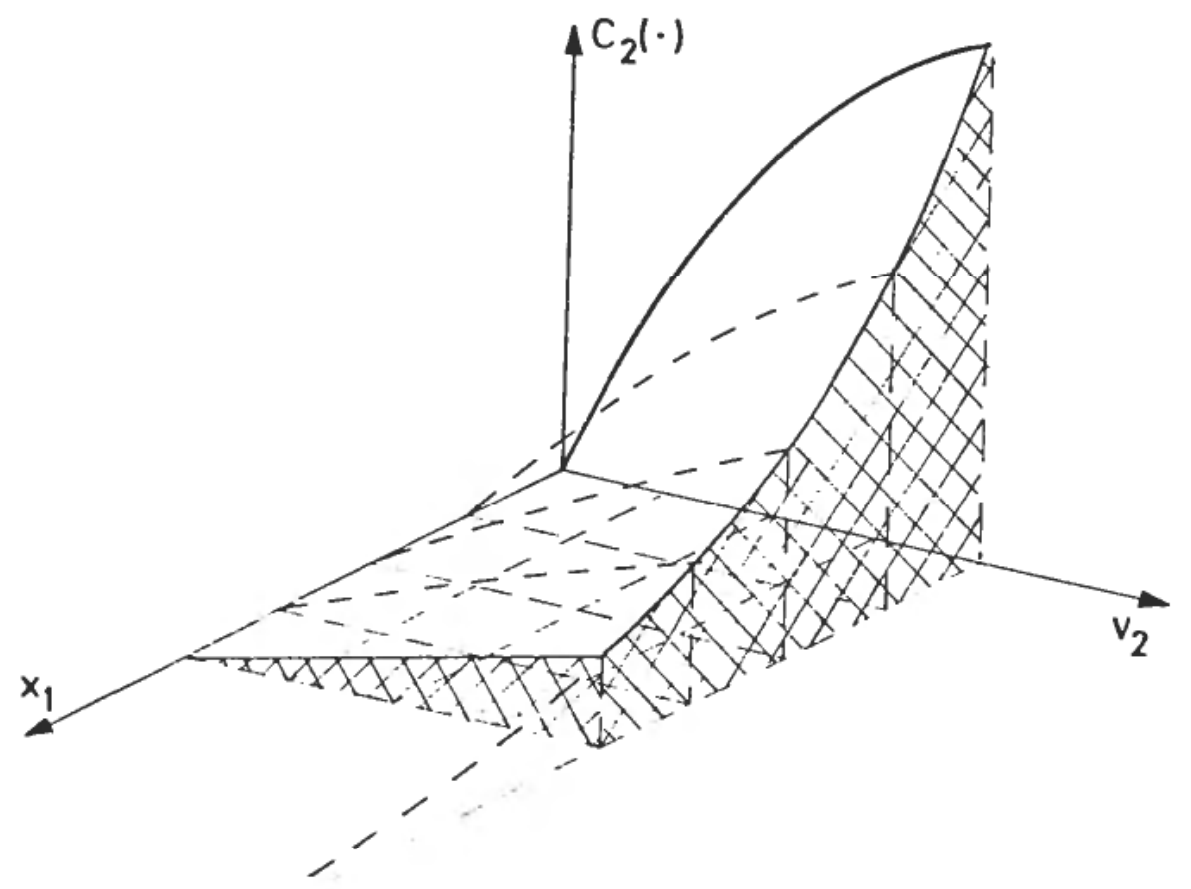

Figure 7. The comfort associated with the concentration of food $(v 2)$ and satiation $(x 1)$. (from Balchen 1979a).

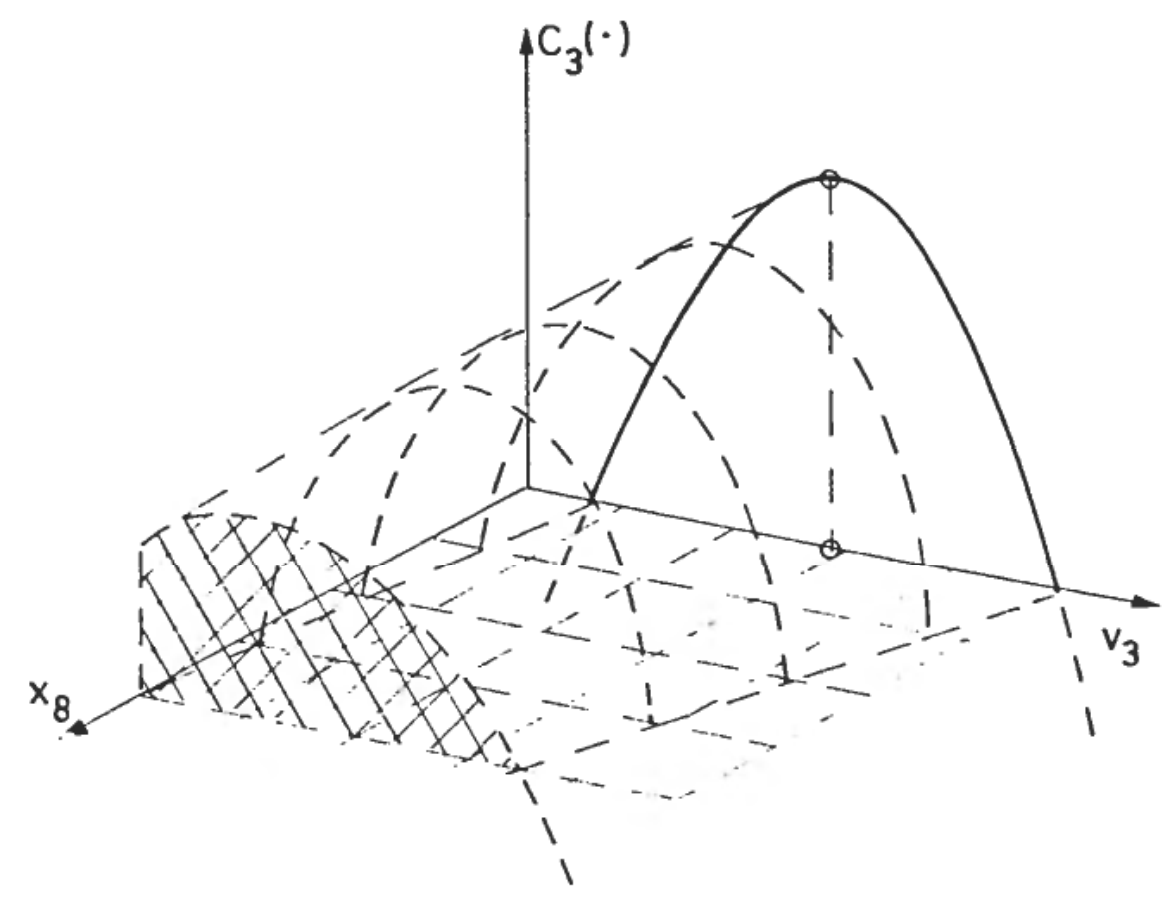

Figure 8. The contribution to comfort by the general light intensity ( $v 3$ ) and the sexual hormon $(x 8)$. (from Balchen 1979a). 
(satiation) and the environmental state variable ( $v 2)$ (concentration of food). It shows that the attraction to food is dependent upon both the level of satiation and the concentration of food.

Finally the contribution to the comfort associated with the general light intensity (v3) is suggested in Figure 8 as $C 3($.). Here it is indicated that one of the physiological states $(x 8)$ (sexual hormone) is contributing in the way that it shifts the preferred light intensity and modifies the sensitivity to changes in light.

The relationships depicted in Figures 6,7 and 8 are interpretations of information available in the literature.

The total comfort function $C($.$) can be regarded as the product of the specialized$ comfort functions $\mathrm{Cl}(),. \mathrm{C2}$ (.) etc. or as a sum if the logarithms of the comfort functions are used.

The environmental state $(v(z, t))$ which influences both the physiological state of the fish and the behavior of the fish through the comfort function can be modeled by itself if there is a negligible influence by the fish upon this environment. On the other hand, the models of other schools of fish which are either predators or preys will have interactions both ways. The same applies to the models of mammals.

The environmental model consists of different layers:

- A hydrodynamic and thermodynamic model in three-dimensional coordinates describing the flow and the energy state of the water.

- A model describing the distribution and transport of nutrients in the water masses.

- A model describing the growth, distribution and transport of phytoplankton.

- A model describing the growth, distribution and transport of zooplankton.

- Models of interacting species of fish.

- A model of mammals.

In Figure 1 a block diagram illustrates these interaction and how they influence the behavior of the fish. The 'matrix' on the left side of Figure 1 is a coarse representation of the interactions. A small circle (o) indicates some degree of interaction.

In equation (2) the gradient of the field of comfort

$$
\partial C(.) / \partial r
$$

appears as the primary driving force for the velocity of migration

$$
d r / d t=\boldsymbol{r}
$$

The question then comes to mind: How do the fish determine the gradient of the field of comfort?

This problem has been studied by sensory physiologists and behaviorists for a long time and much experimental data as well as theoretical hypotheses are available (Balchen 1972, Burgess and Shaw 1979, Fraenkel and Gunn 1961, Glase et al. 1992, Keenleyside 1955/1975). The following basic principles of orientation in animals are found:

(a) 'Tropotaxis': Comparison of sensory stimuli received on a pair of receptors (often symmetrically located on the animal) and rotation of the animal until the difference is zero. This method either requires large gradients or a long distance between the receptors.

(b) 'Klinotaxis': Perturbation of a single or a pair of receptors and cross-correlation of the received stimuli with the perturbation. This method is common in 
many animals but not in fish, because the receptors cannot usually be moved relative to the body.

(c) 'Klinokinesis': Perturbation of the whole animal and cross-correlation of the received stimuli with the turning movements. This method is common in fish behavior.

(d) 'Ortokinesis': Determination of the rate of change of the scalar field of comfort when swimming with a constant speed. This method has much in common with 'kimokinesis'.

A number of other hypotheses than those listed above of gradient determination and orientation in animals can be suggested. An example of this is the radial velocity of migration within a school of fish as a measure of gradients of temperature, salinity, oxygen concentration, food concentration etc.

Combining the hierarchy of environmental models with the behavior model of equation (2) yields a system for the total simulation of the behavior of a single school of fish or schools of non- interacting fish. This has been illustrated for the Barents Sea capelin (Mallotus Villosus) in Reed and Balchen (1982).

The total state of a school of fish can be defined as an augmented vector $\boldsymbol{x}^{t}$ consisting of the physiological state $(x)$ derived from equation (1) and the position state $(r)$ derived from equation (2).

Thus we have

$$
\begin{aligned}
{\left[\begin{array}{c}
\dot{\boldsymbol{x}} \\
\dot{\boldsymbol{r}}
\end{array}\right] } & =\left[\begin{array}{c}
f(x, v,|\dot{\boldsymbol{r}}|, t \\
g(\partial C(\boldsymbol{x}, \boldsymbol{v}, \boldsymbol{a}) / \partial \boldsymbol{r}
\end{array}\right] \\
\boldsymbol{x}^{t} & =\left[\begin{array}{c}
\boldsymbol{x} \\
\boldsymbol{r}
\end{array}\right] \\
\dot{\boldsymbol{x}}^{t} & =\boldsymbol{F}\left(\boldsymbol{x}^{t}, \boldsymbol{v}, \boldsymbol{t}\right)
\end{aligned}
$$

A block diagram illustrating equation (4) is shown in Figure 9.

For computational reasons the differential equation (3.4) must be discretized:

$$
\boldsymbol{x}^{t}(k+1)=\boldsymbol{x}^{t}(k)+\Delta \boldsymbol{t} \cdot \boldsymbol{F}\left(\boldsymbol{x}^{t}(k), \boldsymbol{v}(k), k\right)=\boldsymbol{F}\left(\boldsymbol{x}^{t}(k), \boldsymbol{v}(k), k\right)
$$

where $\Delta t$ is the time increment, $k$ the increment number and

$$
\boldsymbol{v}(k)=\boldsymbol{v}(t, z) \mid
$$

A low comfort (or discomfort) associated with the deviation from any particular direction of migration governed by a directional (vectorial) source of stimuli such as an electrical field, light rays (sun clock), and low frequency sound can be represented by a scalar comfort function which may be interpreted as the 'scalar product' of two periodic phenomena. The 'sun clock' phenomenon is very common in animal behavior and will be used as an illustration of a possible explanation of large scale fish migration, e.g. the migration of the herring (Clupea harengus) across the Norwegian Sea to its spawning grounds along the western coast of Norway.

Suppose that a school of fish during a certain period $t_{p}$ of the day prefers to migrate (swim) toward the sun (when up) and otherwise stay still. If the sun rises in the east and sets in the west and $t_{p}=12$ hours, this will yield a pattern of migration as shown by curve a) in Figure 10. With a constant speed of swimming the pattern of migration 


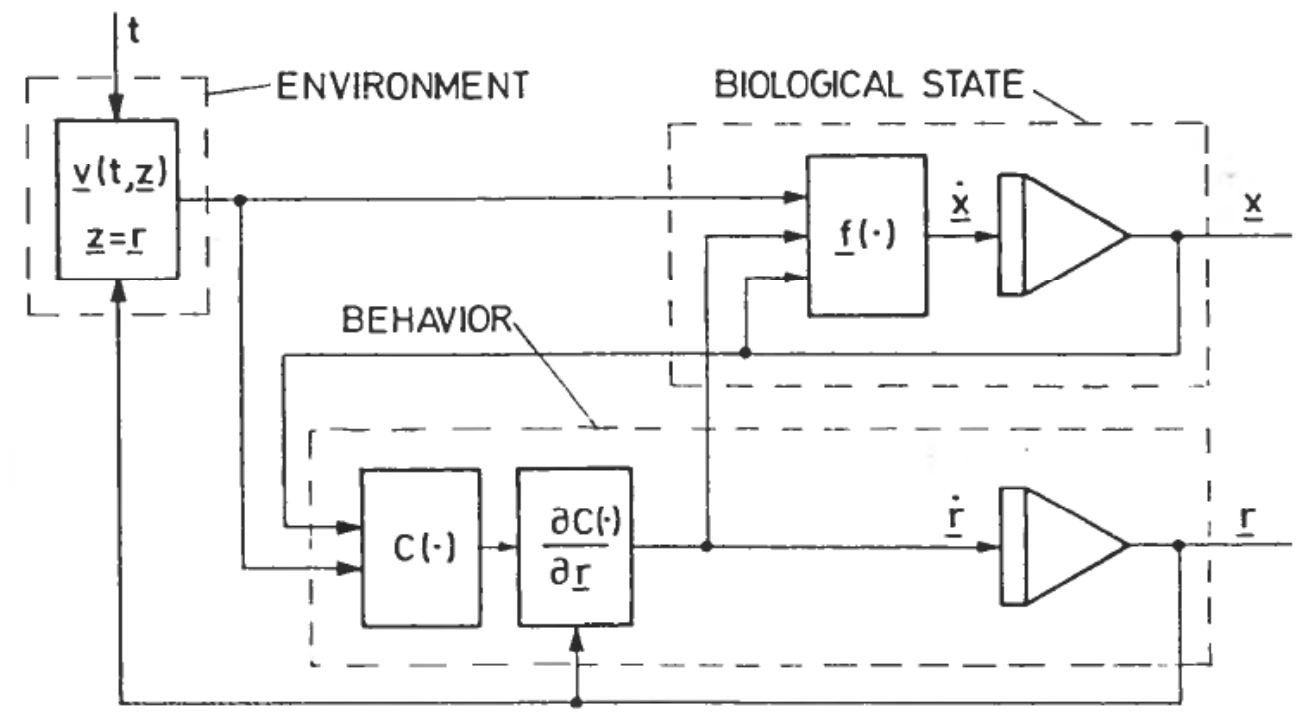

Figure 9. Combining the physiological state (x) with the location of the fish (r) into a total state. (from Balchen 1979a).

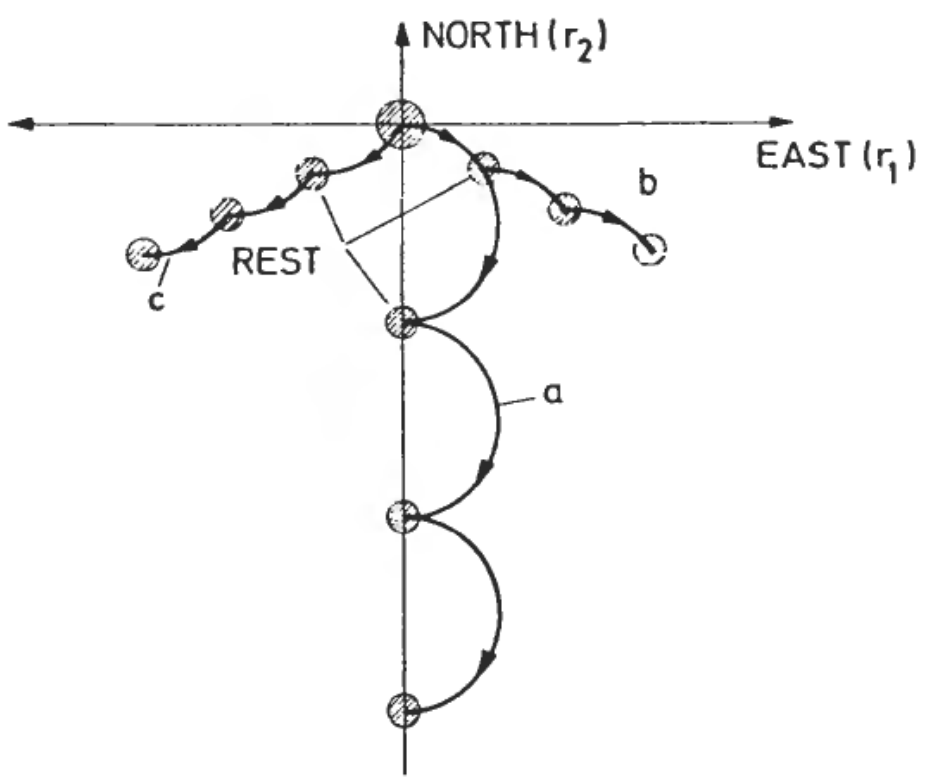

Figure 10. A hypothetical 'sun clock' behavior of migrating 'herring'. (from Balchen 1979a).

will be semicircular, always terminating at the north-south line at night, and thus giving a net southward migration.

Next, suppose that the fish prefers to swim toward the sun only during a relatively short period of the day and rest during the remaining time. Then the direction of migration then will depend on the period of the day during which it swims. If it swims toward the sun only in the morning, the result will be a migration primarily to the 


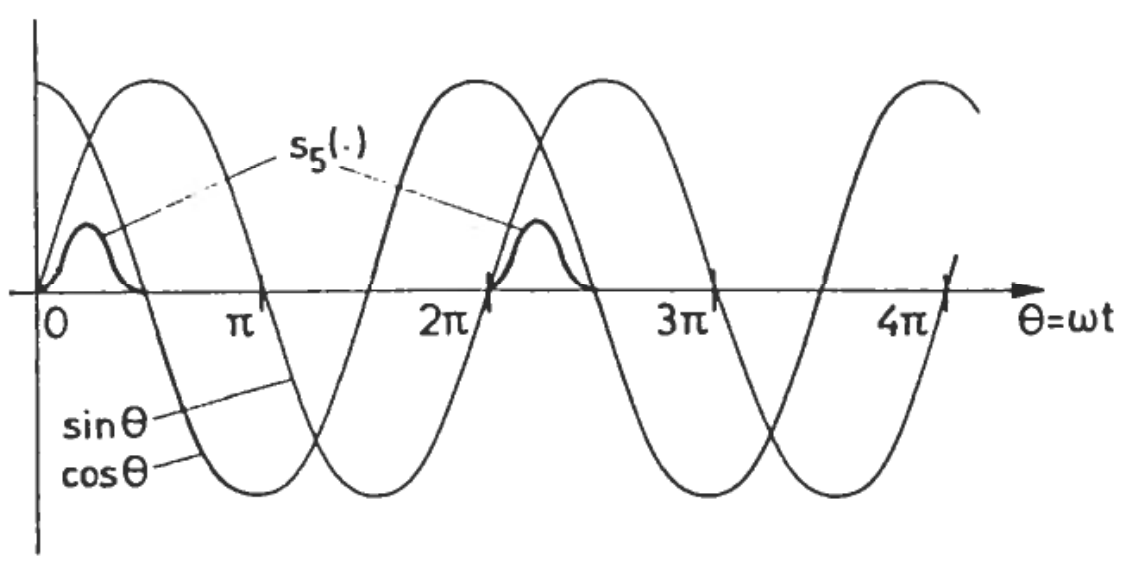

Figure 11. The periodic sensitivity function s5(x). (from Balchen 1979a).

south-east as indicated by curve (b) in Figure 10. If it tends to swim toward the sun only for a short period at the end of the day the migration will be in south-westerly direction as shown by curve (c) in Figure 10. In each of these cases the distance traveled is shorter than for the case of curve (a) because it is assumed that the fish is at rest most of the day.

It is important to note that the tendency to swim toward the sun, say in the morning, is not conscious, but is governed by elementary biochemical processes. Thus the fish does not calculate when it must go toward the sun in order to migrate in a certain direction; rather, the fish migrates in a certain direction because its elementary biochemical processes makes it prefer to swim toward the sun during a certain interval of its daily biochemical cycle.

This phenomenon can be interpreted mathematically in terms of maximization of comfort by employing the scalar comfort function

$$
C_{5}(.)=s_{5}(x) b^{T} r
$$

where

$$
\boldsymbol{b}^{T}=\left[b_{0} \cos \theta, \mathrm{b}_{0} \sin \theta, 0\right]
$$

and

$$
\begin{aligned}
\theta= & \omega \mathrm{t}=\text { angle between east and direction of the sun; } \\
b_{0}= & \text { constant; } \\
\omega= & \text { earth's rotatlonal frequency; } \\
s_{5}(x)= & \text { the periodic sensitivity function govenned by the physiologic state } \\
& \text { (biological clock) as sketched in Figure } 12 .
\end{aligned}
$$

If we assume that the fish searches in the field of comfort in such a way as to move toward the optimum (maximum) with a speed that is proportional to the gradient of the comfort with respect to location, we can derive a differential equation of motion as follows by using equations (2) and (7):

$$
d \boldsymbol{r} / d \boldsymbol{t}=\dot{\boldsymbol{r}}=\partial C_{5}(\boldsymbol{x}, v) / \partial \boldsymbol{r}=s_{5}(\boldsymbol{x}) \boldsymbol{b}
$$

The velocity $d r / d t$ is the average velocity of migration, not the velocity of any searching perturbations necessary to locate and remain on the gradient. If the water masses are moving, the total velocity will be the sum of these two velocities. 


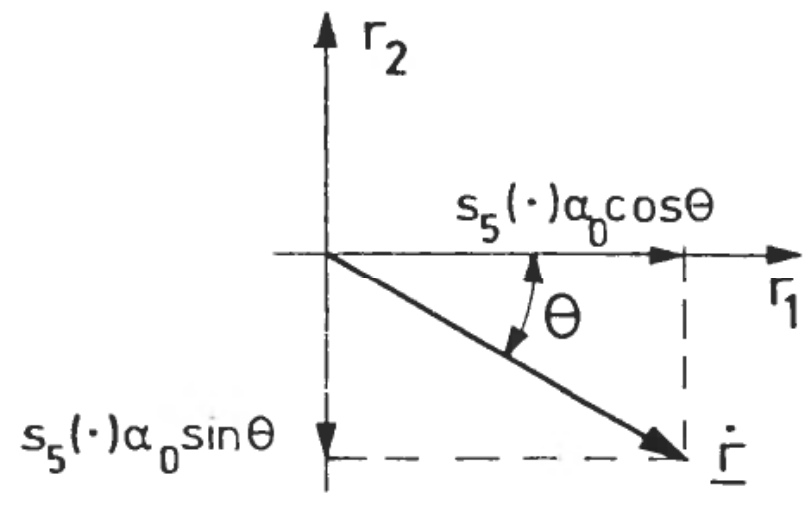

Figure 12. The direction of migration.

Equation (9) states that the velocity of migration in the horizontal plane is proportional to the magnitude of the sensitivity function $s_{5}($.$) and points in the direction of$ the sun as illustrated in Figure 12.

The above very simplified example of possible fish migration as the outcome of an interaction between a biological cycle and a geophysical cycle is significant because it does not assume any 'supernatural' abilities in the fish such as using 'built in navigational senses to find its way across the large oceans to reach a particular point just in time to spawn'.

The momentary optimization assumed to be performed by the fish leads to a long range dynamic optimization through a slow selection of genetic parameters (a) of the comfort functions i.e. preferences. The selection of these parameters may be modeled by a differential equation in which the rate of change of the genetic parameters daldt is a function of the gradient with respect to $a$ of the probability density of survival,

$$
\begin{aligned}
& p(a) \\
& d a / d t=h(\partial p(a) / \partial a)
\end{aligned}
$$

A well-known example of the concept 'probability density of survival' is the relationship between the time of spawning of the Norwegian herring (Clupea harengus) and the hatching of the copepod Calanus finmarchicus (Hjort 1914). Since the only type of food that has been found in the gut of herring larvae is nauphlia of Calanus finmarchicus it is concluded that the spawning of the two species must occur with rather high precision relative to each other in order that the herring larvae shall survive. Those genetic parameters ( $a$ in equation (10)) that determine the arrival time of the herring to the spawning grounds will thus be selected very efficiently in the next generations of herrings.

The notions and hypotheses introduced above of an 'optimization-based behavior' will be difficult to prove without performing large-scale experiments. And many different 'comfort functions' may be proposed that would lead to about the same behavior. But when interpreting behavioral data for schools of fish (say the spawning migration of herring) it is suggested that the adaptation of a behavioral model according to the scheme of Figure 9 could be fruitful. The vector of residuals

$$
\Delta y=y(k)-\bar{y}^{t}(k)
$$

will be a measure of the success of the method and the sensitivity of the residuals with respect to the behavioral parameters (a) will tell about the identifiability of the model. 


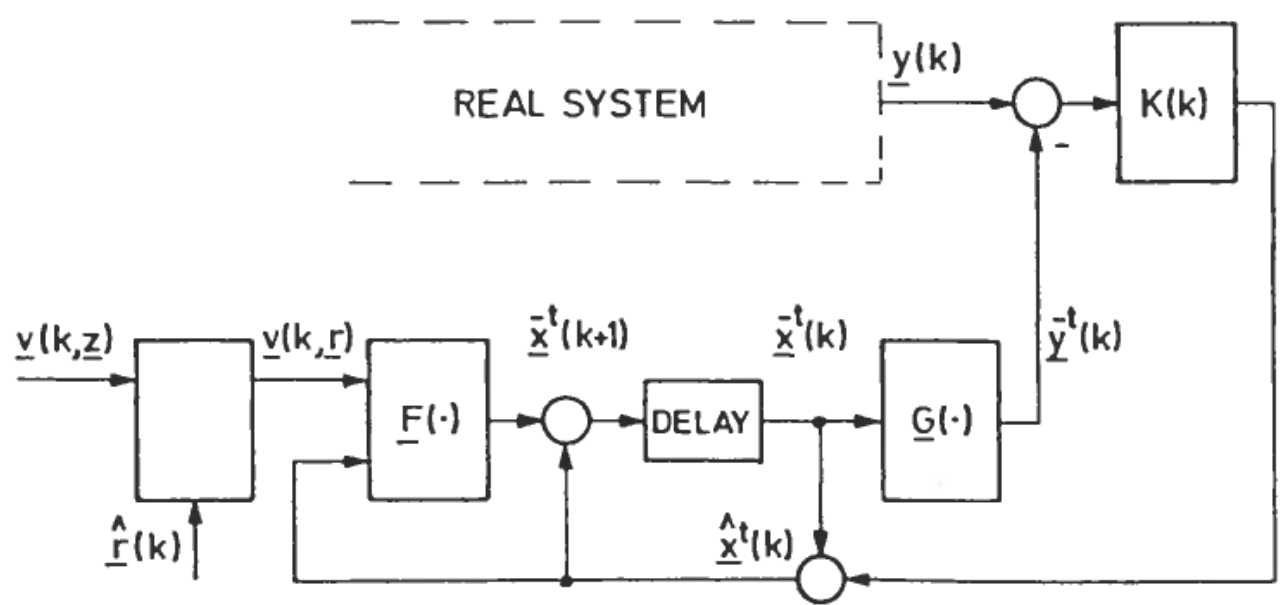

Figure 13. The updating (identification, data-assimilation) of the total system model. (from Balchen 1979a).

The updating (identification, data-assimilation) of a mathematical/numerical model of fish behavior against observed data from the real ocean is an important task with many alternative solutions. Powerful algorithms are available from well established identification theory for the estimation of both states and parameters of general dynamic systems (Henriksen 1998, Ljung 1987, Ljung and Søderstrøm 1987, Ljungquist and Balchen 1994).

The structure of a total system state estimator is shown in Figure 13. Such an estimation scheme would in a real case also include models of the other subsystems of the total ecosystem such as physical and chemical oceanography, zooplankton, fish population, and mammals.

One of the alternative algorithms would be an Augmented Kalman Filter $(A K F)$ in which the updating matrix $K(k)$ is determined by

$$
\begin{aligned}
K(k) & =\hat{X}(k) D^{T}(k) W(k)^{-1} \\
\hat{X}(k) & =\left(\bar{X}(k)^{-1}+D^{T}(k) W(k)^{-1} D(k)\right)^{-1} \\
\bar{X}(k+1) & =\phi(k) \hat{X}(k) \phi^{T}(k)+\Omega(k) V(k) \Omega^{T}(k)
\end{aligned}
$$

where

$$
\begin{array}{lc}
\phi(k)=\partial \boldsymbol{F}(\cdot) / \partial \boldsymbol{x}^{t}(k), & D(k)=\partial \boldsymbol{G}(\cdot) / \partial \boldsymbol{x}^{t}(k) \\
\Omega(k)=\partial \boldsymbol{F}(\cdot) / \partial \boldsymbol{v}(k), & \boldsymbol{y}(k)=\boldsymbol{G}\left(\boldsymbol{x}^{t}(k)\right)+w(k)
\end{array}
$$

and

$$
\begin{aligned}
\hat{X}(k) & =\operatorname{cov}\left(x^{t}(k)-\hat{x}^{t}(k)\right), \quad \bar{X}(k)=\operatorname{cov}\left(x^{t}(k)-\bar{x}^{t}(k)\right) \\
W(k) & =\operatorname{cov}(w(k)), \quad V(k)=\operatorname{cov}(v(k)) \\
\Delta y & =y(k)-\bar{y}^{t}(k)
\end{aligned}
$$

A problem with this solution is that the matrix function $\boldsymbol{F}(\cdot)$ of equation (5) is very sparse. Therefore there is a need for approximations to save computational capacity (Sælid 1978b), (Thunem 1979). 


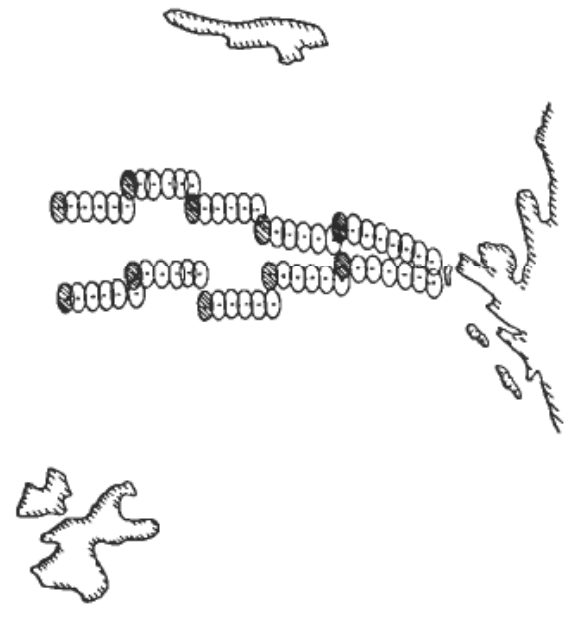

Figure 14. Estimation and updating of fish migration (from Balchen 1979a).

This problem is still not solved in a satisfactory manner and more research needs to be done (Dahl 1998).

Figure 14 illustrates how the motions of two schools of fish migrating in easterly direction are estimated (white circles), observed (dark circles) and then updated.

\section{Signals in the sea}

The sea transmits a large variety of 'signals' or 'stimuli' to and from the fish. Because the number of signals is so large it seems meaningless to discuss all possibilities, but rather concentrate on those that are most significant in determining fish behavior. Furthermore it will be of interest to isolate the type of signals that may become useful in exercising artificial control actions upon the fish behavior.

There are many ways of classifying stimuli with respect to their influence upon the fish behavior. One possibility has the following characteristics (Balchen 1981b):

- With regard to direction:

- Attracting stimuli such as smell of food and certain sounds.

- Repelling stimuli such as smell of a predator and certain sounds.

- Directional (vectorial) stimuli such as sound and light rays.

- Nondirectional (scalar) stimuli such as temperature and smell of food.

- Converging stimuli such as a point source of attracting stimuli.

- Diverging stimuli such as a point source of repelling stimuli.

- With regard to physical origin:

- Acoustic stimuli:

- Mechanical vibrations in the water in the frequency range $10-500 \mathrm{~Hz}$ which can be detected by a number of different sensing organs i.e. the lateral line, the three otholites. Fish can detect both direction and some times distance to an acoustic source.

- 'Biological sounds' (e.g. feeding sounds) carrying a particular message to the fish giving either attracting or repelling stimuli.

- Acoustical signal in connection with a conditioning system (see Section 6). 
- Visual Stimuli:

- General light intensity (scalar).

- Particular light source yielding a directional stimulus e.g. in connection with conditioning.

- Geometrical figures yielding either attracting or repelling stimuli (e.g. prey, predators).

- Olfactory stimuli:

- Source of biochemical agent yielding either attracting or repelling stimuli (mostly nondirectional) (e.g. food, pheromones).

- Electrical stimuli:

- Weak electrical sources which can be detected by specialized organs in some species.

- Strong electrical sources giving electrical shocks yielding electrotaxis (unconscious motion) or 'punishment' related to pain in systems based on conditioning.

- With regard to meaning:

- Some signals (stimuli) received by sensory organs in the fish have no particular meaning in the sense that there is no learning involved about related consequences like rewards or punishment (e.g. arbitrary sound or smell). However, such signals may become meaningful if they become part of a learning process (e.g. conditioning).

- Some signals (stimuli) carry a message known to the fish either as a result of a natural learning process (e.g. feeding sounds $=$ food, particular smell $=$ predator) or as an instinctive reaction (genetic).

- Habituation is a very common phenomenon which means that the fish become insensitive to a signal in terms of behavior when there is no important consequence associated with the signal (e.g. acoustic noise which turns out to be neither very unpleasant nor dangerous).

Whether an individual fish or a school of fish will respond with a change in behavior (e.g. motion) when subject to any signal (stimuli) as described above is a complex question to be analyzed in more detail in the following.

\section{Control of fish behavior}

Control of fish behavior, if control is possible, by the application of artificial signals or stimuli, may be useful for many purposes. The most obvious purposes may be (Balchen 1998):

- Attraction and concentration of fish for harvesting purposes.

- Control of fish motion in relation to fishing gear for harvesting purposes.

- Design of artificial barriers to prevent fish from escaping from storage in an enclosed area.

- Preventing fish from entering hydroelectric power plants.

- Control of fish behavior during farming (aquaculture) in large enclosed areas to achieve optimal feeding, sorting and harvesting.

The uncontrolled behavior of fish is subject to a large variety of signals which in a control context must be regarded as disturbances. The objective of a control system is 

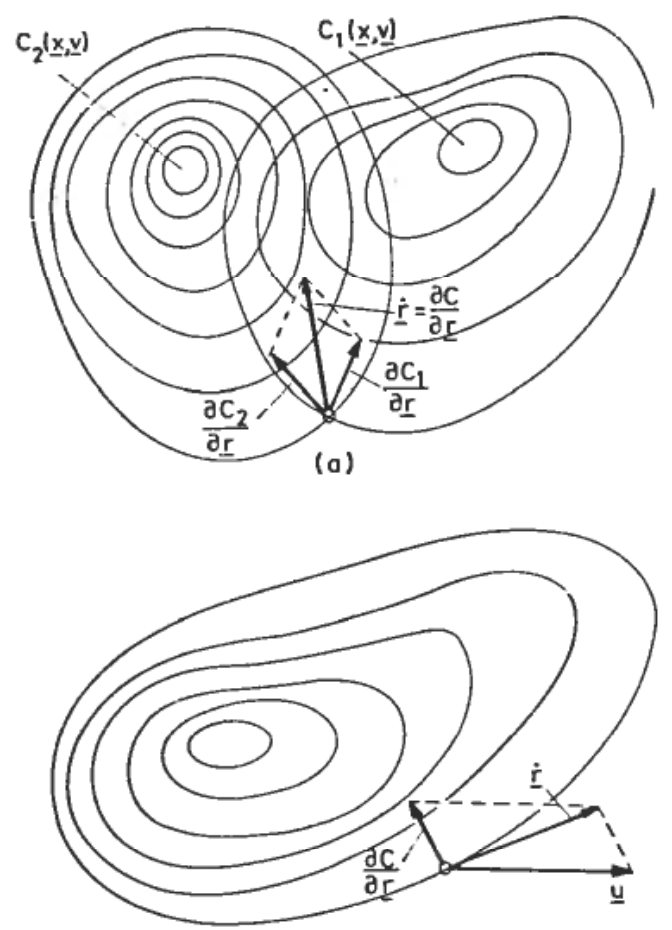

(b)

Figure 15. Combining fields of comfort and external stimuli (from Balchen 1979a).

to generate external signals/stimuli which will modify the behavior in a systematic manner and which are stronger and more persistent than the disturbances.

Some possible control signals may be found among most of those listed in Section 4 above:

- Control of fish (e.g. trout in mountain streams) by 'electro taxis' used by research biologists. Special electrical generators with electrodes submerged in fresh water will attract fish to some extent.

- Controlling the fish motion by external stimuli can be interpreted in terms of the principle of maximization of comfort as introduced in Section 3. First the combination of different contributions to the 'comfort' are regarded as additive as illustrated by the sum of two vectors in Figure 15a.

Second the vector $(\boldsymbol{u})$ of external stimuli is combined by vector summation with the vector of natural stimuli to form the total driving force as shown in Figure 15b.

- The motion of some species (e.g. a school of herring (Clupea harengus)) may be controlled by a strong acoustic projector (loudspeaker), located onboard a boat at a distance of about 5 times the diameter of the school, and generating a strong harmonic sound at a frequency around $20-50 \mathrm{Hertz}$, provided the attracting forces within the school are stronger than the repelling forces due to divergence (Torsen and Dalen 1971, Dalen and Torsen 1973).

The repelling tendency of a low frequency acoustical signal is highly dependent upon the species of fish involved. Herring may respond to a signal that does not give any reaction in cod (Gadus morhua). 


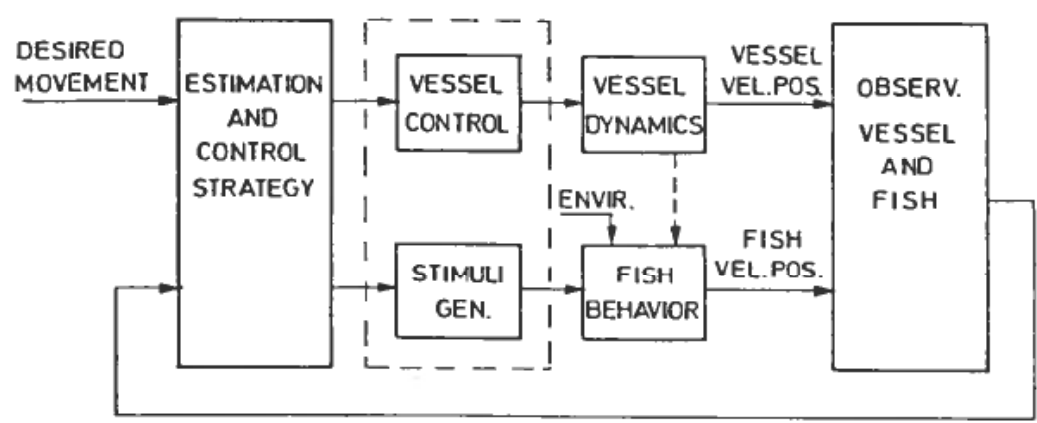

Figure 16. A proposed system for feedback control of schooling fish. (from Balchen 1979a).

Figure 16 illustrates a system of feedback control of a school of fish which has been suggested in Balchen (1981).

This method of control is not very robust because a short disturbance of any kind may divide the school and thereby create general divergence.

- Attracting signals (e.g. 'biological sound $=$ feeding sound') have an advantage over repelling signals because they lead to converging behavior. However, habituation may soon occur if the fish discovers that 'a promised reward' does not materialize (Slagstad 1974a, Slagstad 1974b).

- The 'significance' or 'strength' of a signal, whether attracting or repelling, is a decisive factor in the application for control of fish behavior. But it must also be possible for the fish to detect the direction to the source of the signal (Olsen 1974d). An experiment showing the response of a single saithe (Pollacius virens) to a very strong acoustic pulse from an airgun (for seismic surveying) indicates that if the signal is too strong the fish may lose its ability to detect direction and thus not be able to respond with a logical motion (Balchen 1974). However, if the signal from the airgun is combined with another acoustical signal which the fish can easily detect both in magnitude and direction, then the airgun will act more like a 'punishment' in a conditioning system and the fish will respond with a motion away from the source.

- 'bubble curtain' (a wall of air bubbles from a pipe with a large number of small holes located at the bottom) is a very effective barrier for a number of fish species (e.g. herring, saithe) and less effective for other species (e.g. salmon). The bubbles produce a repelling stimulus which is both acoustic and visual when the fish comes close to the curtain (less than about 2 meters) (Olsen 1974a, Olsen 1974b). The bubble curtain is effective up to a certain 'pressure' (concentration) of fish inside the curtain. When this 'pressure' is exceeded the fish will break through the curtain. Some species (e.g. salmon) have a high concentration of bubbles as their natural environment and will thus not react significantly to a bubble curtain.

- Conditioning is probably the most effective way of controlling fish behavior and will be discussed in detail in Section 6.

\section{Control of fish behavior by conditioning}

It was emphasized in Section 5 that control of fish behavior can be greatly enhanced if the fish can learn that:

- there exists a relationship between 
- one signal (conditioned stimulus, trigger) which can easily be detected by the fish (e.g. sound pulse, light pulse)

- and another signal (unconditioned stimulus, conditioner) which carries a significant impression on the fish (e.g. food (reward), electric shock (punishment)).

- then the fish will respond with a motion when the trigger signal comes, either towards (attracting) or away from (repelling) the point of the conditioner.

Many examples of conditioning systems for control of fish behavior are known (Balchen (1973), Olsen (1974c), Balchen (1976), Jensen and Balchen (1976), Balchen (1977), Balchen (1978a), Balchen (1978b), Balchen (1979a), Balchen (1979b), Mork (1979), Mork and Balchen (1980), Balchen (1981b), Balchen (1998)).

\subsection{Recapture of saith (Pollachius virens) under long-term storage}

One important application of control of fish behavior by conditioning is in the recapture of large amounts of saithe (Pollachius virens) which have been hauled into a bay or fjord for long term storage.

On the west coast of Norway the saithe fisheries result in catches that are far beyond the capacity of the freezing industry. At the same time it is known that the saithe can be kept alive for long periods (from October to March/April) without loss of quality. The background for this is that the saithe stores much energy in its liver during the early fall and will sustain its metabolism by drawing from this energy. The amount of energy stored is measured by the 'liver index' which is the weight of the liver relative to the full body weight. When the saithe is brought into storage it may have a 'liver index' of $14-15 \%$. If the 'liver index' does not go below $6 \%$ the quality of the fish will not be reduced.

When large amounts of saithe (e.g. 100-1000 metric tons) are stored in a narrow fjord it is imperative to have a system for recapture which can be operated by one man and which delivers the necessary amounts of live fish daily to the freezing plant after slaughtering (e.g. 5-10 metric tons per day).

During the fall of 1977 such a system was installed in narrow fjord at the island Frøya in west Norway and 30 metric tons of saithe were brought in from nearby fishing grounds (Holand 1978). The recapture system included:

- a hydraulically operated net in a frame of 16 meter diameter.

- an electronically controlled feeder with timer and light control.

- a source of low frequency sound.

The results of the experiments can be summed up as follows:

- it is quite simple to condition the fish to come to the feeder when the sound pulses are transmitted.

- after a short period of training the fish demonstrate a high degree of confidence; they do not seem to be scared by regular and stable noise from motors etc; and swim freely in and out of the net. This behavior should be compared with that experienced previously when trying to capture saithe with an ordinary shore seine, which turned out to be very inefficient and labor intensive.

- it is important, particularly when the temperature in the water drops below $7 \mathrm{deg}$. Celsius, that the fish under storage are being fed so much during the conditioning that they keep up their motivation for food.

- since the days are quite short in the winter in Norway the conditioning is greatly enhanced when a light source is operated together with the sound source. 


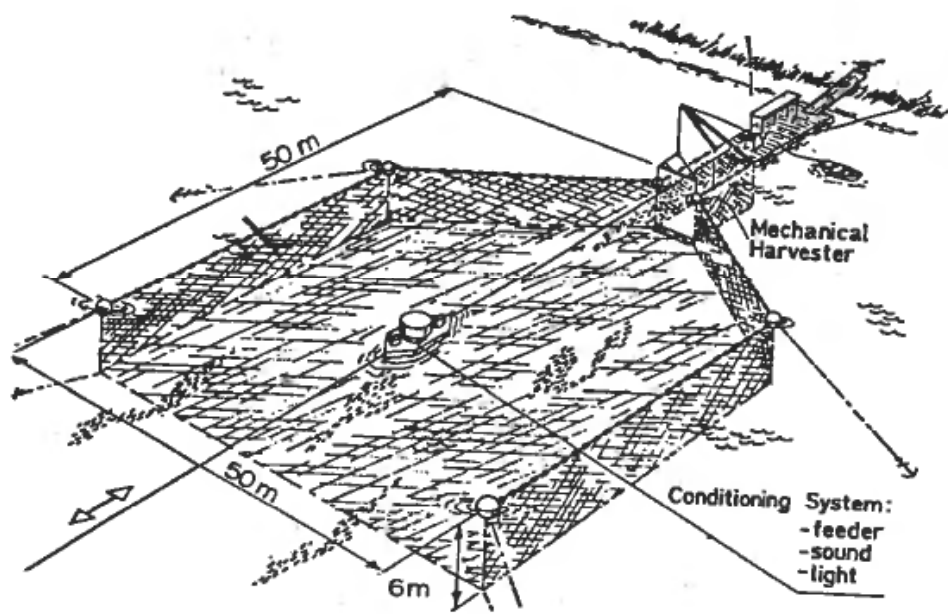

Figure 17. Recapture of stored and conditioned saithe. (from Balchen 1978b).

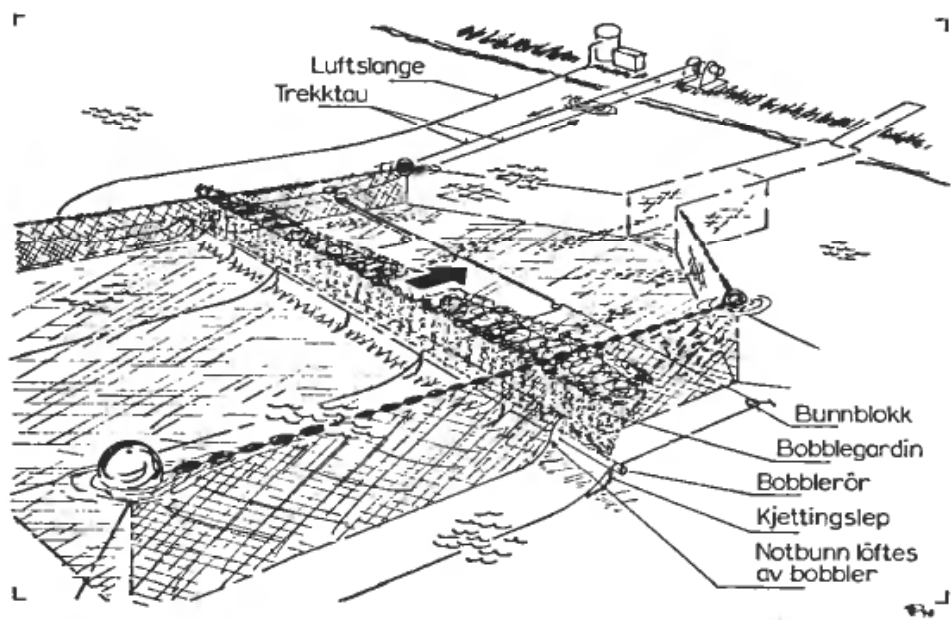

Figure 18. 'Drying' of the capture net for transfer of the fish to the mechanical harvester. (from Balchen 1978b).

Based on the experience gained during these tests a semiautomatic recapture system utilizing conditioning was designed (Balchen 1978b) as shown in Figure 17.

It consists of a mobile conditioning unit containing a feeder, a sound source and a light source. This unit is first located in the center of the bay during the conditioning of the fish. With regular intervals (about every hour) the unit is hauled from the bay into a stationary net (size $50 \times 50$ meters). A major part of the fish gathered around the conditioning unit will follow the unit into the net.

The net can be 'dried' by meants of a 'bubble pipe' which is hauled underneath the net as shown in Figure 18, thereby forcing the fish to swim into a smaller net (mechanical harvester) for final capture and transfer to the slaughtering facility.

\subsection{Electric barrier for fish based on conditioning}

In systems for long term storage of live fish and in large scale fish farming in closed off bays and fjords there is a need for a non-mechanical barrier to prevent the fish 

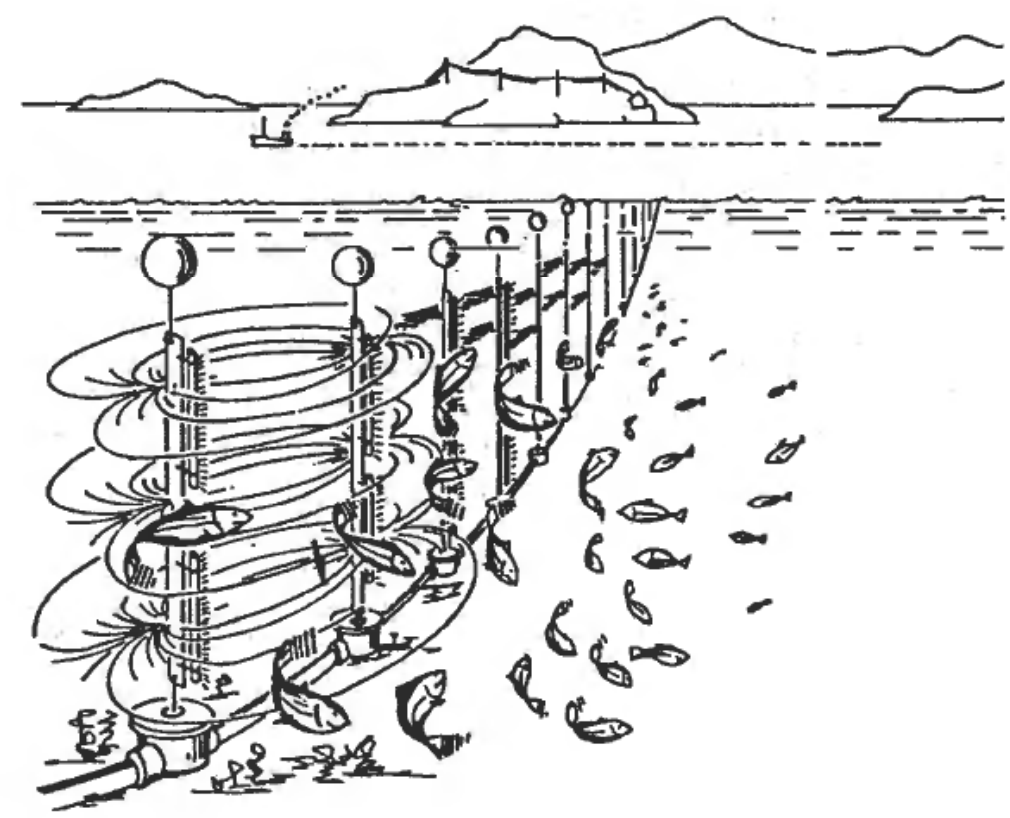

Figure 19. Electric barrier based on conditioning.(from Balchen 1981).

from migrating out of the area. 'Bubble curtains' are simple and inexpensive, but cannot be used in case of salmon. Ordinary nets have a tendency to collect debris and algae such that mechanical forces due to the current and waves will become excessive.

An electric barrier was developed during the period 1974-1985 (partly in cooperation with a Norwegian electrical engineering company) which is illustrated in Figurc 19 (Sølvberg 1977, Balchen 1981, Balchen 1998).

The electric barrier consists of electrodes made of iron plates $(3-5 \mathrm{~m}$ long, $20 \mathrm{~cm}$ wide, $0.3 \mathrm{~cm}$ thick) hanging vertically from floats at the surface at a distance of about $5 \mathrm{~m}$. Each electrode is connected to a high power electronic switch which discharges a strong current pulse from one electrode to a neighboring electrode. Attached to each electrode is one or two incandescent lamps which make a strong light pulse at the same time as the current pulse. The effect of this is as follows:

- when a fish of length $\mathrm{L}$ is closer to the barrier than about $20 \mathrm{~L}$ it will experience a significant electrical shock which is so painful that it will try to avoid it. But the fish does not have any information about the location of the source of the pain.

- the purpose of the lamps is to give the fish directional information. 'The fish will think that the pain is caused by the lamps which it can easily see and avoid.

- acoustic projectors can be added to or replace the lamps in order to improve the directional information when the ambient light intensity is high.

- this can be interpreted as conditioning where the light/sound pulse is the 'trigger' (unconditioned stimulus) and the electric shock is the 'conditioner' (conditioned stimulus).

- even if the main electrical power supply fails for a short time while power is available for the lights, the barrier will be active for some time until the fish has learned that there is no pain associated with the lights. 
The principles employed in the electric barrier can be utilized in other similar applications such as a proposed system for hauling and long-term storage of North Sea mackerel (Scomber scombrus) in fjords on the west coast of Norway (Balchen 1977c). The purpose of such a system is to utilize a valuable resource in a better way for human consumption rather than as a raw material for the fish oil and meal industry.

When utilizing natural landscapes with islands, sounds (inlets), bays and fjords for storing fish it is often discovered that the fish at times do not tend to pass the point of a barrier. Thus at that time there is no need for a barrier. At other times there is a great need for a barrier because the fish demonstrate a strong desire to pass the same point. A logical consequence of this observation is that a barrier should be 'intelligent' in the following sense (Balchen 1990a):

- a sensing system (e.g. narrow beam sonar) could sense the presence of fish at the point of the barrier.

- any kind of controllable barrier could be used

- when the sensor detects the presence of fish the barrier is activated, otherwise not.

This type of 'intelligent barrier' would have some advantages:

- it would use less energy (if electric barrier or bubble curtain). it would collect less debris (if mechanical net).

- it would not be costly.

- it would require less maintenance.

\subsection{A fish trap based on conditioning}

Conditioning has been suggested as a means for enhancing the efficiency of fish traps by attracting the fish with the combination of a single frequency acoustic signal and small amounts of attractive food.

Based on introductory experiments in 1973-74 (Olsen 1974c), new equipment was designed in the mid 1970s aimed at developing 'a system based on conditioning for harvesting of fish in coastal waters' (Presterud and Sølvberg 1976, Balchen 1976d).

The equipment consisted of:

- two electronically controlled feeders including programmable sound sources.

- an underwater TV-camera to be located 5 meters below one of the feeders (no. 1).

This equipment was used in an experiment in 1976 where for the first time 'wild' fish in an open fjord were conditioned with sound and food (Jensen and Balchen 1976).

A sonic tag was successfully introduced into the stomach of a fish (saithe (Pollachius virens)) by hiding it in a small bait which was swallowed by the fish.

The position of the fish was estimated by means of the 'Analog Fish Position Estimator' described in Håndlykken (1974). Thereby the motion of the fish between the feeders during the different experiments could be monitored as shown in Figures 20,21 and 22

The conclusions drawn from these experiments were:

- when fish exists in an area with radius 500 meters (possibly larger) it will be attracted to the conditioning system provided it has participated in the conditioning sequence. 


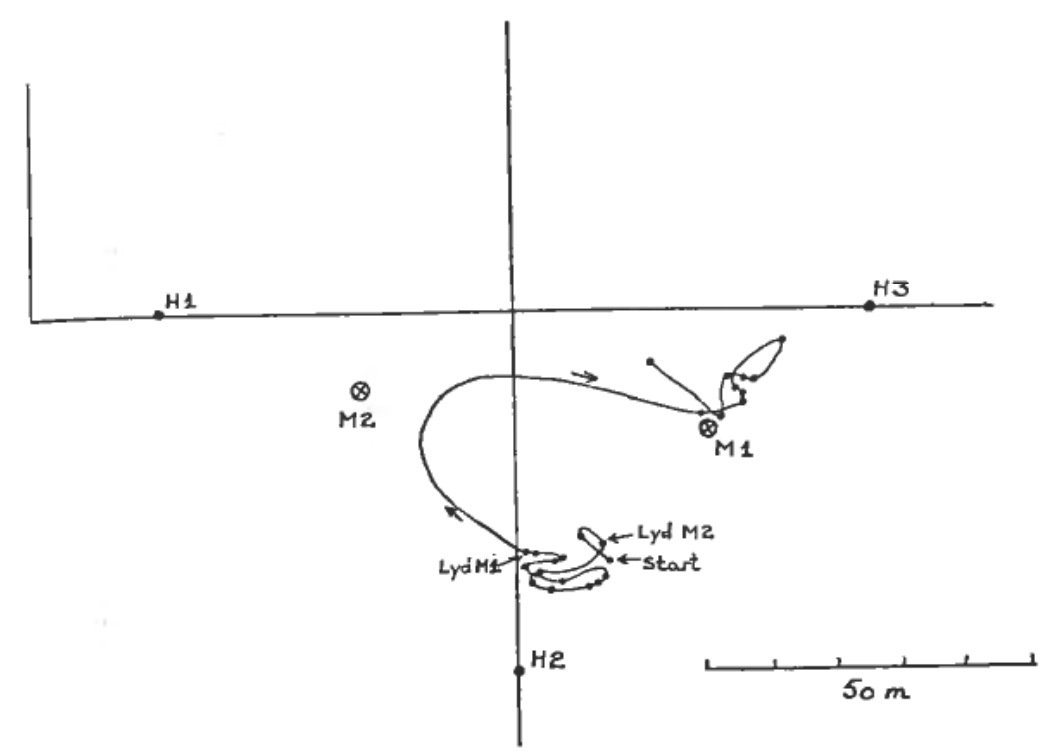

Figure 20. Motion of saithe after trigger sounds (lyd) from feeders Ml and M2. ANPOINT hydrophones at H1, H2 and H3. (from Jensen and Balchen 1976).

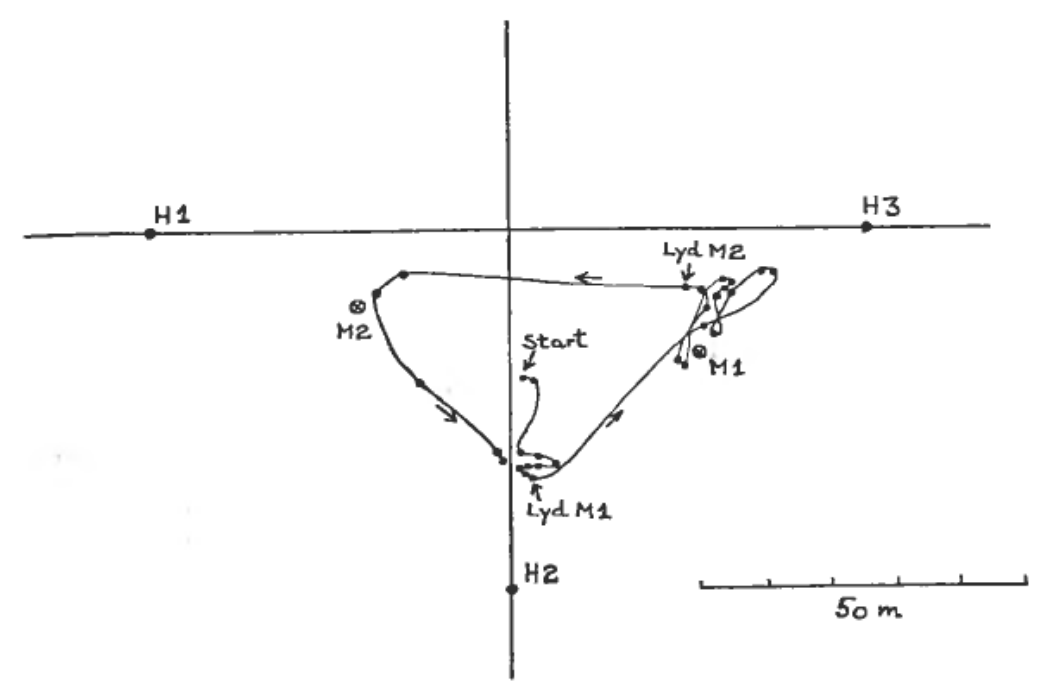

Figure 21. Same as Figure 6.4. but in a different experiment.

- no fish are seen on the TV-monitor when the conditioning sequence starts.

- the first fish appears after the second sound/food-pulse. other fish are rapidly attracted by copying behavior

- within about 2 hours 40-50 fish are observed on the monitor (see Figure 21).

- it is observed that when feeder no. 2 (without TV-camera) is active there are only a few fish at feeder no. 1 (with TV-camera). This indicates that the desired motion over about 50 meters has been achieved.

Based on these results a trap as shown in Figure 23 was built and tested in 1977. It 


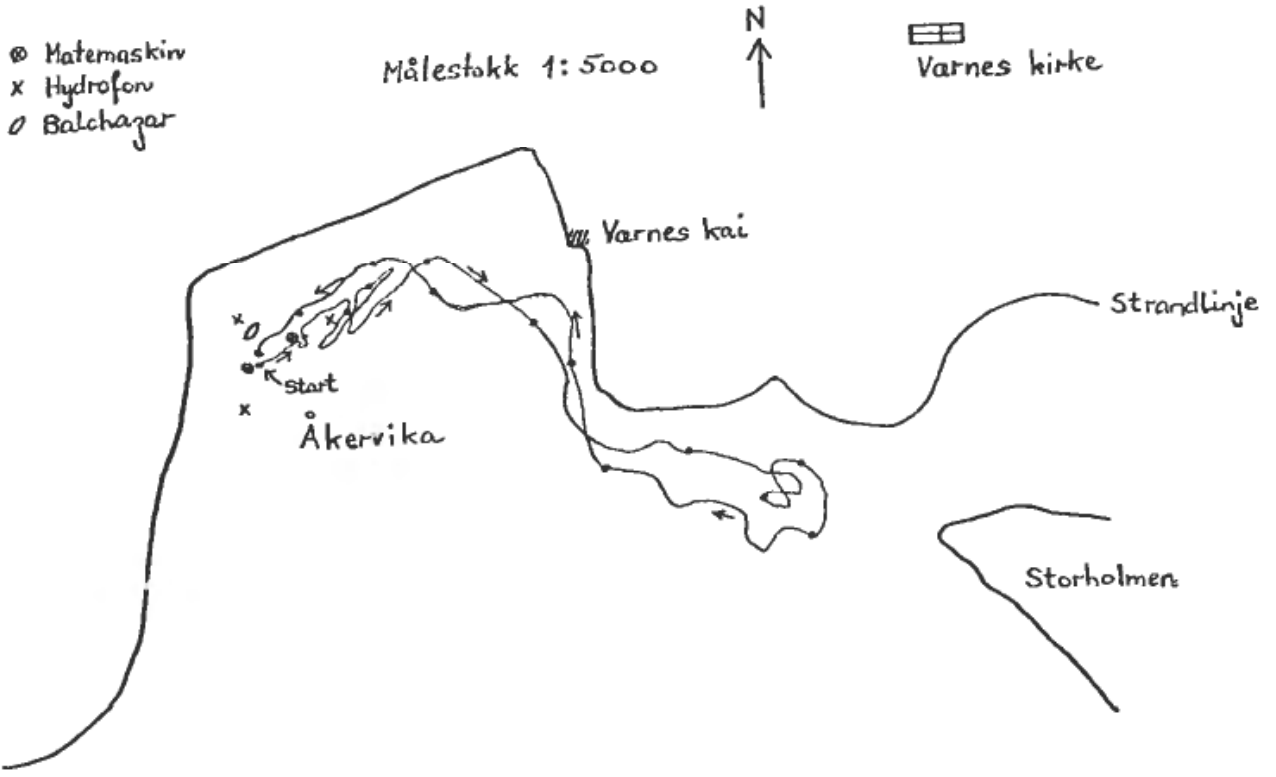

Figure 22. Experiment with attraction of a conditioned saithe over a distance of 500 meters. (from Jensen and Balchen 1976).

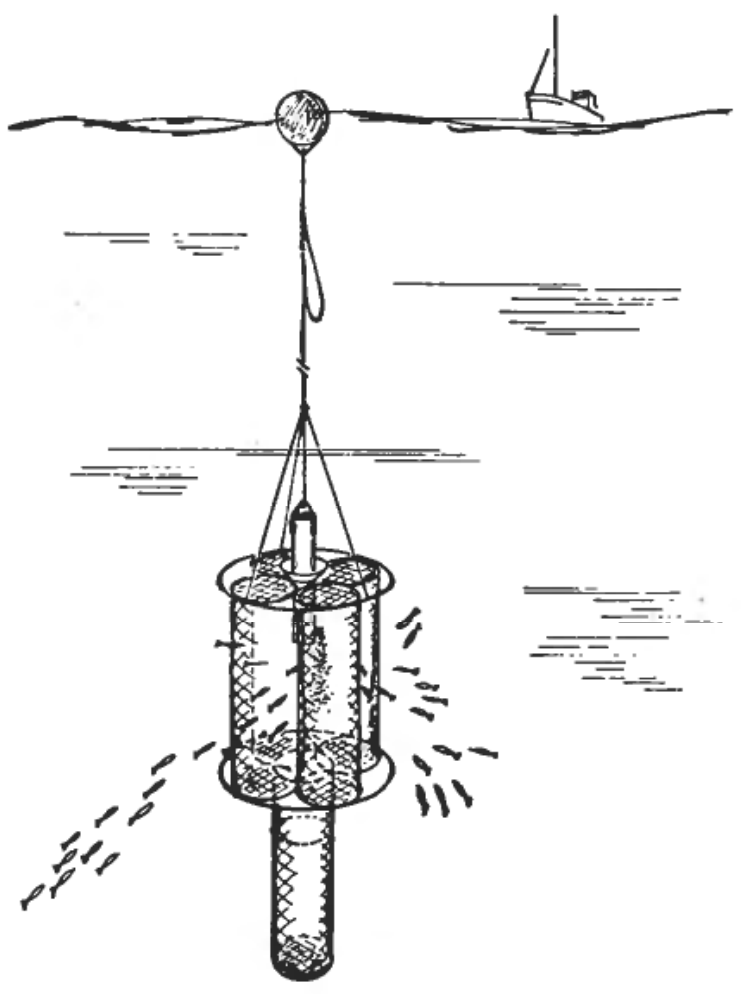

Figure 23. An experimental fish trap based on conditioning. (from Balchen 1978a). 
was discovered however that a number of operational difficulties occurred related to strong current and wind forces on the surface ship and the trap. Also the quality of the available TV-camera presented severe limitations on the experiments. As a consequence the 1977 experiments did not yield adequate results and it was decided to continue with improved equipment in another location during the summer of 1978 (Balchen 1978a).

The same operational difficulties occurred in 1978 (extraordinary weather), but the net results were useful and confirmed the opinion that $a$ fish trap based on conditioning could be designed. A number of design details had to be solved:

- the automatic feeder should be simplified and improved with respect to power consumption.

- the trap should be designed so that it was less voluminous when onboard the surface vessel, but with the ability to expand in the sea.

- the active devices for capture of the fish should be simplified.

After the experiments in 1978, the development activities in this field were reduced for some years particularly because of changes in research priorities in Norway and the lack of funding from the fisheries equipment industry. The problems were still there, however, and in the late 1980s new attempts were made to continue the development of the new fish trap.

Finally in 1994 a cooperative development program was organized between the Department of Engineering Cybernetics and a Norwegian fisheries equipment company sponsored by the Research Council of Norway. Also a new general research program on 'Control of fish behavior by conditioning' was started in 1996 which will terminate in 2000. This program includes theoretical and experimental research of a doctoral student which will be completed early year 2000 (Alfredsen 1999a).

\subsection{Control of fish behavior during aquaculture (farming) in large closed-off coastal areas}

The most common traditional way of farming fish (e.g. Atlantic salmon (Salmo salar)) is in floating pens in protected coastal waters. This technology has been developed to a high level productivity and quality particularly in Norway.

There are, however, many aspects of this method that could be questioned, and proposals have been made for alternative techniques offering apparent advantages (Mork 1979, Balchen 1979b, Mork and Balchen 1980, Balchen 1998).

One such proposal which has been studied in Norway over many years and supported by large-scale experiments can be described as follows (Figure 24):

- The floating pen is replaced by a natural coastal enclosure (bay, inlet, fjord etc) with good natural water circulation and closed off with a non-mechanical barrier (e.g. electric barrier).

- The enclosure should be $0.2-5$ square $\mathrm{km}$. Such enclosures are abundant in Norway, Scotland, and Canada.

- Mechanical barriers (e.g. nets) cannot be used because they collect debris and are easily destroyed.

- Juvenile fish that have been conditioned with sound/food during their first year(s) in tanks and pens are released in the bay under conditioning.

- Automatic feeding stations with conditioning equipment, sensing systems and remote control are anchored at different locations in the bay. 


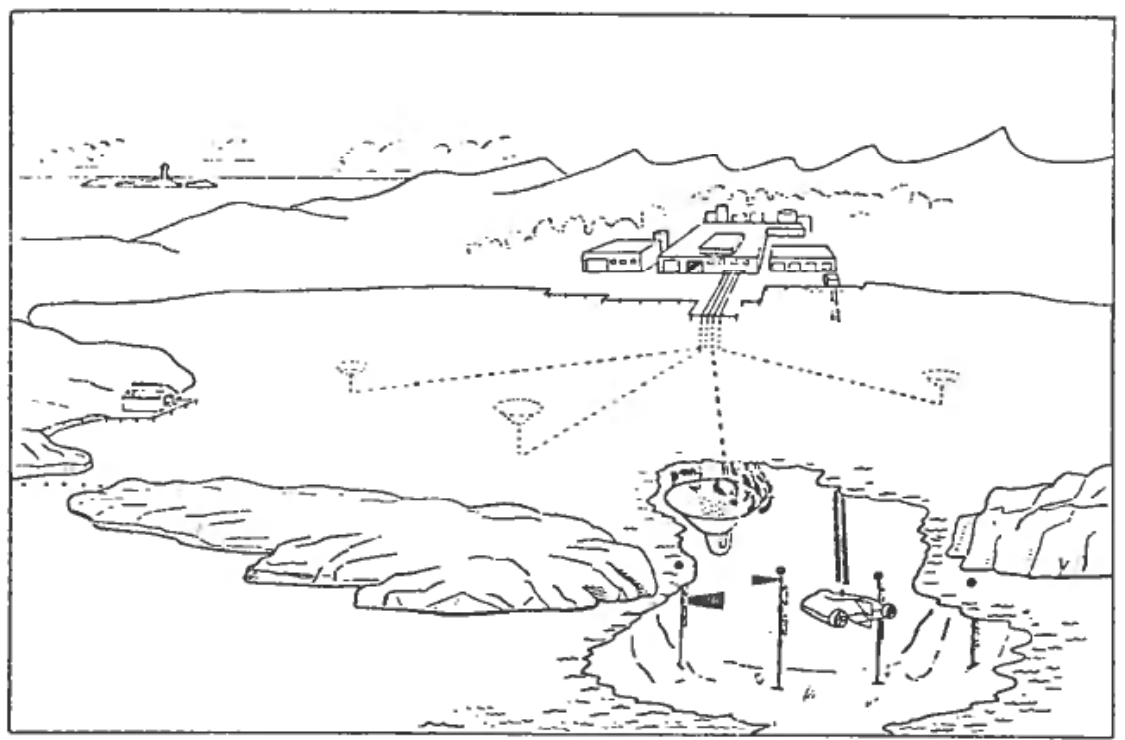

Figure 24. Proposed system for fish farming in large closed-off waters (from Balchen 1987b).

- This system can be operated in a number of ways:

- Each class of juveniles can be assigned to specific conditioning feeders (cond-feeders) with specific signatures (frequencies) thereby controlling that class to stay in a specific location.

- Different classes of juveniles can be controlled by the same cond-feeders

- The system can be used to separate fish of different size based on their difference in swimming speed.

- Harvesting conditioned fish is very simple.

This new technology for fish farming has many potential advantages compared to traditional 'floating pen technology', but obviously also some new problems may arise. The most apparent advantages to be expected with the new technology are:

- the cost of installations and operation of a large farming facility will be only a small fraction of the cost for an equivalent large 'floating pen' facility.

- due to much lower density of fish the problems of spreading infection and viral diseases are greatly reduced.

- greatly reduced probability of losses due to escape of fish during bad weather conditions because the fish are not 'imprisoned' and do not want to escape.

- lower losses of feed and thus better feed economy and less pollution since the fish are not prevented by the net of the pen to take feed that otherwise would leave the pen.

- easy to arrange for fish to get more physical exercise and thereby improve the quality of the product.

Among the 'new problems' to be expected, the following should be mentioned:

- the need for separating large from very small fish to avoid predation. The smallest fish could be kept in pens.

- some fish with different behavior may seek isolation and should be identified and located in order to be brought together with others or slaughtered. 
- the population of other species of wild fish (e.g. saithe) which have entered the system as juveniles may become excessive and should be controlled. A possible way to do that is through the behavioral differences of the species.

- if the population of one category of fish is very large (say more than 50000 individuals) it must be expected that they could become divided into two or more sub-populations. This phenomenon should be identified and control of the new population(s) should be established by adding new conditioning systems. The cause could be that there is an upper limit to how many fish each conditioning unit can handle due to the competition at the feeding stations.

- By putting small sonic tags on a small number of fish ( 0.1 percent) the locations of the different sub-populations are easily determined.

- in general there is a need for detecting and monitoring the state of the fish population in such an open system in which the fish is not observed all the time as they are in pens. This problem has many solutions and it will the subject of future research and development to select the best methods from technical and economical points of view.

\subsection{Model-based control in fish farming}

The dynamics of the growth process in fish farming is quite well understood and mathematical models have been established which are useful for the control of the process (Tyssø 1987a). With a dynamic model it is possible to predict the future development of the growth process assuming certain external conditions such as temperature, ambient light intensity, amount of feed and essential parameters related to feed quality. Depending on which variables are chosen to be manipulated different control strategies can be developed with the goal of maximizing the yield in some way.

Computer based instrumentation and control of aquaculture plants have become a successful business in Norway during the 1980-1990s and this technology has been adopted also in other countries (Tyssø 1987b, Balchen 1987a).

\section{Instrumentation and Biotelemetry}

It has been pointed out in the previous sections that a variety of measurements are required to obtain knowledge about the actual conditions in the physical and biological systems of the ocean. The application of commercially available instrumentation systems and the development of new instrumentation sensors occupy a major part of the life of research physicists, engineers and biologists.

During 30 years of investigations at Department of Engineering Cybernetics and SINTEF Division of Automatic Control the number of development projects in instrumentation has become very large and it is not possible to describe all the talented solutions invented during all this time.

The scientific discipline 'Engineering Cybernetics' under which 'Aqua-BioCybernetics' is a subset, has 'Instrumentation Engineering' and 'Biotelemetry' as important topics of research as well as education. These branches of engineering, which include most of the content of this paper are expected to become more and more important in the near future to the economy of Norway.

Some of the major lines of development in 'Instrumentation and Biotelemetry' within this sector are reviewed below. 


\subsection{Fish telemetry}

Since 1973 and during 13 years thereafter a major activity has been centered around what was popularly referred to as 'Fish telemetry'. With funding primarily from the Research Council of Norway (previously: The Royal Norwegian Council for Scientific and Industrial Research and The Norwegian Fisheries Research Council), a research and development program was undertaken with quite a wide scope.

The behavior of fish may be studied by means of small ultrasonic transmitters attached to them. Signals received can reveal the position and the depth of the fish, indicate the temperature of the environment and even give emotional clues through heartbeat measurements.

Out of a large number of development projects and experiments which are reported in the references under 'Fish Telemetry' only the following will be outlined:

- Systems for tracking of fish motion:

- PINPOINT Microprocessor System (Mohus 1974-1975)

- ANPOINT- analog fish position estimator (Håndlykken 1974)

- MANPOINT- a simple manual fish position estimator (Sølvberg 1978)

- Telemetry of:

- temperature

- depth

- tail beat

- heart beat.

\subsection{Tracking fish motion}

Figure 25 shows the PINPOINT-system for tracking free swimming fish which was used for many years particularly in the experimental facility at the Hopavagen bay near Trondheim.

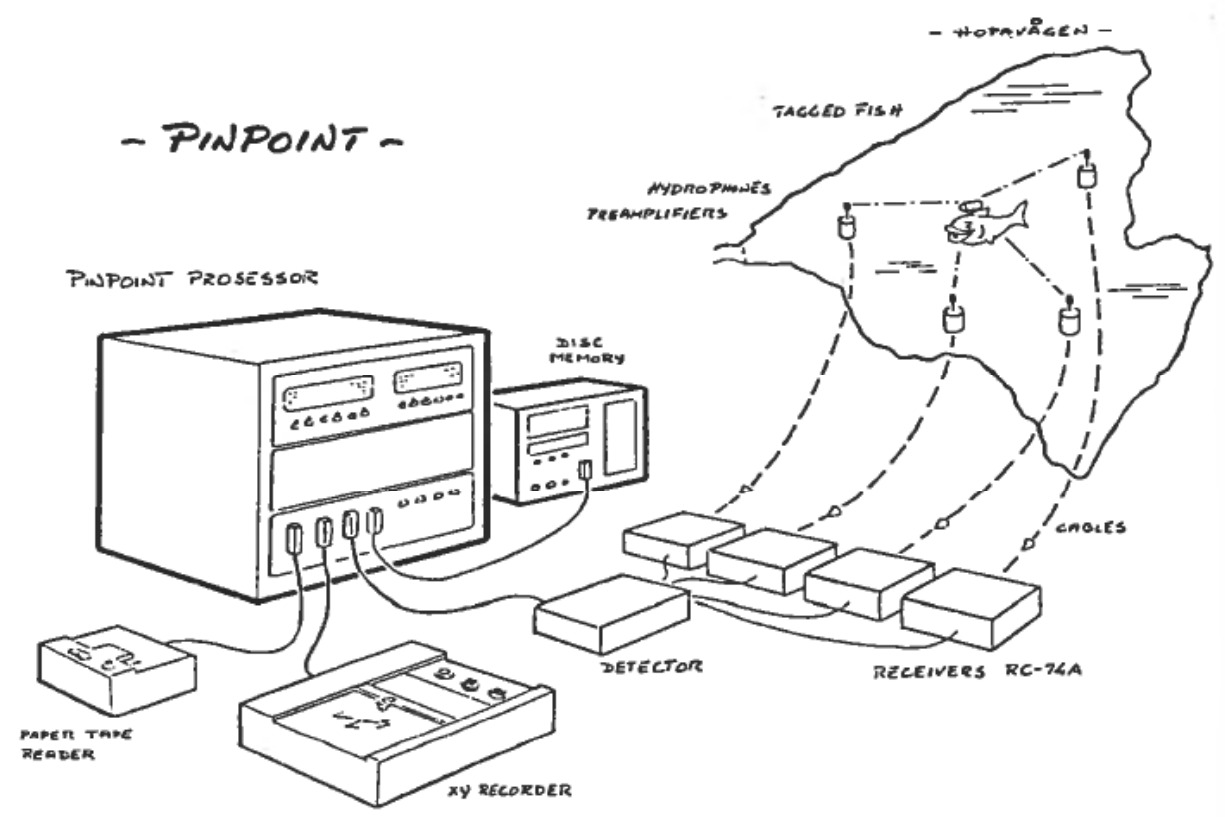

Figure 25. The PINPOINT- fish tracking system installed in Hopavågen (from Mohus 1974a and $b$ ). 


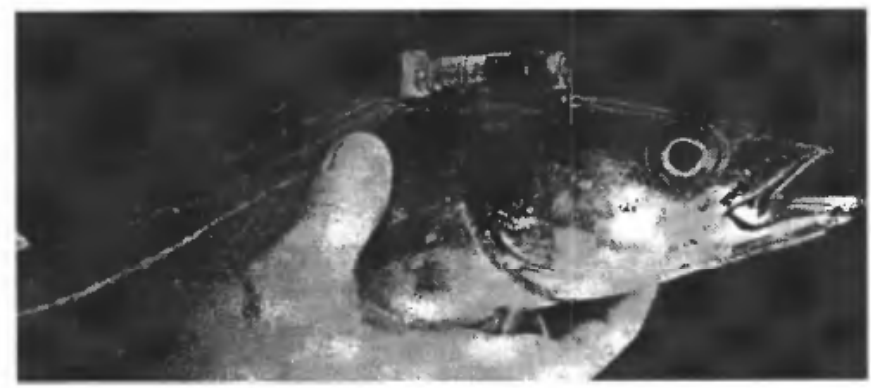

Figure 26. Saithe with ultrasonic tag attached to its back. (from Holand 1975).

The system consisted of:

- ultrasonic tag attached to the fish (Figure 26).

- four hydro-phones with preamplifiers located at known positions and connected through cables to receivers on shore.

- microprocessor-based computer system with disc memory to calculate an estimated position of the fish.

- $x$-y-recorder to make plots of the position.

(This system was a unique development utilizing the first microprocessor available Intel 8008 at an early stage).

Figure 27 shows a selection of five different ultrasonic tags used for different

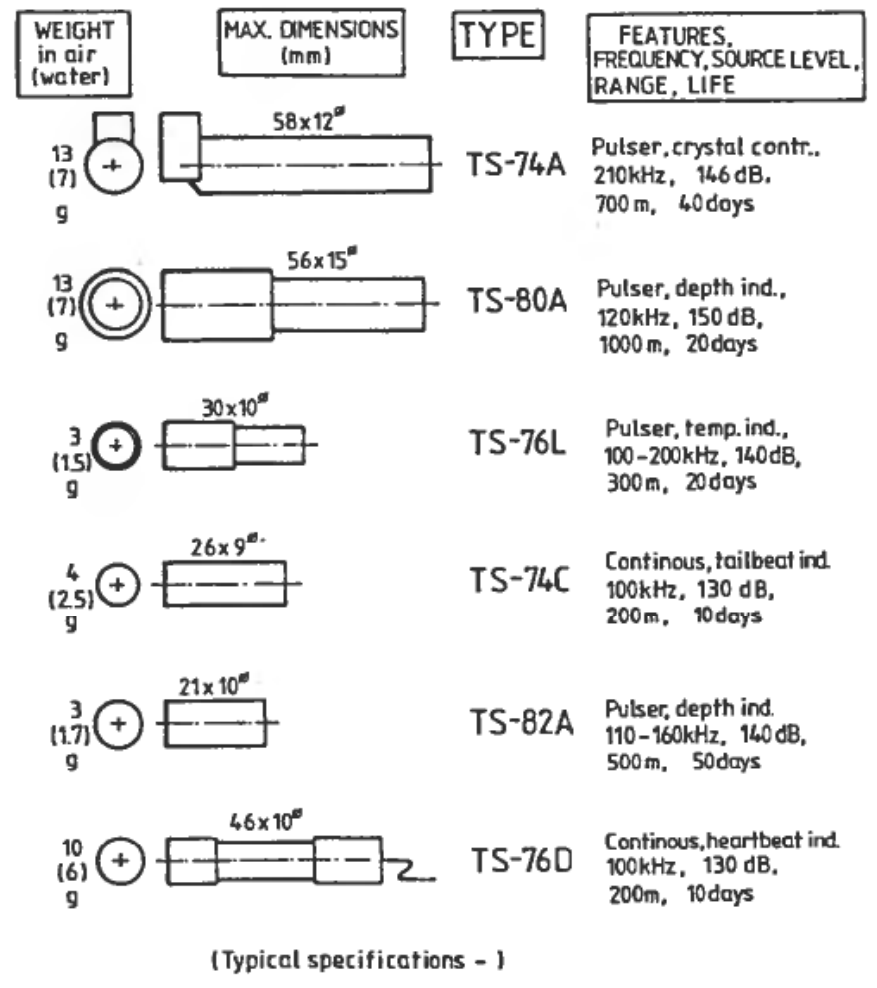

Figure 27. Five different ultrasonic tags. (from Mohus and Holand 1983). 
purposes and having different characteristics described in the figure (Holand 19731985, Holand and Mohus 1973-1977, Mohus and Holand 1983-1986).

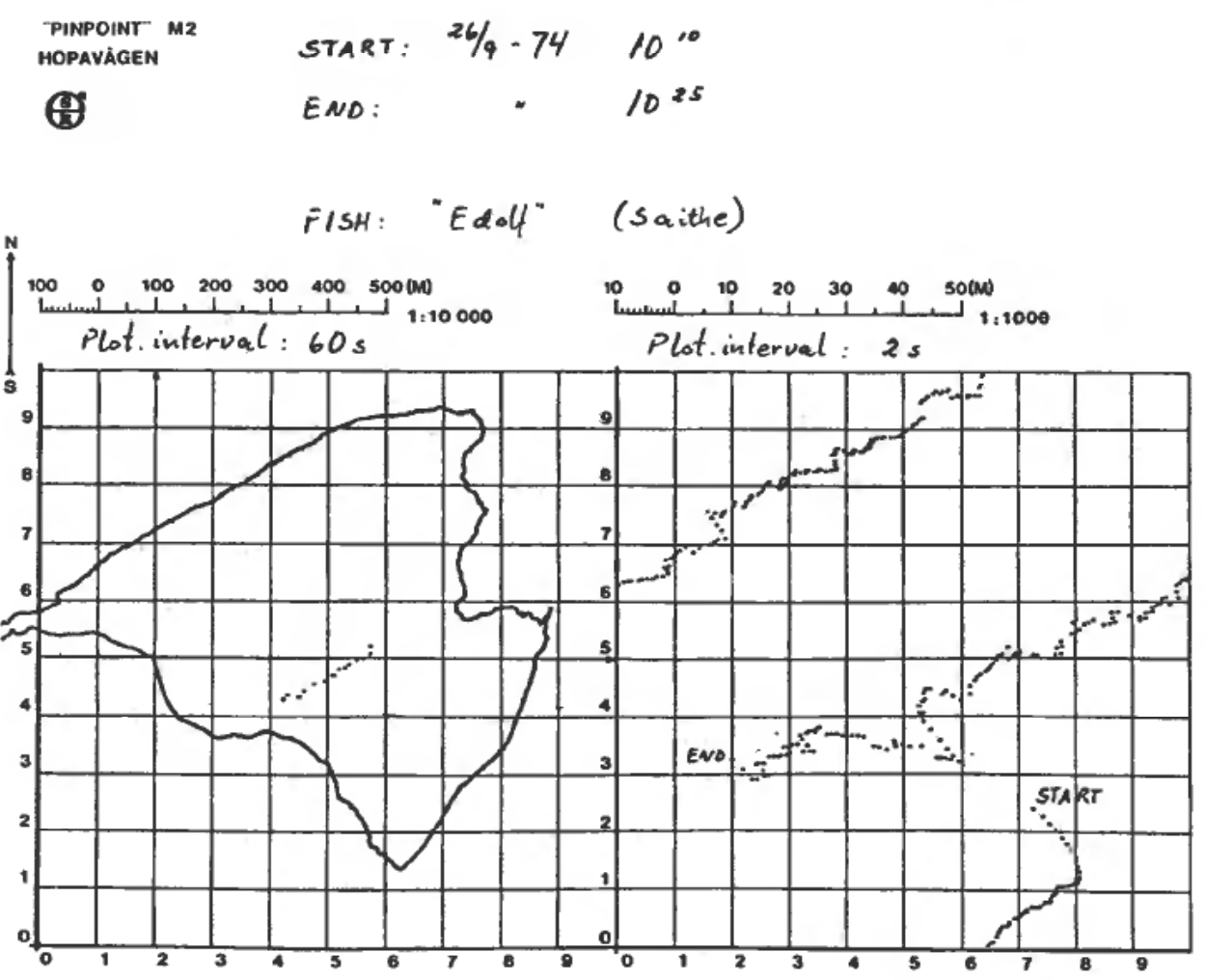

Figure 28. The PINPOINT- system tracking a saithe in Hopavågen. (from Holand et al. 1974).

Figure 28 illustrates the use of the PINPOINT-system to record the motion of a fish in Hopavågen during a particular experiment. The position is estimated every 2 seconds and a plot is made by the recorder pen with a resolution of about 0.5 meters.

The recorder makes two plots with different scale factors:

- one (right) with scale 1:1000 (i.e. $1 \mathrm{~cm}$ equals $10 \mathrm{~m}$ )

- one (left) with scale 1:10000 (i.e. $1 \mathrm{~cm}$ equals $100 \mathrm{~m}$ )

In the 1:10000-plot the time interval between points is 60 seconds.

As can be seen in the left figure the fish moves in 3 different squares each $100 \times 100$ meters. This results in 3 different trajectories in the right figure where each small square is $10 \times 10$ meters. The resolution of the detailed behavior is excellent. Where the distance between dots is large the fish swims fast.

This system has been used to record the behavior of different species of fish in a variety of experiments related to:

- conditioning with sound and food

- electric barriers

- control by acoustic repulsive stimuli

- natural behavior in Hopavågen

ANPOINT was an analog version of PINPOINT which was used successfully in a number of experiments (Se Section 6.3). Based on the experience gained with these 


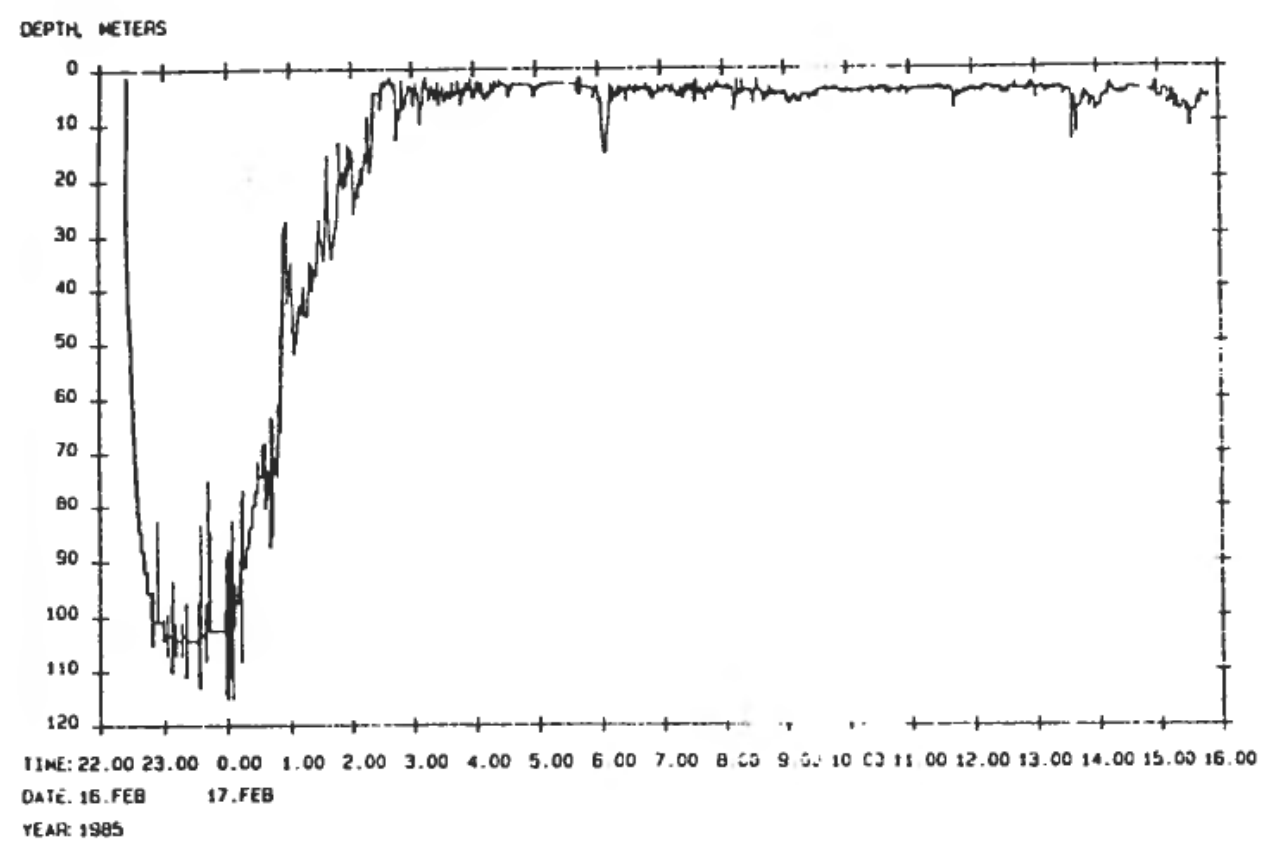

Figure 29. Depth recording from a salmon. (from Holand 1985).

rather sophisticated systems a very much simpler solution named MANPOINT was introduced. It was based on manual plotting of the fish motion, but had satisfactory performance in many cases and required much less preparation than the other systems (Berge 1977).

\subsection{Biotelemetry from fish}

In the development of techniques for controlling fish behavior it is of the highest importance to be able to record data which not only reflect the response in terms of motion in the horizontal plane, but also vertical migration and other quantities revealing the state of activity and stress such as tail beat and heart beat and even ECG. Furthermore, the sea temperature near the fish and the body temperature may be important measurements.

Figure 29 illustrates the use of an ultrasonic tag equipped with a depth sensor to record the vertical migration of a salmon in a particular experiment. Note the large and rapid excursions. Similar recordings of data transmitted from the fish showing temperature, tail beat and heart beat are very useful to the behavioral scientist in learning about the fine details of both natural and controlled behavior.

\subsection{Underwater vehicles in fisheries technology}

Underwater vehicles may be tools for fisheries research in many ways (Balchen 1991). Such vehicles appear in a variety of forms:

1. with electric cable for energy supply and signal transmission (tethered) (zero percent energy autonomy, zero percent information autonomy)

2. with cable (electric or fiber) for signal transmission only (100 percent energy autonomy, zero percent information autonomy). 
3. with no cables, but ultrasound signal transmission (untethered, free swimming) (100 percent energy autonomy, 50 percent information autonomy (limited bandwidth)).

4. with no cables or ultrasound connection (100 percent autonomy) (Autonomous vehicle, AUV).

A special vehicle belonging to the category 1 (DAHABU) is described in Section 8 .

Around 1980 the author initiated a program for the development of a vehicle belonging to the category 2 . The participating parties in this program were the Norwegian underwater technology company SIMRAD Subsea AS, the research organization SINTEF and the Department of Engineering Cybernetics, Norwegian Institute of Technology ( Klepaker et al. 1987)

One of the sectors of application of such a vehicle was in studies of fish behavior in the ocean in general and in relation to fishing gear in particular. The project was brought to a successful demonstration of the vehicle in 1985, but due to lack of response from the market further investments were not made in this concept at that time.

As part of the Program for Robotic Research at the Norwegian Institute of Technology (1988-1996) a comprehensive study was completed on 'Model Based Teleoperation of an Underwater Vehicle Over a Narrow Band Communication Link' in the MOBATEL-project (Balchen and Yin 1994).

A MOBATEL vehicle (category 3) should be controlled over an ultra sound communication link based on video images transmitted over the same link to a surface vessel after efficient compression of the signals.

In these studies it was concluded that the severe limitations in control bandwidth caused by the narrow band ultra sound communication, if the operator should control the vehicle directly from the received images, could be overcome by a virtual reality technique as illustrated in Figure 30 The 'pilot' then will control a real time

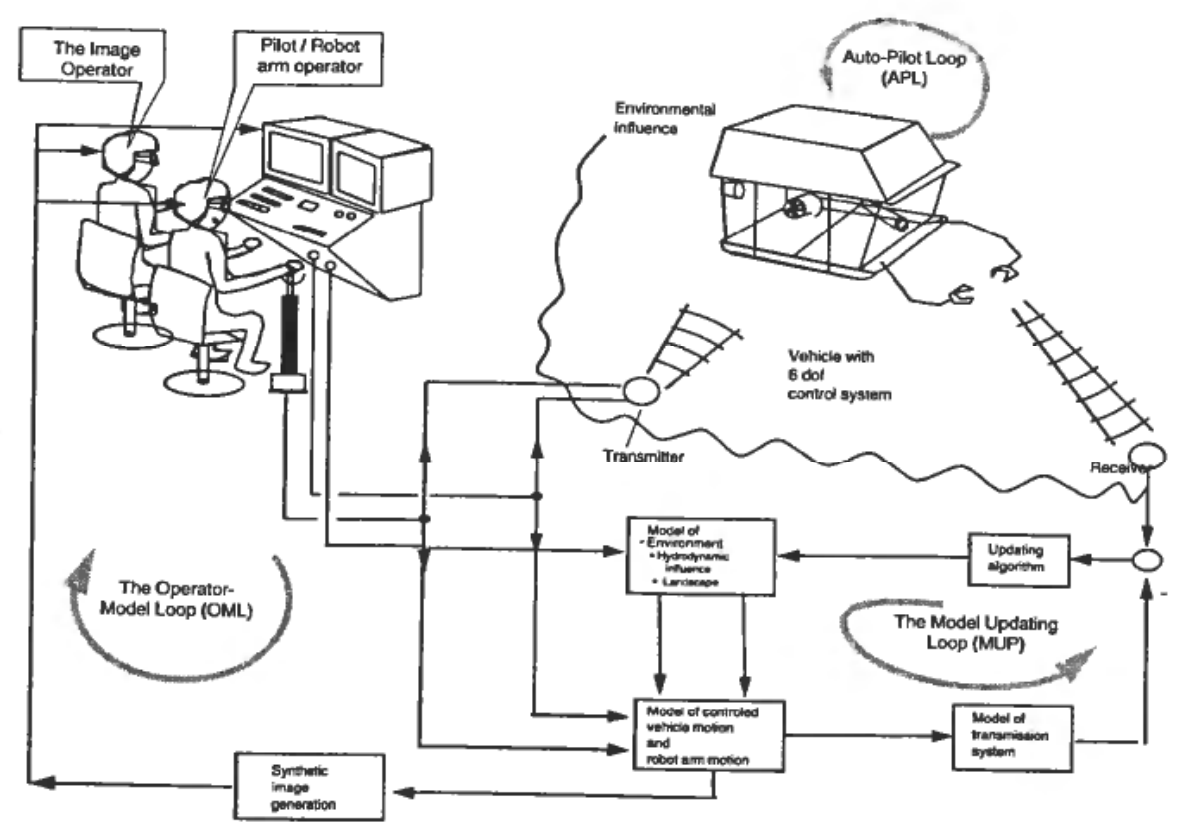

Figure 30. The MOBATEL-system (from Balchen and Yin 1994). 
simulated model (with no delay) of the vehicle which is updated by the 'image operator' matching simulated images to received (compressed and delayed) images. This concept will perform particularly well if the vehicle navigates in a stationary (known and stored) or very slowly varying 'landscape'.

The MOBATEL-concept is expected to become a strong candidate for remote control of vehicles in tomorrows deep sea oil exploration (2000 meters and deeper).

Vehicles in the category 4 have been developed for military purposes and tested for use in oceanographic surveying, but have so far not been studied in the programs reported here.

\section{Technology for lobster culture and ocean ranching}

\subsection{Background}

Along the southern and western coast of Norway the European lobster (Homarus gammarus) was very abundant in the period $1600-1800$ just like it is nowadays on the East Coast of USA and Canada.

Primarily due to heavy fishing for export to Holland and England the lobster population declined and according to official statistics the commercial catch in recent years has only been around 30 metric tons per year (a more realistic number is probably 300 metric tons). For many years biologists in several countries have been working on developing efficient methods for raising lobster juveniles for release in coastal waters to enhance the population. In 1975, the author initiated a cooperative program with the Norwegian tobacco manufacturer Tiedemanns Tobaksfabrik with the aim of developing large scale industrial production of lobster juveniles for ocean ranching.

This effort led to the building of a production facility, designed by the author and his coworkers, with a yearly capacity of 120000 juveniles of age 9 months. This facility was in operation from 1982 and delivered the first juveniles in August 1983 (Grimsen et al. 1987).

In 1988 Tiedemanns decided to abandon their development program, primarily because the Norwegian fisheries authorities had failed to prepare the necessary legislation to protect the ownership of lobsters released in specific coastal areas.

The first planning phase was focused at a location in conjunction with the STATOIL refinery at Mongstad north of Bergen on the west coast of Norway. A company was founded with the name Mongstad Hummer AS in 1990 to sponsor and manage the development work. Some support was obtained from the PUSH-program to cover administrative costs. Around 1995, STATOIL decided that they would prefer the lobster production facility to be built at another site called Tjeldbergodden somewhat further north. There a large complex for methanol production based on offshore gas was under planning and it was already required that the effluent energy should be used for aquaculture purposes.

In 1997 the company Mongstad Hummer AS was renamed Norsk Hummer AS and sufficient capital was raised to complete the detailed planning of the new industrial facility with a production capacity now increased to 4.8 million lobster juveniles per year. These plans were presented to the stockholders in June 1998 together with a business plan indicating a highly profitable enterprise. Some details about the chosen technology are given below.

\subsection{Technology for mass production of lobster juveniles (Homarus gammarus)}

The new facility for mass production of lobster juveniles consists of the following units (Balchen 1998b): 
- Water supply with flow and temperature control (700-1000 m3/hour)

- Quarantine storage for egg bearing (berried) lobsters

- Hatching system with individual temperature control of 500 lobsters to obtain hatching at predetermined times.

- Sorting system for distribution of first stage larvae at a rate of 8 larvae per second into separate compartments in production frames (trays).

- Process for the production of 100 million live preadult Artemia salaris per day as feed for the lobster larvae.

- 8300 plastic frames with 144 compartments each to be divided in 1, 2 or 4 sub compartments yielding a total capacity of 4.8 million lobster juveniles.

- 830 stacks with 10 frames in each equipped with floating collars

- A circular pool, $1.8 \mathrm{~m}$ deep, about $60 \mathrm{~m}$ diameter, with a channel about $2 \mathrm{~m}$ wide in the form of a spiral where the 830 stacks are floating from the center toward the periphery in 1 to 2 days.

- A 'Radius plant', located along a radius of the circular pool, where digitally controlled mechanical machines are:

- taking the stacks out of the pool in an 'Elevator'.,

- disassembling the stacks into frames,

- identifying the code of each frame for further control

- inspecting and cleaning the small compartments,

- feeding the juveniles with an appropriate feed and

- reassembling the frames into stacks before they are put back into the pool.

Figure 31 illustrates the circular pool with the spiral channel. A plastic frame with

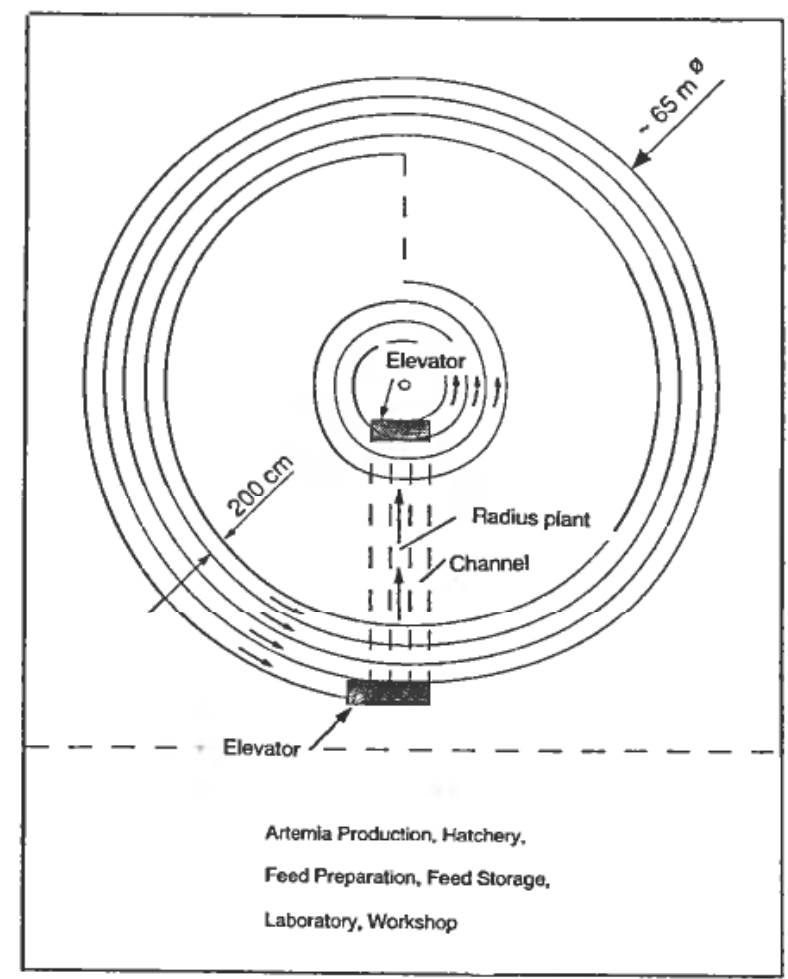

Figure 31. General layout of a production facility for juvenile lobsters (from Balchen 1998b). 


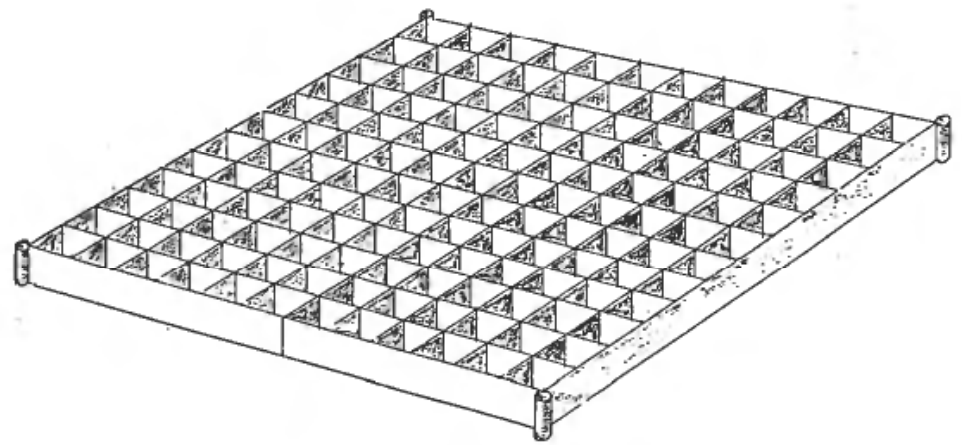

Figure 32. A frame containing 144 compartments (from Balchen 1998b).

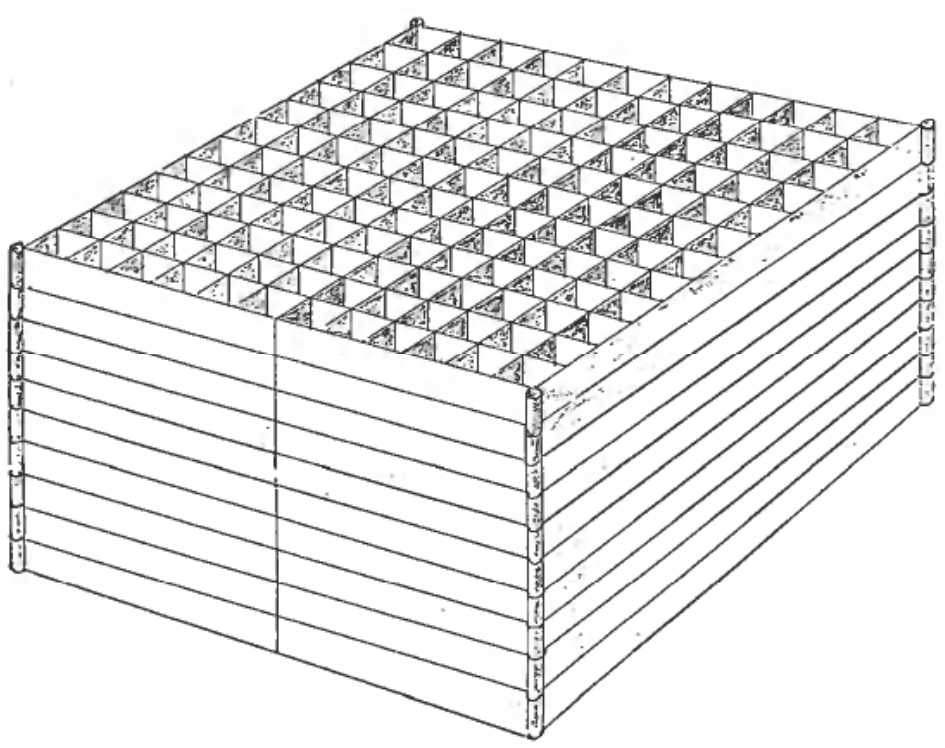

Figure 33. A stack with 10 frames (from Balchen 1998b).

$12 \times 12$ compartments each $12.5 \times 12.5 \mathrm{~cm}^{2}$ is shown in Figure 32 and a stack with 10 frames is shown in Figure 33.

A critical unit in the system is the machine for the sorting and distribution of the newly hatched larvae into the frames. A functional diagram of the unit is shown in Figure 34 (Lønne 1998).

It consists of:

- 48 solenoid driven valves which guide the larvae into either the 48 sub-compartments or to a return duct to the storage tank on top.

- 96 photodetectors, 2 in each tube leading to the valves. The purpose of the first photodetector is to detect the time of a passing larvae, determine the time increment to the next larvae and the frequency of passing larvae. The purpose of the second photodetector is to determine the velocity of the water in each tube and pass on information for the operation of the valve. 


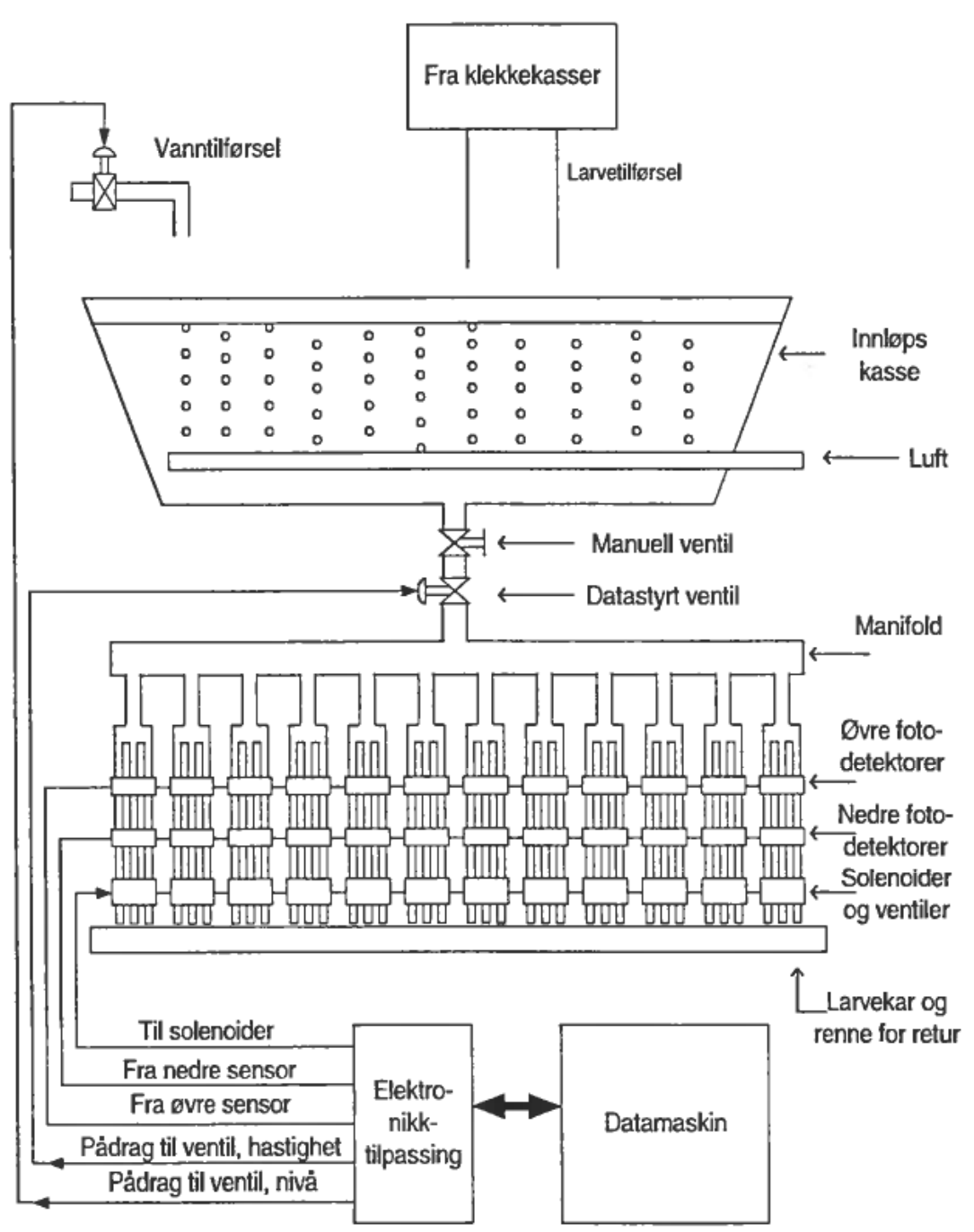

Figure 34. A computer controlled machine for sorting of lobster larvae, (from Lønne 1998).

- A computer with I/O-equipment for the calculation of the number of larvae, determining the conditions for selecting the larvae and controlling the valves.

In addition to this 'machine for sorting and distribution of larvae' which is computer controlled there are a number other computer control tasks as follows:

- disassembling and reassembling the stacks of frames

- identification of each frame to select proper feeding programs etc.

- controlling the feeders

- performing and analyzing video images of the lobster juveniles in each compartment at regular intervals to obtain measures of growth and possible mortality and controlling replacement of new juveniles.

- controlling the installation and removal of thin dividing walls in frames

- controlling the removal of 5-6 month old juveniles

- controlling the packing machine 
- management and control of the transportation and release process

- general process monitoring and control

- real-time database management.

The standard products from this production facility will be:

- nominally 2.4 million lobster juveniles age 5-6 months in October-November.

- nominally 2.4 million lobster juveniles age 9-11 months in February-March.

\subsection{Technology related to ocean and fjord ranching of lobsters}

When the lobster juveniles have reached the desired age in the 'circular pool' they will be packed in special transportation frames and brought to the release sites by boat. This operation must be precisely planned and executed to avoid holdups in the production process.

The release process is very critical to the survival of the juveniles. A number of factors influence the probability that the juvenile will survive and grow to marketable size. The most important factors are:

(a) natural mortality which is highest the first period after release (one day) and will diminish thereafter.

(b) predation by fish, crabs and other crustaceans and seabirds during and immediately after release.

(c) normal predation after settlement dependent on habitats etc.

(d) fishing activities.

Factor (a) is mostly dependent upon the quality of the juyeniles at the time of release. Factor (c) is to some extent influenced by the quality of the bottom substrate and the availability of food, but the lobster is a robust animal with wide tolerances for its survival. Factor (d) is obvious and will be highly controlled in a system where the harvesting is based on special permits.

Factor (b) is the most critical. It has been shown that a combination of a habitat with an abundance of hiding places combined with a removal of the dominant predators is the most effective way of improving the Survival rate (Wahle 1992, Wahle and Steneck 1991).

Prior to the release of the juveniles the bottom substrate should be surveyed and mapped with respect to the quality of the habitat. The best habitat for juveniles of age around 6-10 months is cobbles and boulders with a size distribution closely related to the size of the juveniles. Also certain kinds of gravel which permit the juveniles to dig burrows turn out to be attractive.

As a consequence, areas with a suitable bottom substrate will exhibit a higher population of lobsters than areas with just bare rock face, clay or mud.

In some cases it has been shown that the quality of the bottom substrate can be improved by discharging heaps of artificial cobbles and boulders, often referred to as 'artificial reefs'. The crushed rock for this purpose may be taken from quarries on shore and brought to the site by boat or simply made at the site by underwater explosions.

The release of the juveniles should be conducted through a pipe hauled along the bottom from a surface vessel in such a way that the juveniles can find shelter within few seconds after the release. In order to reduce the probability of predation even more, the release operation should be combined with an active removal of potential 
predators or be performed at a time when the predators are not present. An active removal of fish can be done by employing a strong source of sound, Say an airgun, or by means of a source of a repelling olfactory stimulus, say part of a seal. Most predators will exhibit low activity or will be at deeper waters when the temperature in the water is low, as it is around the month of March in Norway.

It is well known that the European lobster (Homarus gammarus) seldom migrates deeper than about $\mathbf{4 0}$ meters. The consequence of this is that if lobster juveniles are released in the waters around an island surrounded by waters which are much deeper than 40 meters, most of the lobsters will stay at this island. This is very convenient because it yields a natural fence for the lobsters under ocean ranching. The coast of Norway has an abundance of such islands.

A number of different strategies have been described (Balchen 1995) for ocean ranching and culture of lobsters. One of these employs a combination artificial shelters and collectors for blue mussel culture.

\subsection{Digital mapping of ocean floor quality}

As described above, the quality of the ocean floor substrate is of great importance for the survival and growth of the lobster juveniles after the release in coastal waters. Therefore it is necessary to map the ocean floor prior to the release to make certain that the juveniles end up on a substrate where they can find shelter immediately. Such mapping can be done by many means such as scuba divers, under water cameras.

As a result of some support through the PUSH-program, the Department of Engineering Cybernetics started the development of a computer controlled underwater vehicle for efficient digital mapping of ocean floor quality, (DAHABU), in 1994 (Balchen 1997).

DAHABU consists of an underwater vehicle as shown in Figures 35 and 36 which is hauled by a surface vessel and automatically controlled by means of motor driven thrusters to follow the bottom at a desired distance (say 2 meters). The vehicle carries a high quality underwater color camera. A control desk on the surface vessel has two operators, the pilot and the image classifier, and contains a control computer, a dGPS navigation system, an image monitor- and video recorder, and a keyboard for manual registration of substrate quality estimates. Figure 37 shows a block diagram of the

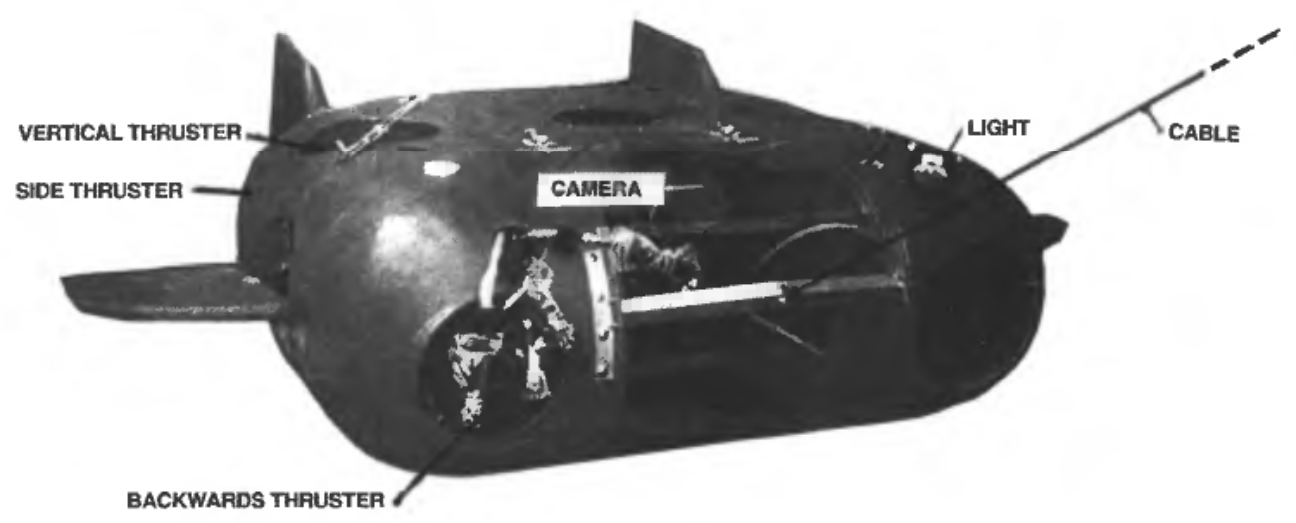

Figure 35. The DAHABU underwater vehicle (from Balchen 1997). 


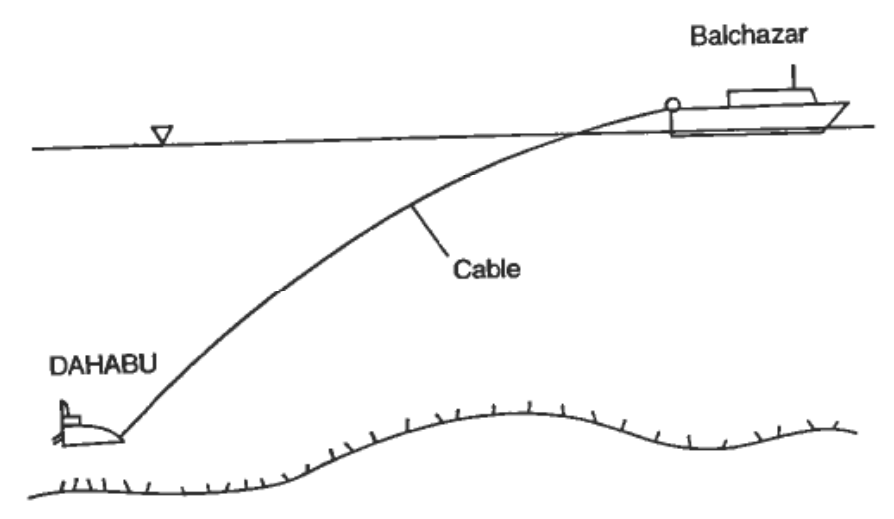

Figure 36. DAHABU system Operation (from Balchen 1997).

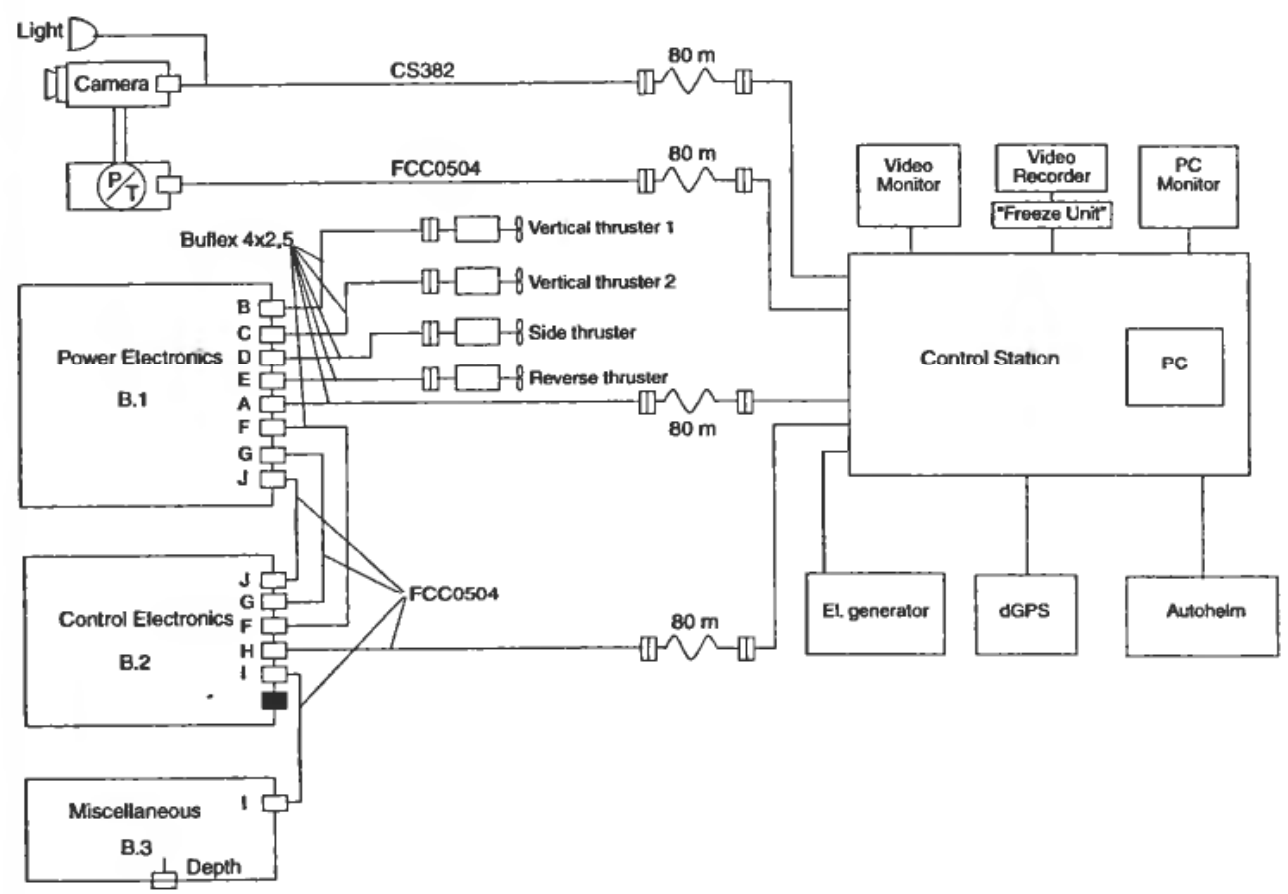

Figure 37. Block diagram of the DAHABU control system. (from Balchen 1997).

control system and Figure 38 an example of a sea map with depth contours and registration of the quality of the bottom substrate.

Ocean tests of the DAHAB U-system were conducted with satisfactory results in 1997 and 1998 and the development will continue toward a commercially operational system when adequate funding is made available.

\section{CYBERFISH}

\subsection{Background}

The control of fish behavior dealt with in Sects. 5 and 6 utilizes signals transmitted in the sea and sensed by the fish to influence its direction of motion. In this connection it is shown that conditioning (training) is beneficial. 


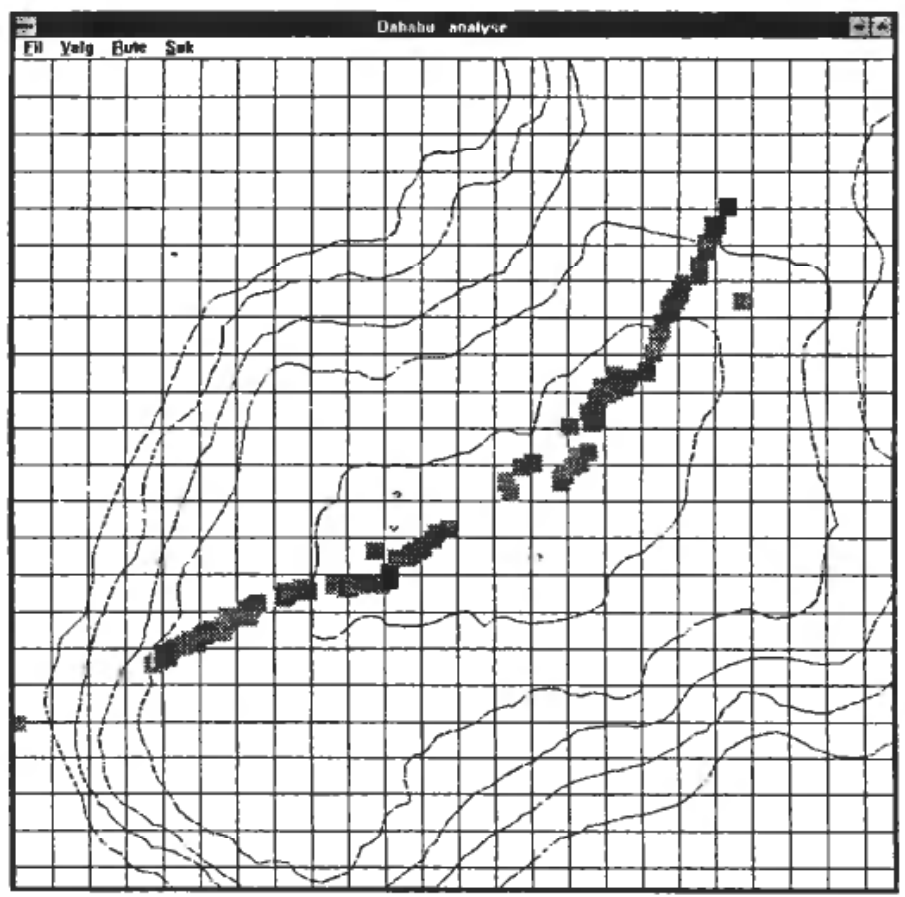

Figure 38. Sea map with depth contours and substrate quality registration (from Balchen 1997).

Another entirely different approach to the control of fish motion would be to regard an individual fish as a vehicle and to install a physical auto-pilot inside it or onto it which could receive ultrasonic signals from a surface vessel and produce 'corrective stimuli' to make the fish change its course of motion until a desired course were obtained. This artificially controlled fish has been named 'CYBERFISH' or 'the cybernetic fish'.

The following pages bring a survey of a development project which has been under way for about 20 years without really getting started, mainly due to lack of funding. A number of proposals for development programs have been submitted to different funding sources, but they have not been taken seriously, until recently. The first mention of CYBERFISH (with another name) was in an unpublished talk given by the author at a Norwegian conference on marine technology in Horten in 1979. It was then suggested that using an ordinary large fish with control equipment to carry payloads in naval underwater investigations could be an alternative to the use of dolphins.

The motivation for entering into research activities of this sort are that:

- if successful, CYBERFISH would lead to a large number of very useful applications:

- carrying a payload such as an instrumentation capsule or an underwater camera

- carrying a source of attractive olfactory stimulant which could a form a school of fish to 'follow the leader'.

- utilizing the sensory system of a pretrained fish to locate certain sources of release of olfactory agents (e.g. hydrocarbons) or other stimuli. 
Compared to a 'mechanical fish' the live CYBERFISH has many advantages such as:

- 'produced by non-skilled labor'

- can operate for a long time (weeks) without 'refueling'.

- has no problems with leakage or corrosion

- very inexpensive.

Some disadvantages of the CYBERFISH compared to a 'mechanical fish' will be:

- it will be more difficult to control because it has an 'independent will'.

- it will have a limited carrying capacity ( $1 \mathrm{~kg}$ in air, $0 \mathrm{~kg}$ in water).

Controlling a wild animal through the application of artificial stimuli may lead to an ethical problem. In the opinion of the author this problem should be easy to avoid by first recognizing that the problem exists and then obeying the general rules adopted for experimentation with live animals. These rules include statements that the animal shall not be subject to pain and that the constraints to its motions shall not lead to undue pain.

On the other hand it seems reasonable to compare the concept of controlling the motion of a live fish with that of controlling a horse or a dog which has been generally accepted for a long time.

\subsection{Survey of technical solutions of CYBERFISH}

The technical problems of remotely controlling the motion of a live and free swimming fish are related to the following functions:

- ultrasonic communication between a surface vessel and the fish in order to:

- transmit commands about the desired course, depth and velocity and

- receive information about measured quantities such as temperature, light intensity, salinity, compressed images, etc.

- an ultrasonic transponder for retransmission from the fish of the signal from the surface vessel sonar to increase the range of sonar operation.

- measurement of the course of swimming using a device (compass) which is small, has high bandwidth and uses little energy. Some new devices are available for this purpose.

- manipulation of the fish direction of swimming by means of either mechanical or electrical stimulation driven by an electronic control device.

- computational capacity to perform necessary operations for the digital communication, the control algorithms and the manipulator functions.

- the electronics and instrumentation associated with the payload which could be a camera, oceanographic Sensors or devices related to the CYBERFISH as an active unit for control of a school of fish.

Figure 39 shows a sketch of the main units of the CYBERFISH-system.

\subsection{The surface vessel operator console, sonar system and sonic data communication system}

Onboard the surface vessel there is a sonar operating at a fairly high frequency, for example $150 \mathrm{kHz}$. The carrier pulse transmitted by the sonar is received by the CYBERFISH receiver and retransmitted to the sonar receiver. This function is referred 


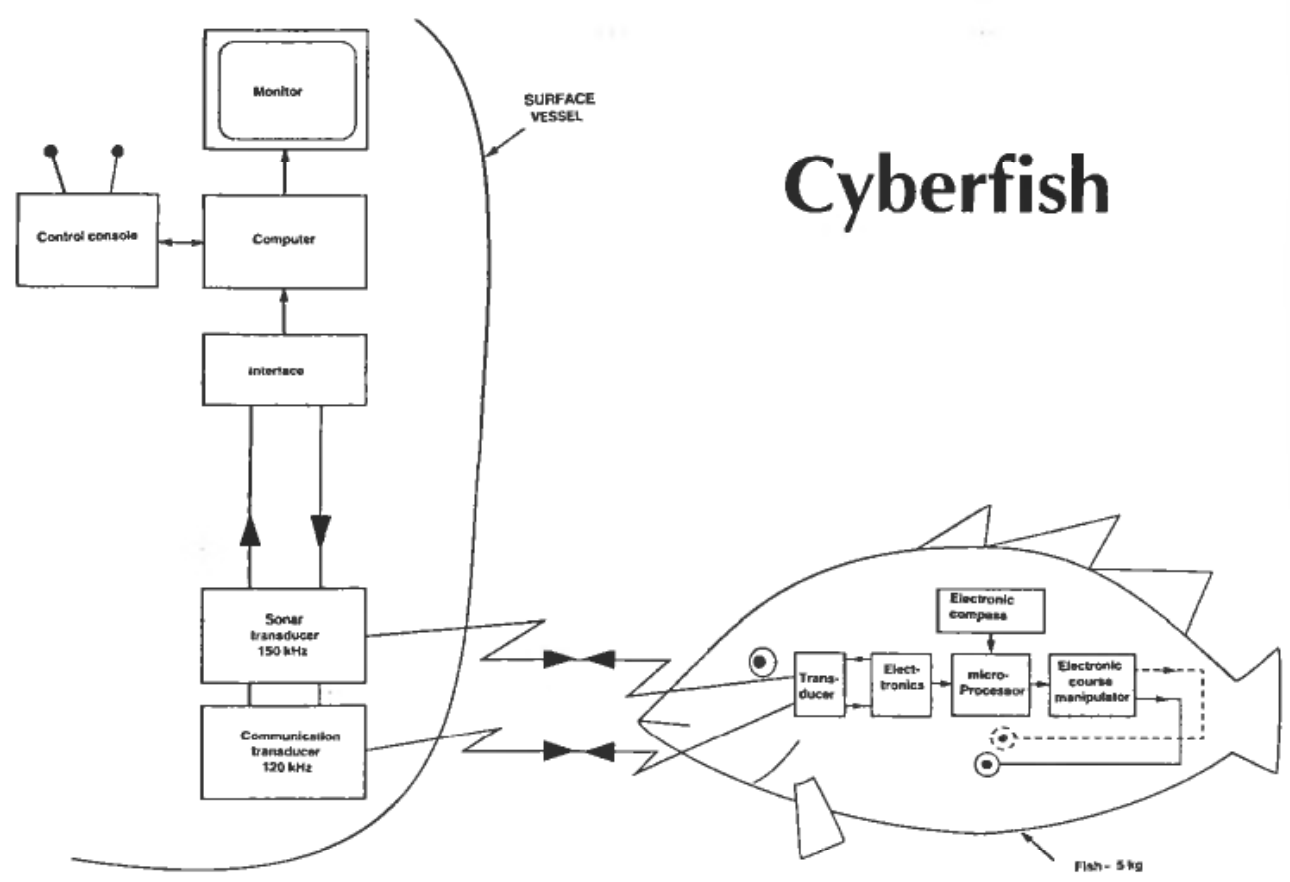

Figure 39. The CYBERFISH system.

to as a 'transponder' and is used for plotting the position of the fish relative to the vessel.

The same sonar system can be used, on a time sharing basis, for communicating messages to and from CYBERFISH. An introductory study of the principles to be employed in the digital communication system is presented in a student project report by Silgjerd (1997).

The sonar system is interfaced to a digital computer with associated graphics to give the operator convenient means of observing the CYBERFISH motion, sending commands and receiving operational information.

\subsection{The microprocessor}

The information received by CYBERFISH is processed in the microprocessor and used for a number of different purposes. In the introductory investigations an ATMELmicroprocessor model AVR8535 has been chosen based on an estimate of necessary future processing demands (Kjempekjenn 1998).

\subsection{The course sensor}

An essential element in the auto-pilot for CYBERFISH is the sensor which is to sense the course of swimming. Many different types of sensors can be suggested, but most of them will be impossible for a number of reasons. After the completion of an introductory investigation of alternative principles, focus has been placed on a 'magneto-resistive' device manufactured by Honeywell Inc., USA. This device appears in a number of versions (HCM10xy, HCM20xy, where $x, y$ refers to different details).

The first experiments with this device were done by Hunstad (1998). The results 


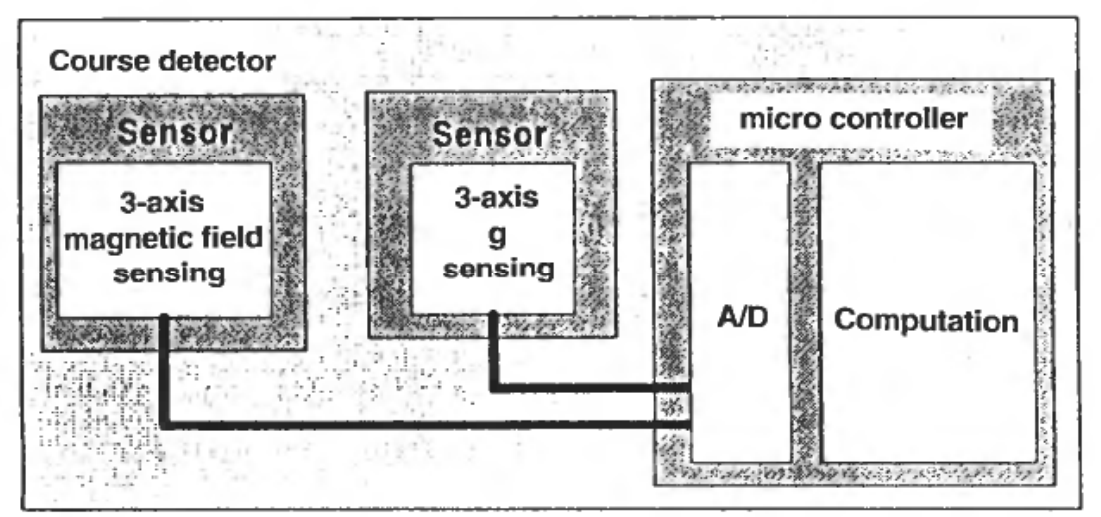

Figure 40. Course detector system (from Kjempekjenn 1998).

were useful, but not conclusive. Therefore a new study was initiated which eventually led to very important results and conclusions (Kjempekjenn 1998). In this study it was concluded that a correct estimation of the swimming course in the horizontal plane (heading) by means of the Honeywell-sensor requires a 3-axis vertical reference sensor, which could be a 3-axis linear accelerometer.

The complete course detector system reported by Kjempekjenn (1998) and shown in Figure 40 is quite complex, but still, so far the only system to meet the requirements in terms of volume, precision, bandwidth and energy consumption.

In order to test the performance of this system particularly with respect to dynamic response a new student project was initiated (Adli 1999). Even though each of the elements of the system have high bandwidths the total system will be slower because of the time required by the microprocessor to complete some quite demanding transformation calculations. The net result is that the dynamic performance including the oscillatorymotion of the fish is acceptable.

\subsection{The manipulating device}

The microprocessor will compute the necessary corrective actions according to the control algorithm of the auto-pilot and this is transferred to the manipulating device.

A number of alternative ways have been suggested of manipulating the fish in order to achieve a systematic change in the direction of motion.

The first method (Method 1) which was tested for some time was based on the concept that a small electrical current pulse discharged into the fish near the lateral line on one side would result in a small turning motion to that same side and similarly on the other side.

A live cod (Gadus morhua) (weight about 3-4 kg) was furnished with a soft belt around the body, as shown in Figure 41.

In the belt two round electrodes (diameter 8 millimeter) were located. A short string ( 0.5 meter) led from the belt to a small float securing that the fish would not dive deep. The two electrodes were connected to two thin electric wires which were connected to a source of electric pulses over a long fishing pole. These pulses could be changed in strength and shape.

When the fish was released from a boat it could easily be observed and its behavior in response to different electric pulses be recorded. 


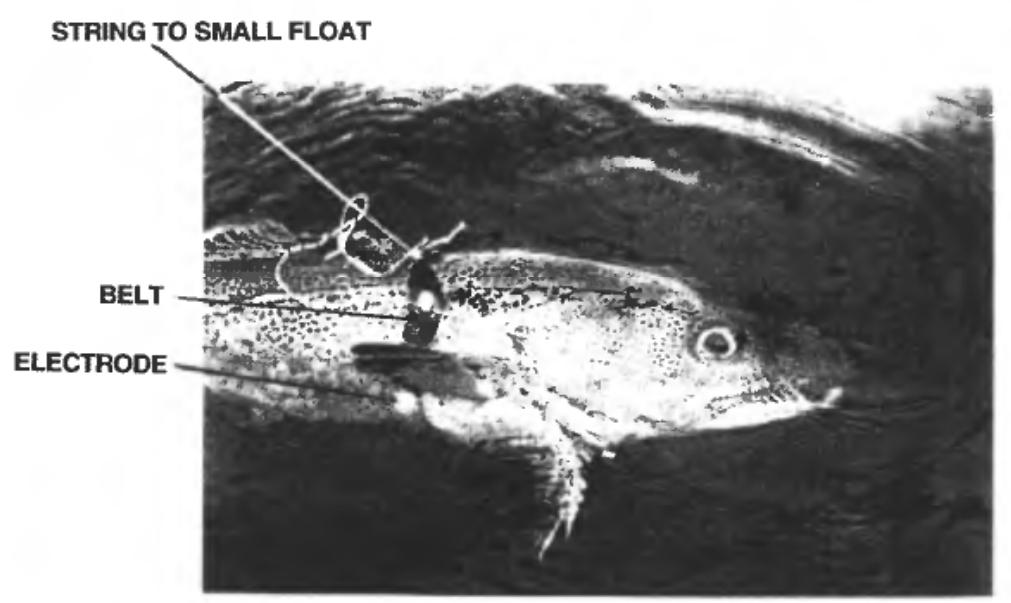

Figure 41. Cod with 'electrical stimulation', Method 1.

The conclusions drawn from these experiments with Method 1 were as follows:

1. electrical stimulation near the lateral line did not seem to yield a reproducible and systematic response with a consistent relationship between strength of stimulation and strength of response.

2. there was a relatively high threshold of the stimulation before a response was observed, sometimes strong and sometimes weak.

3. it was suggested that on possible explanation for the failure of this method could be the choice of fish for the experiment (Gadus morhua).

4. it was decided that more detailed research into the physiological aspects of this method will be needed before a final conclusion can be drawn and that alternative methods of manipulation should be investigated first.

The second method to be tested (Method 2) is based the well known concept used when controlling a horse with a rein. This method, though very crude and primitive, seems to have a number of advantages. Method 2, illustrated in Figure 42, has the following characteristics:

- attached by two metal rings to the two jaw bones of the fish are elastic strings (reins) leading backwards toward a servomotor.

- an electric DC servomotor with encoder and gearbox is mounted in a waterproof housing and connected via a magnetic coupling to a spool with two thin strings fastened to the elastic reins.

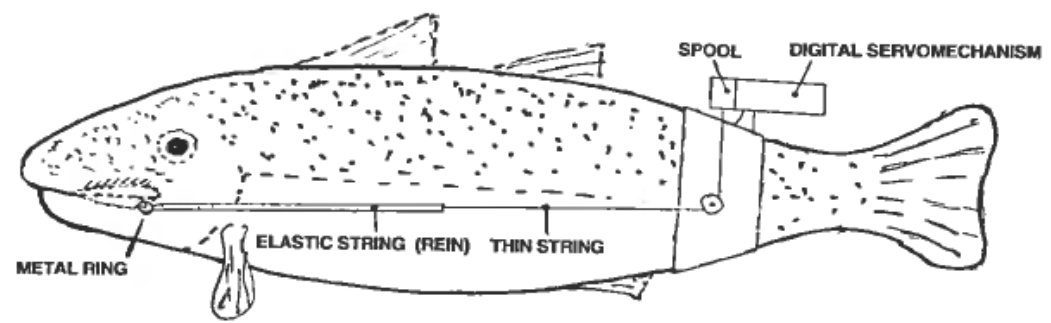

Figure 42. Fish controlled by a 'rein', Method 2. 


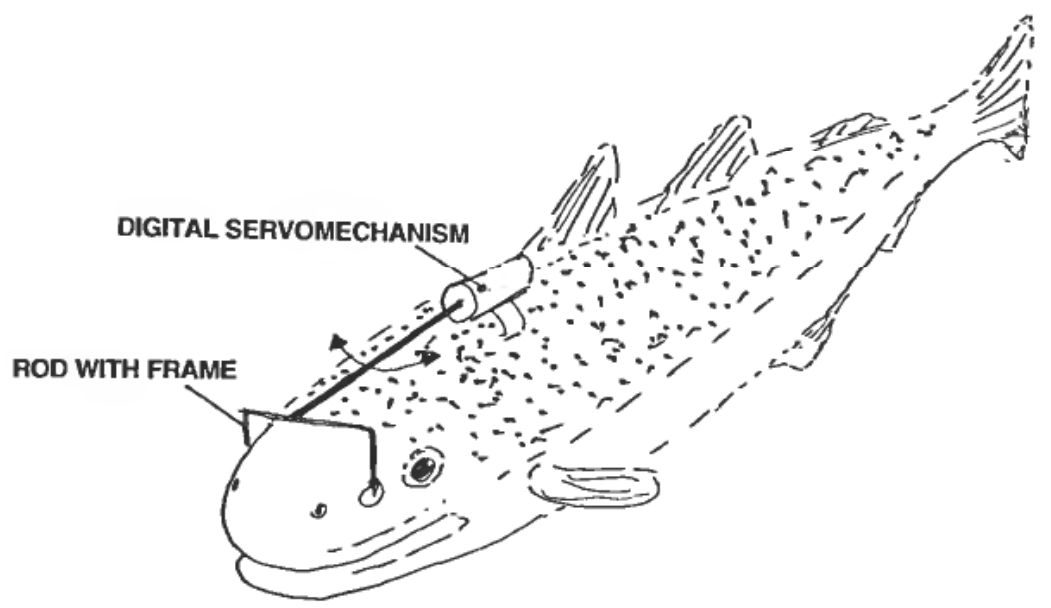

Figure 43. A fish controlled by 'a rod and frame', Method 3.

- the servomotor controlled by an electronic power unit driven by the microprocessor forms a servomechanism manipulating the fish motion by pulling the left or the right elastic rein.

Introductory tests have been made with the 'rein concept' with encouraging results (Snildal 1998). The tests show that when a fish is subject to a constant pulling force in one of the elastic reins it will swim in a circular trajectory $(\sim 0.2 \mathrm{kp}$ force yields diameter $\sim 10$ meters). This is a satisfactory result for planning more detailed investigations.

A number of variations of the 'rein concept' can be suggested and tested to find an acceptable solution.

The digital servomechanism has been designed and tested with satisfactory performance in the laboratory (Hestnes 1999). The designs of the other mechanical components are not yet completed.

A third method (Method 3) has much in common with Method 2, but may prove to have some advantages. Figure 43 illustrates its components.

It consists of a small digital servomechanism (same as in Method 2) fastened to the back of the fish and carrying a light 'rod with a frame' which always points in the desired swimming direction (controlled by the servomechanism and the auto-pilot). The frame has two soft pads which will touch the skin of the fish on either side if it does not swim in the desired direction. It is anticipated that the fish will soon learn how to avoid this 'touch' by swimming in the desired direction. Experiments to verify this concept will be conducted shortly.

\subsection{Choice of fish species for CYBERFISH}

The choice of species of fish for CYBERFISH was thought to be simple, but it turned out to involve a number of interesting aspects.

The first choice was cod (Gadus morhua) because it was thought that it would be a strong and well behaved animal suitable for the task. A number of medium sized cod, 4-5 kg, were ordered and supplied by local fishermen. It turned out however that this choice was not the best possible for the following reasons: 
- when the cod was caught with standard fishing equipment at normal depths and brought to the surface, its swim bladder was injured due to the decompression and needed a very long time to recover. Many of the cod did not survive.

- it took a long time (some weeks) before the wild cod wanted to accept natural food given to it (slices of herring etc.) and it never accepted pelleted formulated feed.

- the cod is rather 'stubborn' and has a tendency to dive to the bottom and find a place to be still, in other words, not move in the water masses, which is the desired behavior. It appears that it has 'a strong will'.

- as an alternative to 'the wild cod' it was decided to launch the following approach:

- in the Norwegian salmon farming industry it is a well known problem that a large number of fry and juveniles of saithe (Pollachius virens) find their ways into the pens where they mix with the salmon and, if not removed, will grow to considerable size. This has an influence on the consumption of feed and should be avoided.

- thus it is suggested to use this kind of fish for CYBERFISH because:

- it is familiar with and prefers pelleted formulated feed

- it is used to live near the surface and is not afraid of people

- the behavior of the saithe is different from cod in that the saithe tends to be a more active swimmer utilizing the entire water column and during certain periods forming schools.

- the price per fish will be much lower than wild fish delivered live by local fishermen.

Arrangements have been made with a fish farming company to take care of an adequate number of young saithe in the spring of 1999 and feed them together with the salmons until a weight of about $4 \mathrm{~kg}$ is reached around September 1999.

Should this approach turn out not to be successful it is also possible to use a $5 \mathrm{~kg}$ salmon from a salmon farm available at any location along the coast of Norway.

\subsection{The control algorithm}

The algorithm for the control of a surface vessel or a submarine can be developed based on well established control theory (Balchen et al. 1999) (Fossen 1994). In the case of a live fish it must be expected that some difficulties may occur because the relationships between the control actions and the response of the fish will be more uncertain. Thus the control algorithm must be more robust than normally needed in the case of vessel control.

In the introductory phase of the development of the control algorithm it should be discussed whether it is desirable to aim for a control loop with very high bandwidth or 'tight' control or whether we have to accept that the control will have to be low bandwidth or a 'soft' one.

A high bandwidth control would act in such a way that the manipulating device e.g. rein, would respond very fast, but not trying to counteract the oscillating swimming motions. A feasible strategy could be to give the control device a 'dead-zone characteristic' just allowing the oscillating motion within a tight control loop. This method would bear some similarity with the control of a horse with a loose rein when it has the proper course, but applying rather strong force (tight control) to correct the course. The consequence of this argument would be, in case of Method 2, that the spring constant (force per distance) of the elastic string of the rein should be rather high. In 


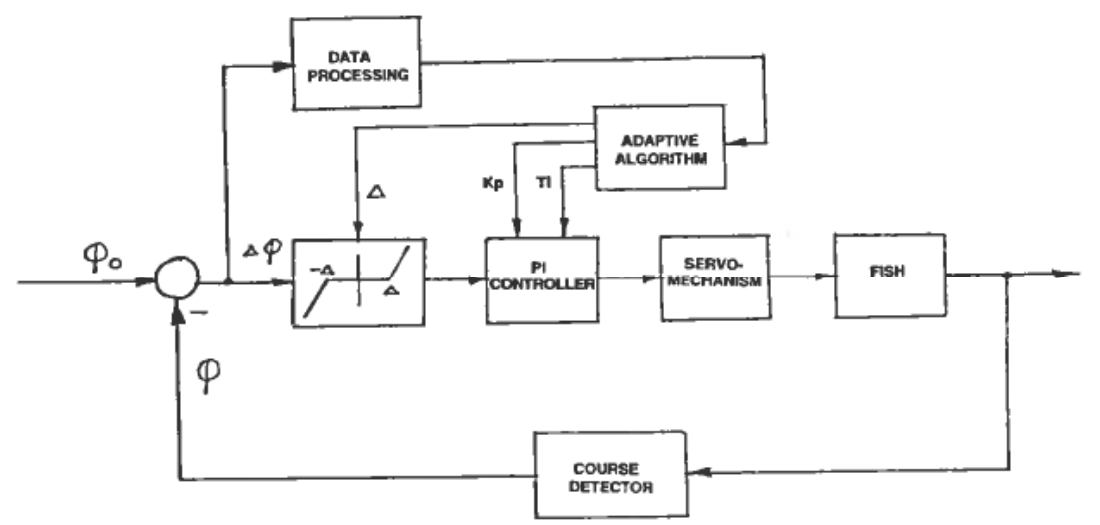

Figure 44. Block diagram of control algorithm with 'dead-zone' and adaptive feature.

case of Method 3 the 'dead-zone' would be equal to the opening between the frame and the head of the fish.

It could be expected that the fish will learn the relationship between large errors in course and the tactile signal associated with the rein (Method 2) or the frame (Method 3). Only an experimental test will confirm whether this assumption is correct and such experiments are under way.

The block-diagram of Figure 44 is a first version of a control algorithm with a 'dead-zone' and a proportional plus integral action in the loop. This strategy will be tested to find parameters yielding sufficient robustness.

A low bandwidth, 'soft' control would let the fish make larger excursions around the desired course. This would make sense in case experiments show that the fish will not tolerate 'tight' control over a longer period. But control must be exercised to some degree, therefore it appears that the 'softness' could be obtained by either increasing the 'deadzone' or reducing the gain periodically. Thereby the fish will have a chance to 'relax' from time to time.

An adaptive strategy will result if the width of the 'deadzone' is adjusted according to some measure of 'unrest' in the fish, say, the variance of the turning motions. Also the averaging time in the variance calculation can be made 'adaptive' to cope with difficult cases.

Figure 44 includes this adaptive feature.

\section{Cybernetics vs. Biological Abundance}

\subsection{How Nature does it}

Most processes in Nature are characterized by an overwhelming abundance in the number of offspring in the first stages and a corresponding low efficiency in survival of the later stages. This fact applies to most species except mammals.

A typical female fish may have 100000 eggs and the male many million sperms. Even though only a fraction of the eggs are fertilized the number of fish larvae per female will be very large. The natural order is that these larvae start to feed on small particles and plankton and are themselves the food for animals on the next trophic level. The ratio between the bio-masses on the different 'neighboring' levels is often estimated to be about 10:1. For some species the survival ratio between the number 
of mature animals ready for spawning and the number of eggs on a female, is very small. A lobster female may carry 10000 eggs and maybe only 2 will survive to spawn.

A high percentage of the eggs may not survive in the hatching process or may be eaten as eggs. If the temperature is low the newly hatched larvae may die. If the time of hatching does not match with the occurrence of proper food the larvae may starve to death. After that the larvae, small fry and juveniles are subject to massive predation since they represent the natural food for other animals like fish, birds and mammals.

\subsection{The possibilities of Cybernetics}

This is part of the background for human interaction with Nature by applying the techniques of culture in which the survival ratio from egg to mature animal is greatly increased. The farmer applies great care to protect his lambs and chicken from being prey for wild animals and the aquaculture industry develops processes with very high efficiency for raising large salmon or halibut from eggs.

In such culture processes it is of interest to distinguish between animals with larvae or fry with a pronounced cannibalistic behavior, and animals with offspring suitable for 'communal rearing'. Most aquatic larvae are cannibalistic to some extent, but some species are much worse than others. Among the very cannibalistic species is the lobster (Factor 1995), (Cobb and Phillips 1980).

Many experiments have been conducted to develop substrates for communal rearing of lobster larvae from stage 1 to stage 5-6, but the results have not been convincing. Thus it still seems necessary to keep each lobster larvae apart in isolated compartments from the beginning just after hatching all the time until the juvenile is ready for release at the age of say 6 or 9 months (see Section 8). To succeed in the practical handling of a very large number of lobster larvae and juveniles (say 5 million) then becomes a problem of cybernetics.

A process for the annual production of 5 million lobster juveniles must start with about 7 million eggs. These eggs will hatch during a period of about 35 days, i.e. about 200000 larvae per day. If the handling of the larvae is to be restricted to 8 hours per day this leads to an amount of about 7 larvae per second. Such a speed of handling of very small and tender creatures is impossible by human operations. If a human could handle one larva in 5 seconds it would take 35 human operators continuously working in parallel without interruption all day long.

With a computer controlled sorting machine as shown in Figure 34 the task is possible. In this 'cybernetic machine' each sorting operation becomes so inexpensive and is so fast that 'the Machine can compete with Nature'.

Sorting lobster larvae into separate compartments with a 'cybernetic machine' to increase the survival ratio from, say 0.001 to say 0.7 is only one out of many applications of 'information technology' in aquaculture. Some others are mentioned in the description of the 'Radius-plant' of the lobster factory in Section 8 and in the description of systems for the control of fish behavior in Section 5 and Section 6. The most typical alternative to the 'cybernetic solution' is the use of human attention and labor which can become prohibitive due to the high cost at least in high cost countries.

\subsection{Some possible consequences}

Applying new man-made solutions to Nature's processes can have consequences which are not desirable and should be understood and evaluated beforehand. 
One such consequence, in the case of production of lobster juveniles for enhancement of the population, is that an increase in the yield may lead to local inbreeding and thus genetic degeneration. On the other hand, it has been pointed out that particular genetic properties characteristic of local physical and biological environmental features may be selected over time under natural conditions with the consequence that bringing in the offspring of females from a remote location could mean that more failed to thrive.

Thus it has been recommended that the lobster juveniles that are released in a particular location should be offspring of females caught at that same location. To avoid large scale inbreeding care should be taken to distribute the juveniles in an appropriate manner.

Similar problems appear in the fish farming industry. Large amounts of farmed salmon escape every year from fish farms and end up in nearby rivers where they mix with the natural stock. According to one opinion this is not desirable from a genetic point of view. Thus it is important to be able to take measures at an early stage to avoid such problems. In this connection 'cybernetic methods' can play an important role by:

- making fish farming systems from which the fish do not want to escape particularly by closing off large natural areas where the fish motion is controlled.

- making 'intelligent' non physical barriers which are robust to weather conditions.

- making systems based on conditioning for recapturing escaped fish.

\section{Final remarks}

Applying the methods of Cybernetics in the very old and traditional activities connected with fisheries and the farming of aquatic animals is regarded as an important task also in the future. The possibilities of this branch of science and technology have so far only been touched upon and are not yet fully explored.

One reason why the development of new applications goes slower than could have been expected is that the communication between different fields of knowledge is often very weak. This is in part caused by the educational system and the way research funding is organized. Typically a biologist is taught by a biologist and an engineer is taught by an engineer. In committees evaluating proposals for biological systems research one finds mostly biologists and few systems researchers. This is normal and generally accepted, but leads to inbreeding. A more active approach to the transfer of methods and knowledge across the scientific boundaries seems to be required.

It has taken too long, from the days when mathematical modeling of ocean processes was first suggested in the early 1970 s for the purpose of making computerized systems for model- based resource estimation, until today, around thirty years later, when plans are being made for doing the job.

When the biological resources of the oceans are becoming more scarce due to heavy utilization it will be even more essential to use the best tools for planning and controlling the harvesting operations. The interactions between the different processes in the ocean must become more apparent to the politicians making the decisions about the general principles of resource allocation. An example of this is the competition for the biological resources between the human race and the large mammals of the oceans (seals and whales). This issue must soon be addressed with a rational attitude and some choices must be made based on facts and goals.

The Norwegian University of Science and Technology in Trondheim has established 
a new academic program in 1999 in the field of 'Aqua-Bio-Cybernetics' to be offered by the Department of Engineering Cybernetics. New faculty are being hired to fill teaching and research positions and an extensive program with 8 Dr.ing candidates (Ph.D) is proposed over a period of 6 years. It is expected that this program will attract a large number of young Norwegians because it offers a new and appealing combination of mathematics, biology, electronics, instrumentation-,control- and computer technology.

\section{Acknowledgements}

The activities reported in this paper have been the joint effort of a large group of people of many categories in the Department of Engineering Cybernetics, NTNU, and in the Department of Automatic Control of SINTEF. They have been students doing their research projects, doctoral candidates undertaking longer investigations, technicians developing and maintaining complex equipment, research associates within specialized fields and faculty members contributing their knowledge and experience in a wide range of fields. At times, particularly when the experiments were done in Hopåvagen, the group could have 15-20 members interacting with great skill and enthusiasm.

The author wishes to express his gratitude to all his coworkers for their extraordinary contributions.

The support granted by The Royal Norwegian Council for Scientific and Industrial Research (NTNF) and The Norwegian Fisheries Research Council the first 20 years and The Research Council of Norway the last 10 years is highly appreciated. Without this support none of the activities would have been possible. Also the support given by a large number of Norwegian companies, particularly in the forrn of costly equipment, is highly valued and acknowledged.

\section{References and Bibliography}

A large number of reports, theses and papers in international journals have been written by the participants of the projects on the subjects of this paper. Only a few of these are referred to in the paper, but it is considered of value to the reader to have a complete listing available.

Below is a listing of three categories (A, B, and C) of publications. The fourth category (D) contains some important references from external literature.
A. Fisheries technology, Aquaculture, Modeling of fish behavior, Control of fish behavior
B. Ocean-Bio-Modeling, Model-based Resource Estimation
C. Fish Telemetry
D. References to external literature

\section{REFERENCES}

A. Fisheries technology, Aquaculture, Modeling of fish behavior, Control of fish behavior.

AASLID, R. (1974) Simulation of the individual cardiovascular system-A pilot study. Dr. med.thesis at University of Oslo.

ADLI, E. (1999) Expermental test of electronic course sensor (in Norwegian). Student project report, Dept. Eng. Cybernetics, NTNU, Trondheim.

AlFredSEN, J. A. (1999a) Conditioned behaviour in free ranging fish - methods and experiences 
from experiments in Norway. Presentation at The Marine Laboratory, Aberdeen, Scotland, May 1999, Dept. Eng. Cybernetics, Report 99-10-W.

Balchen, J. G. (1972) Feedback control of schooling fish. Proc. 5 IFAC World Congress, Paris, Pt 1, Instr. Soc. Amer.

BALCHEN, J. G. (1973) Short resume of ideas, hypotheses, experimental results, conclusions and plans for 'Feedback control of fish' (in Norwegian). Division of Automatic Control, Norw. Inst. of Techn. Report 73-101-R.

BALCHEN, J. G. (1974) Response of saithe (Gadus virens) to acoustic pulses from an airgun (in Norwegian). SINTEF Report: STF48 F74051.

BALCHEN, J. G. (1975a) Mathematical modelling of fish behaviour. Principles and applications. Proc. 6th IFAC World Congress, Boston, Instr. Soc. Amer.

BALCHEN, J. G. (1975b) Control of fish behavior (in Norwegian). Teknisk Ukeblad, 122(16), 6-7.

BALCHEN, J. G. (1976a) Modeling of the biological state of fishes SINTEF Monograph, STF 48 A76023.

BalCHEN, J. G. (1976b) Principles of migration in fishes SINTEF Monograph, STF48 A76045.

BALCHEN, J. G. (1976c) Control of fish behavior. SINTEF Monograph, STF 48 A76082.

BALCHEN, J. G. (1976d) A proposed system for harvesting of fish in coastal waters (in Norwegian). SINTEF Report: STF48 F76055.

BALCHEN, J. G. (1977a) Manipulation of fish schools. In Research in Norway ed. M. S. Mortensen, pp 47-51 H. Lyche \& Co, Drammen, Norway.

Balchen, J. G. (1977b) Mathematical modeling of fish migration. Proc. IFAC Symposium on Control Mechanisms in Bio- and Eco Systems, Leipzig, Germany, 5, pp 146-157.

BALCHEN, J. G. (1977c) System for hauling and long term storage of live North Sea mackerel (in Norwegian). SINTEF Report: STF48 F77042.

BALCHEN, J. G. (1978a) Introductory experiments with an active fish trap based on conditioning (in Norwegian). SINTEF Report: STF48 F78042.

BALCHEN, J. G. (1978b) Methods for recapture of saithe (Gadus virens) in long term storage, (in Norwegian). SINTEF Report: STF48 F78060.

BalChen, J. G. (1979a) Modelling, Prediction, and Control of Fish Behavior. In C. T. LeONDES (ed), Control and Dynamic Systems. 15, pp 99-146 Academic Press Inc

BAlChEN, J. G. (1979b) Presentation of a system for farming of Atlantic salmon under control in large, closed off coastal areas (in Norwegian). SINTEF Report: STF48 F79045.

BALChEN, J. G. (1981a) Control of fish behavior. Final project report (referring to 127 technical reports) (in Norwegian). SINTEF Report: STF48 A81050.

BALCHEN, J. G. (1981b) Recent progress in the control of fish behaviour. In H. AKAAHI (ed) Proc. Eighth Triennial World Congress of the International Federation of Automatic Control (IFAC), pp 3627-3632, Pergamon Press also in Modeling, Identification and Control, 5(2), pp. 113-122 (1984).

Balchen, J. G. (1987a) Automation and Data Processing in Aquaculture, Editor, Proceedings of IFAC Symposium, No 9, Pergamon Press.

BALCHEN, J. G. (1987b) Bridging the gap between aquaculture and the information sciences. Proc. IFAC Symp. Automation and Data Processing in Aquaculture, pp 11-15, Pergamon Press also in Modeling, Identlfication and Control, 7(4), pp. 163-162.

BALCHEN, J. G. (1987c) Educational Needs in Aquaculture Engineering with Special Reference to Automation, Report on Panel Session, Proc. IFAC Symp. Automation and Data Processing in Aquaculture, pp. 273-275, Pergamon Press.

BALCHEN, J. G. (1989) Instrumentation, Information and Control Systems in Aquaculture. In J. A. Wyban and E. Antill (eds), Proc. of Special Session at World Aquaculture Society 1989 Annual Meeting, pp. 1-10, The Oceanic Institute, Honolulu, HI.

BALCHEN, J. G. (1990a) Norwegian Patent no. 164812.

BALCHEN, J. G. (1990b) The state of the art in offshore fish farming. Proc. Conf on 'Engineering for Offshore Fish Farming', Glasgow, Scotland, 17-18 Oct. 1990. Thomas Telford, London.

BALCHEN, J. G. (1991) Possible roles of remotely operated underwater vehicles (ROV) and robotics in mariculture of the future. Modeling, Identification and Control, 12(4), pp. 207-217.

Balchen, J. G. (1994) Modeling of fish behavior. In J. Grasman and G. van Straten (eds), Predictability and Nonlinear Modelling in Natural Sciences and Economics, Kluwer Academic Publishers, Dordrecht. 
Balchen, J. G. (1995) Lobster Ranching in Coastal Waters. In N. D. Croce, S. Connell, R. ABEL (eds), Coastal Ocean Space Utilization III., E\&F.N.SPON, London.

BALCHEN, J. G. (1997) Digital mapping of ocean floor quality for lobster ranching (DAHABU). In E. Moksness (Ed) Preprints First Int. Symp. On Stock Enhancement and Sea Ranching, PUSH - The Norwegian Sea Ranching Program, Bergen.

Balchen, J. G. (1998a) Control of fish behavior by conditioning. In D. Holdsworth (Ed), Proc. STOA Panel, European Parliament, Brussels.

Balchen, J. G. (1998b) Description of a facility for production of lobster juveniles Homarus gammarus (in Norwegian), (Restricted) Report for Norsk Hummer AS, Oslo.

BALChEN, J. G., ANDRESEN, T., Foss, B. A. (1999) Control Engineering (in Norwegian). TAPIR Publishers, Trondheim.

Balchen, J. G. and Yin, S. (1994) The Mobatel Project, Dept. Eng. Cybernetics Report: ITK94-129-W.

BERGE, J. A. (1977) Control by conditioning of the behavior of salmon. Introductory investigations. (in Norwegian). SINTEF Report: STF48 F77071.

Borthen, J., Agnalt, A-L., Nøstvold, E. and Sørensen, J. (1998) Ocean Ranching of Lobsters (in Norwegian), Report from the Research Council of Norway, Oslo.

Flatval, L. (1980) A Kalman-filter for the estimation of fish density based on an echo sounder signal and a model of the fish behavior (in Norwegian). Siving (MSc) thesis, Dept. Eng. Cybernetics, NTNU, Trondheim.

FossEn, T. I. (1994) Guidance and Control of Ocean Vehicles, John Wiley \& Sons Ltd.

Grimsen, S., Jaques, R. N., Erenst, V., Balchen, J. G. (1987) Aspects of automation in a lobster farming plant. Proc. IFAC Symp. Automation and Data Processing in Aquaculture, pp. 221-225, Pergamon Press, also in Modeling, Identification and Control, 8(1), pp. 61-68.

HeStNES, M. E., (1999) A digital servomechanism for fish manipulation (in Norwegian). Student project report, Dept. Eng. Cybernetics, NTNU, Trondheim.

Holand, B. A., (1978) Description of experiments with recapture of saithe by conditioning at Frøya Island during the winter 1977-78 (in Norwegian). SINTEF Report. STF48 F78027.

HOLAND, B. A. (1987) Underwater telemetry as a tool in aquaculture research and development. Proc. IFAC Symp. Automation and Data Processing in Aquaculture, pp. 77-181, Pergamon Press also in Modeling, Identification and Control, 8(1), 11-18.

HunstAD, A. M. (1998) A miniaturized autopilot with low power consumption (in Norwegian). Siving. (MSc) Thesis, Dept. Physical Electronics, NTNU, Trondheim.

JENSEN, A., BALCHEN, J. G. (1976) Conditioning of saithe (Gadus virens) in a natural environment. (In Norwegian). SINTEF Report STF48 F76075.

KJEMPEKJENN, H. R. (1998) Electronic course sensor (in Norwegian). Siving. (MSc) thesis Dept. Eng. Cybernetics, NTNU, Trondheim.

Klepaker, R. A., VestgÅRD, K., Hallset, J. O. and Balchen, J. G. (1987) The application of a free swimming ROV in aquaculture. Proc. IFAC Symp. Automation and Data Processing in Aquaculture, pp. 181-187, Pergamon Press also in Modeling, Identification and Control, 8(1), pp. 19-26.

LøNNE, R. (1998) Sorting machine for lobster larvae (in Norwegian) (restricted). Siving. (MSc) thesis, Dept. Eng. Cybernetics, NTNU, Trondheim.

Mork, O. I. (1979) Control of the behavior of salmon (Salmo salar) by conditioning (in Norwegian). SINTEF Report: STF48 F79039.

MORK, O. I., BALCHEN, J. G. (1980) Farming of salmon (Salmo salar) under conditioning with one or two feeders (in Norwegian). SINTEF Report: STF48 F80043.

OLSEN, K. (1974a) Introductory test of a bubble curtain for the control of fish behavior (in Norwegian). SINTEF Report: STF48 F74020.

OLSEN, K. (1974b) Test of a mobile bubble curtain for control of fish behavior (in Norwegian). SINTEF Report: STF48 F74038.

OLSEN, K. (1974c) Conditioning of saithe (Gadus virens) with sound and food (in Norwegian). SINTEF Report: STF48 F74040.

OLSEN, K. (1974d) Directional hearing in sạith (Gadus virens) (in Norwegian). SINTEF Report: STF48 F74046.

Olsen, O. A. and Balchen, J. G. (1992) Structured Modeling of Fish Physiology. Mathematical Biosciences, 112, pp. 81-113, Elsevier Science Publ., New York Also in Modeling, Identification and Control, 14(1), pp. 3-26. 
Presterud, T. and Sølvberg, E. (1976) The design of a controlled fish feeder (in Norwegian). SINTEF Report: STF48 F76002.

REED, M. and BALCHEN, J. G. (1982) A multidimensional continuum model of fish population dynamics and behaviour: Application to the Barents Sea capelin (Mallotus Villosus), Modeling, Identification and Control, 3(2), pp. 65-110.

Silgjerd, A. (1997) Cyberfish- Communication (in Norwegian). Student project report, Dept. Eng. Cybernetics, NTNU, Trondheim.

SLAGSTAD, D. (1974a) Recording biological sounds from saithe (Gadus virens) (In Norwegian). SINTEF Report: STF 48 F74044.

SLAGSTAD, D. (1974b) Response of saithe (Gadus virens) to attracting biological stimuli (in Norwegian). SINTEF Report: STF48 F74045.

SNILdAL, P. I.(1998) Test of manipulation of fish motion (in Norwegian). (Unpublished) Report to Dept. Eng. Cybernetics, NTNU, Trondheim.

SølvBerG, E. (1977) An electrical barrier for fish in the sea (in Norwegian). SINTEF Report STF 48 F77004.

Tyssø, A. (1987a) Computer-aided modeling of aquaculture plants. Proc. IFAC Symp. Automation and Data Processing in Aquaculture, pp. 81-87, Pergamon Press, also in Modeling, Identification and Control, 7(4), pp. 189-198.

Tyssø, A. (1987b) The Need for Reliable and Robust Measuring Devices in Aquaculture Facilities, Report on Panel Session, Proc. IFAC Symp. Automation and Data Processing in Aquaculture, pp. 275-277, Pergamon Press.

B. Ocean-Bio-Modeling, Model-based Resource Estimation.

BAKKE, S. (1981) Graphical display of plankton data (in Norwegian). Siving. (MSc) thesis, Dept. Eng. Cybernetics, NTNU, Trondheim.

BALCHEN, J. G. (1980) Modeling and identification of marine ecological Systems with applications in management of fish resources and planning of fisheries operations. Modeling. Identification and Control, 1(2), pp. 67-69.

Balchen, J. G. (1981a) Mathematical and numerical modeling of physical and biological processes in the Barents Sea. In Statistical Ecology Series, 13, Quantitative Population Dynamics, pp. 267-284, (ed) Chapman; Calluci, International Co-operative Publishing House.

Balchen, J. G., Iversen, T., Berntsen, H., Saelid, S. and Nowakowski, V. A. (1979) A survey of the projects of the Ocean-Bio-Models-program (in Norwegian). SINTEF Report: STF48 F79019.

BERNTSEN, H. E. (1978) A depth-integrated hydrodynamic model of the Barents Sea. SINTEF Report: STF48 F78026.

BERNTSEN, H. E. (1983a) ODIN, an interactive presentation program for 3-dimensional data. SINTEF Report: STF48 F83004.

BERNTSEN, H. E. (1983b) HODIN, an interactive plotting program for 3-dimensional data. SINTEF Report: STF48 F83005.

BERNTSEN, H. E. (1983c) OCEAN, a 3-dimensional hydrodynamical simulation program with closed boundaries. SINTEF Report: STF48 F83006.

BERNTSEN, H. E. (1983d) An eigenvalue method for specification of open-sea boundaries in 3dimensional hydrodynamical modelling. SINTEF Report STF48 F83007.

Berntsen, H., Kowalik, Z., S Stl.iD, S. and Sorli, K., (1981) Efficient numerical simulation of ocean hydrodynamics by a splitting procedure. Modeling, Identification and Control, 2(4), pp. 181-200.

Carlotti, F. and Slagstad, D. (1997) Population dynamics model of interacting copepod species coupled with a 1-D model of phytoplankton dynamics in the Greenland Sea Gyre. Environmental Modelling and Assessment, 2, pp. 29-36.

DAHI, B. M. (1998) Decentralized Estimation in Large Scale Systems, Siving. (MSc) thesis Dept. Eng. Cybernetics, NTNU, Trondheim.

EвENHøH, W. (1980a) A model of the dynamics of plankton patchiness. Modeling, Identification and Control, 1(2), pp. 69-93.

EвеNнøн, W. (1980b) Instability of a uniform plankton distribution. Modeling, Identification and Control, 2(2), pp. 83-95.

ERIKSEN, J. O. (1980) Computerized systems for the detection of plankton (in Norwegian). Siving. (MSc) thesis, Dept. Eng. Cybernetics, NTNU, Trondheim. 
FIKSEN, Ø., GISKF, J. and SlaGstaD, D. (1995) A Spatially explicit fitness-based model of capelin migrations in the Barents Sea. Fish. Oceanogr. 4, pp. 193-208.

Gislefoss, J. S., Nydal, R., Slagstad, D., Sonninen, E. and Holmen, K. (1998) Carbon time series in the Norwegian Sea. Deep-Sea Research, 46, pp. 433-460.

Henriksen, R. (1998) Stochastic Systems (in Norwegian). Report 98-12-X Lecture notes Dept. Eng. Cybernetics, NTNU, Trondheim.

HÅNDlykKen, M. (1974) Analog Fish Position Estimator (in Norwegian). SINTEF Report: STF48 F74050.

IVERSEN, T. (1978) Sensitivity analysis of a depth-integrated model (in Norwegian). SINTEF Report: STF48 F78025.

IvERSEN, T. (1979a) Digital bathymetric map of the Barents Sea, SINTEF Report: STF48 F79014.

IVERSEN, T. (1979b) Interpolation in one, two and three dimensions. SINTEF Report: STF48 F79021.

IVERSEN, T. (1979c) Measurements of flow and tides in the Barents Sea (in Norwegian). SINTEF Report: STF48 F79036.

IVERSEN, T. (1981) Air-sea-ice interaction and ice modeling. SINTEF Report: STF48 F81051.

Jensen, A. (1978a) Growth of Pollock (Pollachius virens) in Hopavagen, Agdenes, recorded by tagging and recapture (in Norwegian). SINTEF Report: STF48 F78018.

Jensen, A. (1978b) Experiments with the growth of Pollock (Pollachius virens) (in Norwegian). SINTEF Report: STF48 F78041

JENSEN, A. J. (1979) Energy content analysis from weight and liver index measurements of immature Pollock (Pollachius virens). J. Fish. Res. Board Can. 36, pp. 1207-1213.

KowaLiK, Z. (1981) A study of the M2 tide in the ice-covered Arctic Ocean, Modeling, Identification and Control, 2(4), 201-224.

LJUNGQUIST, D., BALCHEN, J. G. (1994) Recursive prediction error methods for online estimation in nonlinear state-space models. Modeling, Identification and Control, 15(2), pp. 109-121.

NowAKOWSKI, V. A. (1978) Limitations of hormonal analysis to behavioral modeling of fish. SINTEF Report: STF48 A7805I.

NowakowsKı, V. A. (1979) Cluster Analysis- Part 1: Experimental design of the sample size, N. SINTEF Report: STF48 F79024.

NowakowsKI, V. A. (1980) Structural reduction of an energy biomodel. SINTEF Report: STF48 F80009.

Olsen, O. A., Balchen, J. G. (1992) Structured Modeling of Fish Physiology. Mathematical Biosciences, 112, pp. 81-113, Elsevier Science Publ., New York. Also in Modeling, Identification and Control, 14(1), pp. 3-26.

REED, M. and BALCHEN, J. G. (1982) A multidimensional continuum model of fish population dynamics and behaviour: Application to the Barents Sea capelin (Mallotus Villosus) Modeling, Identification and Control, 3(2), pp. 65-110.

Rivrud, S. T. (1980) Analysis of Systems for the estimation of the vertical profile of the horizontal currents of water in the ocean (in Norwegian). Siving. (MSc) thesis, Dept. Eng. Cybernetics, NTNU, Trondheim.

SAKSHAUG, E. and SlagstaD, D. (1991) Light and productivity of phytoplankton in polar marine ecosystems: A physiological view. Polar Res. 10, pp. 69-85.

SAKShaug, E., Rey, F. and SlaGstad, D. (1995) Wind forcing of marine primary production in the Northern atmospheric low-pressure belt. In H. R. SKJoldal, C. HopKINS, K. E. ERIKSTAD and H. P. LeINAAS (Eds.): Ecology of fjords and Coastal Waters. Elsevier, Amsterdam.

SFLID, S. (1976) The need for computer capacity for the Ocean-Bio-Model-project (in Norwegian). SINTEF Report: STF48 F76080.

SÆLID, S. (1977a) Numerical models of ocean hydrodynamics. SINTEF Report: STF48 F77020.

SFLID, S.(1977b) Observability theorems for some linear hyperbolic systems. SINTEF Report: STF48 F77037.

SALID, S. (1977c) Predictability range of two dimensional flow models. SINTEF Report: STF48 F77064.

SALID, S. (1977d) Filtering experiments in hydrodynamic flow. One dimensional case. SINTEF Report: STF48 F77066.

SÆLID, S. (1978a) Three dimensional mathematical model for hydrodynamic simulation of the Barents Sea. SINTEF Technical note TN-36. 
SfeLID, S. (1978b) An analytical solution for a filtering problem in two dimensional hydrodynamic flow. SINTEF Report: STF48 F78024.

SFLID, S. (1979) A 3-D model of ocean hydrodynamics (in Norwegian). SINTEF Technical note May 18-79.

SlaGSTAD, D. (1981a) Modeling and simulation of physiology and population dynamics of copepods. Effects of physical and biological parameters. Modeling, Identification and Control, 2(3), pp. 119-162.

SlagstaD, D. (1981b) The copepod model adapted to an Arctic/Boreal environment. SINTEF Report: STF48 F81056.

SLAGSTAD, D. (1982) A model of phytoplankton growth- effects of vertical mixing and adaptation to light, Modeling, Identification and Control, 3(2), pp. 111-130.

Slagstad, D. (1983) The ocean-plankton model (OCEAN-BIO-MODELS/HAVBIOMODELLER), User's guide. SINTEF Report: STF48 F83003.

SLAGSTAD, D. (1984) A model of phytoplankton production in the marginal sea-ice zone of the Barents Sea, Modeling, Identification and Control, 5(3), pp. 129-140.

SlaGsTAD, D. et al. (1985) Computer aided modelling and simulation using a direct-executing simulation language. 11th IMACS World Congress on System Simulation and Scientific Computation, Oslo 1985.

SLAGSTAD, D. (1985) A model of phytoplankton in the Marginal Sea-ice zone of the Barents Sea. Paper presented at the 218th European Symposium on Marine Biology, Oslo 1983. In Gray \& Christiansen: Marine Biology of Polar Regions and Effects of Stress on Marine Organisms. John Wiley \& Sons Ltd.

Slagstad, D. (1987). A 4-dimensional Physical Model of the Barents Sea. SINTEF Report: STF48 F87013. Trondheim.

SLAGSTAD, D. (1993) Simulation of currents of the Vøringplatået. Report for the ministry of Oil and Energy. SINTEF Report: STF 93005.25 pp.

Slagstad, D., Downing, K., Carlotti, F. and Hirche, H.-J. (1996) Modelling the carbon export and air-sea flux of $\mathrm{CO}_{2}$ in the Greenland Sea, pp. 584-596. In WADHAMS, P., Wilkinson, J. P. and Wells, S. C. S.: European Subpolar Ocean Programme (ESOP). Sea Ice - Ocean Interactions. Scientific report. Report to the EU Commission (MAST).

Slagstad, D., Downing, K., Carlotti, F. and Hirche, H.-J. (in press) Modelling the carbon export and air-sea flux of $\mathrm{CO}_{2}$ in the Greenland Sea. Deep-Sea Research $I L$.

Slagstad, D., IverSEN, T. (1997) Simulation and visualization of coupled hydrodynamical, chemical and biological models. Modeling, Identlfication and Control, 18(2), pp. 123-136.

Slagstad, D., Olsen, Y. and Tilseth, S. (1987) A model based system for control of live feed level for larval fish. Proc. IFAC Symp. Automation and Data Processing in Aqua Culture, pp. 215-221, Pergamon Press also in Modeling, Identification and Control, 8(1), pp. 51-60.

SlaGSTAD, D. and oG STOKKE, S. (1994) Simulering av strømfelt, hydrografi, isdekke og primæproduksjon i det Nordlige Barentshav. Fisken og Havet, Nr. 9, 1994. 47 pp.

Slagstad, D. and Støle-Hansen, K. (1991) Dynamics of plankton growth in the Barents Sea: Model Studies. Polar Research, 10(1), pp. 173-186.

Slagstad, D., Støle-Hansen, K. and Loeng, H. (1990) Density driven currents in the Barents Sea calculated by a numerical model. Modeling, Identification and Control, 11(4), pp. 181-190.

SLAGSTAD, D. and TANDE, K. (1981) A mathematical model of the assimilation process in the copepod Calanus finmarchicus: Computer simulations discussed in relation to experimental results. SINTEF Report: STF48 F81008.

SLAGSTAD, D. and TANDE, K. S. (1996) The importance of seasonal vertical migration in across shelf transport of Calanus finmarchicus. Ophelia, 44, pp. 189-205.

SLAGSTAD, D. and WASSMANN, P. (1996) Climatic change and carbon flux in the Barents Sea: 3-D simulations of ice-distribution, primary production and vertical export of particulate organic carbon. Mem. Natl. Inst. Polar Res., Spec. Issue 51, pp. 119-141.

Slagstad, D., Westgård, T., Olsen, K., Salid, S. and Balchen, J. G., (1975) Mathematical modeling of the amount, quality, motion and distribution of important species of fish in an ocean. SINTEF Report: STF48 A75050.

Støle-Hansen, K. and Slagstad, D. (1991) Simulation of currents, ice melting and vertical mixing in the Barents Sea using a 3-D baroclinic model, Polar Research, 10(1), pp. 33-44.

Swane, E. (1977) Remote sensing for Ocean-Bio-Models. What can be measured from satellites and airplanes? (in Norwegian). SINTEF Report: STF48 F77019. 
SørLI, K., BERNTSEN, H. and S SALID, S. (1981) A numerical model of ocean hydrodynamics SINTEF Report: STF48 F81061.

TANDE, K. (1981) Feeding rates, gut passage time and variations in digestive enzyme activity in copepodite stage V Calanus finmarchicus. SINTEF Report: STF48 F81037.

TANDE, K. and SlaGSTAD, D. (1981) Seasonal and short time variation in enzyme activity in copepodite stage V and VI males and females Calanus finmarchicus. SINTEF Report: STF48 F81013.

TANDE, K. S and Slagstad, D. (1992) Regional and interannual variations in biomass and productivity of the marine copepod, Calanus finmarchicus, in subarctic environments. Oceanologia Acta., 15, pp. 309-321.

Thunem, Aa. J. (1979) A Kalman Filter approach in updating a hydrodynamic model SINTEF Report: STF48 F79042.

Villabø, M. (1976) A model of the physical oceanography of the Barents Sea (in Norwegian), Siving. (MSc) thesis, Dept. Eng. Cybernetics. NTNU, Trondheim.

WASSMANN, P. and SLAGSTAD, D. (1991) Mathematical modeling, an important tool to explore the dynamics of vertical flux of organic matter. In: WASSMANN, P., HeISKANEN, A.-S., LINDAHL, O. (eds): Sediment trap studies in the Nordic countries 2, 255-279, NunniPrint OY; Nurmijarvi.

Wassmann, P. and SlaGstad, D. (1993) Seasonal and annual dynamics of particulate carbon flux in the Barents Sea. A model approach. Polar Biol. 13, pp. 363-372.

WASSMANN, P. and SLAGSTAD, D. (1998) Klimatisk påvirkning av produktivitet i Barentshavet. Naturen, Nr. 1, pp. 31-55.

\section{Fish Telemetry}

Alfredsen, J. A. (1999b) A data storage tag with geo-localisation capability. Presentation at meeting at The Freshwater Fisheries Laboratory, Pitlochry, Scotland, May 1999. Dept. Eng. Cybernetics Report: 99-11-W.

HoLAND, B. (1973) Fish Telemetry, Report 1, - Signals in the water (in Norwegian). SINTEF Report: STF48 A73038.

Holand, B. and MoHus, I. (1973) Fish Telemetry, Report 2, - 1973 Equipment - SINTEF Report: STF48 A73051. HoLAND, B. (1973) Fish Telemetry, Report 3, - 1973 Experiments - SINTEF Report: STF48
A73052.

Holand, B. (1974) Fish Telemetry, Report 4, - Ultrasonic tagging of cod in Lofoten-SINTEF Report: STF48 A74018.

Holand, B., Mohus, I. and BERnTSEn, R. (1974) Fish Telemetry, Report 5, - Devices and Results 1974 - SINTEF Report: STF48 A74049.

Holand, B. (1975) Fish Telemetry, Report 6, - Devices and Results 1975 - SINTEF Report: STF48 A75065.

Holand, B. (1979) Fish Telemetry 1978, SINTEF Report: STF48 A79002.

HolaND, B. (1980) Fish Telemetry 1979, SINTEF Report: STF48 A80004.

HoLAND, B. (1981) Fish Telemetry 1980, SINTEF Report: STF48 A81001.

HoLAND, B. (1982) Fish Telemetry 1981, SINTEF Report: STF48 A82001.

HolaND, B. (1983a) Fish Telemetry 1982, SINTEF Report: STF48 A83001.

Holand, B. (1983b) Fish Telemetry 1983, SINTEF Report: STF48 A83039.

HolAND, B. (1984) Fish Telemetry 1984, SINTEF Report: STF48 A84032.

HoLAND, B. (1985) Fish Telemetry 1985, SINTEF Report: STF48 A85023.

HolAND, B. and MoHus, I. (1976a) Fish Telemetry, Report 7, - Devices and Results 1976 SINTEF Report STF48 A76076.

Hol.AND, B. and MoHUS, I. (1976b) Bio Telemetry 1976. SINTEF Report STF48 A76077.

HolAND, B. and MoHUS, I. (1977) Fish Telemetry, Report 8, - Final Report - SINTEF Report STF48 A77076.

HÅNDLYKKEN, M. (1974) Analog Fish Position Estimator (in Norwegian). SINTEF Report: STF 48 F74050.

MoHUS, I. (1974a) 'PINPOINT'- Microprocessor system - USERS MANUAL - SINTEF Report: STF48 A74011.

MoHUS, I. (1974b) 'PINPOINT'- FISH TRACKING PROGRAM - SINTEF Report STF48 A74032. 
MoHUS, I. (1975) 'PINPOINT'- Microprocessor system - DISC USERS MANUAL - SINTEF Report: STF48 A75006.

MoHuS, I. and HolAND, B. (1983) Fish Telemetry Manual, SINTEF Report: STF48 A83040.

MoHUS, I. and HolaND, B. (1986) Fish Telemetry Experiments, SINTEF Report: STF48 A86024.

SølvBerg, E. (1978) MANPOINT- a simple system for manual plotting of fish position (in Norwegian). SINTEF Report: STF48 F78001.

\section{References to external literature}

BRETT, J. R. (1979) Energetic response of salmon to temperature: A study of some thermal relations in the physiology and fresh water ecology of sockeye salmon (Oncorhyncus nerka), Am. Zool. 11, pp. 99-113.

Burgess, J. W. and Shaw, E. (1979) Development and ecology of fish schooling. Oceanus, pp. 2211-2217.

CoBb, J. S. and Phillips, B. F. (1980) The biology and management of lobsters, Vol I and Vol II. Academic Press.

FACTOR, J. R. (1995) Biology of the lobster, Homarus americanus, Academic Press.

Fraenkel, G. S. and GunN, D. L. (1961) Orientation of animals. Clarendon Press, Oxford.

Giske, J., Huse, G. and FikSEN, Ø. (1998) Modelling spatial dynamics of fish. Reviews in Fish Biology and Fisheries, 8, pp. 57-91.

Glase, J. C., Zimmerman, M. C. and Waldvogel, J. A., (1992) Investigations in orientation behavior. pp 1-26, In Tested studies for laboratory teaching, Volume 6, C. A. GoldmaN, S. E. Andrews, P. L. Hauta, R. Ketcham (eds), Proc. of the 6th Workshop/Conference of the Association for Biology Laboratory Education (ABLE).

HJORT, J. (1914) Fluctuations in the great fisheries of northern Europe, viewed in the light of biological research. Rapp. P.V. Réun. Cons. Perm. Int. Explor. Mer 20, 228 pp.

KeENleyside, M. H. A. (1955) Some aspects of schooling behaviour of fish. Behaviour, 8, pp. 183-248.

KeEnleyside, M. (1975) Schooling behaviour in fish. In E. O. Price and A. W. StoKes (eds) Animal behavior in laboratory and field, Ch. 31, pp 101-104, W. H. Freeman, San Francisco.

LuUnG, L. (1987) System Identlfication: Theory for the user. Prentice Hall.

LuUng, L. and SøDerstrøM, T. (1987) Theory and Practice of Recursive Identification. The MIT Press, Cambridge, Mass.

NiHOUl, C. J., DJENIDI, S. (1986) Perspectives in three-dimensional modelling of the marine system. Proc. Eighteen International Liege Colloquium on Ocean Hydrodynamics, Belgium.

SANnOMIYA, S. and MATUdA, K. (1984) A mathematical model of fish behavior in a tank. IEEE Trans. Systems, Man and Cybernetics, 14, pp. 157-162.

SHaw, E. (1978) Schooling fishes, American Scientist, 66, pp. 166-175.

Solemdal, P. (1997) Maternal effects - a link between the past and the future. J. Sea Res. 37, pp. 213-227.

WEIHS, D. (1973a) Mechanically efficient swimming techniques for fish with negative buoyancy, Journ. of Marine Research, 31, pp. 194-209.

WEIHS, D. (1973b) Hydromechanics of fish schooling, Nature, London, 241, pp. 290-291.

WEIHS, D. (1982) Bioenergetic considerations in fish migration. In: MCCLEAVE, J. D. et.al. (eds). Mechanisms of Migration in Fishes, pp. 487-508. Plenum Press, New York, USA.

WAHLE, R. A. (1992) Substratum constraints on body size and the behavioral scope of shelter use in the American lobster, J. Exp. Mar. Biol. Ecol. 159, pp. 59-75.

WAHLe, R. A., STENeCK, R. A. (1991) Recruitment habitats and nursery grounds of the American lobster Homarus american us: a demographic bottleneck. Mar. Ecol. Progr. Ser. 69, pp. 231-243. 